\title{
Thermal Remote Sensing of Urban Heat Islands: Greater Toronto Area
}

\author{
By \\ Matthew Maloley \\ A thesis submitted to \\ the Faculty of Graduate Studies and Research \\ in partial fulfilment of the requirements of the degree of \\ Master of Science \\ Department of Geography and Environmental Studies \\ Carleton University \\ Ottawa, Ontario \\ August 2010
}




$\begin{array}{ll}\begin{array}{l}\text { Library and Archives } \\ \text { Canada }\end{array} & \begin{array}{l}\text { Bibliothèque et } \\ \text { Archives Canada }\end{array} \\ \begin{array}{l}\text { Published Heritage } \\ \text { Branch }\end{array} & \begin{array}{l}\text { Direction du } \\ \text { Patrimoine de l'édition }\end{array} \\ \begin{array}{l}\text { 395 Wellington Street } \\ \text { Ottawa ON K1A ON4 } \\ \text { Canada }\end{array} & \begin{array}{l}\text { 395, rue Wellington } \\ \text { Ottawa ON K1A ON4 } \\ \text { Canada }\end{array}\end{array}$

Your file Votre référence
ISBN: 978-0-494-71591-8
Our file Notre référence

ISBN: 978-0-494-71591-8

NOTICE:

AVIS:

The author has granted a nonexclusive license allowing Library and Archives Canada to reproduce, publish, archive, preserve, conserve, communicate to the public by telecommunication or on the Internet, loan, distribute and sell theses worldwide, for commercial or noncommercial purposes, in microform, paper, electronic and/or any other formats.

The author retains copyright ownership and moral rights in this thesis. Neither the thesis nor substantial extracts from it may be printed or otherwise reproduced without the author's permission.

L'auteur a accordé une licence non exclusive permettant à la Bibliothèque et Archives Canada de reproduire, publier, archiver, sauvegarder, conserver, transmettre au public par télécommunication ou par l'Internet, prêter, distribuer et vendre des thèses partout dans le monde, à des fins commerciales ou autres, sur support microforme, papier, électronique et/ou autres formats.

L'auteur conserve la propriété du droit d'auteur et des droits moraux qui protège cette thèse. $\mathrm{Ni}$ la thèse ni des extraits substantiels de celle-ci ne doivent être imprimés ou autrement reproduits sans son autorisation.

In compliance with the Canadian Privacy Act some supporting forms may have been removed from this thesis.

While these forms may be included in the document page count, their removal does not represent any loss of content from the thesis.
Conformément à la loi canadienne sur la protection de la vie privée, quelques formulaires secondaires ont été enlevés de cette thèse.

Bien que ces formulaires aient inclus dans la pagination, il n'y aura aucun contenu manquant.

\section{Canadä}




\begin{abstract}
Over the past 20 years, numerous peer reviewed studies have used thermal remote sensing to map urban heat islands. This study examines assumptions made in previous research through comparisons of in situ air temperatures and remotely sensed estimates of surface temperatures. Landsat thermal data collected from 4 heat event days over the summers of 2007-2008 are correlated with air temperatures from 30 sites across the Greater Toronto Area. Weak relationships between surface and air temperature are strengthened by incorporating information on source area and urban geometry. Results suggest that the higher and more densely packed the urban structures are, the lower the rate of cooling and more pronounced the heat island effect. Surface temperatures averaged upwind of the monitoring sites, and frontal area density estimates are highly correlated with night-time air temperatures and well suited for mapping urban heat island intensities.
\end{abstract}




\section{Acknowledgements}

First and foremost, I'd like to thank Dr. Scott Mitchell and Dr. Elyn Humphreys for their invaluable, multidisciplinary supervision. Dr. Doug King and the Department of Geography and Environmental Studies are also thanked for providing the opportunity within the M.Sc. program.

I'd like to acknowledge the support from the Enhancing Resilience to Climate Change Program at Natural Resources Canada. The program provided funding for field work and data purchases used in the thesis. Raymond Soffer, Emma Hemmingsen and Amy Gartshore are thanked for their work in the "field", handling hours on hot roof tops or navigating the impossible Toronto traffic. It should also be noted that this research would not have been possible without the support of Dr. Jennifer Penney and Virginia Mersereau from the Clean Air Partnership, who provided unprecedented access to urban sites for field measurements. This research also depended on data access from the City of Toronto, University of Toronto, York University, Toronto Regional Conservation Authority and Ministry of Transportation Ontario.

Finally, I'd like to thank my wife Andrea and my family for their patience, support and for helping to keep things cool. 


\section{Table of Contents}

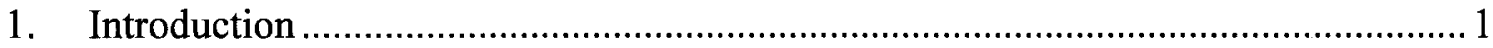

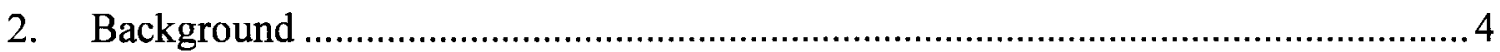

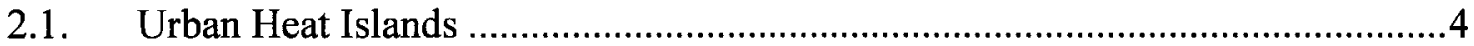

2.1.1. Urban Heat Island Modelling ..................................................................

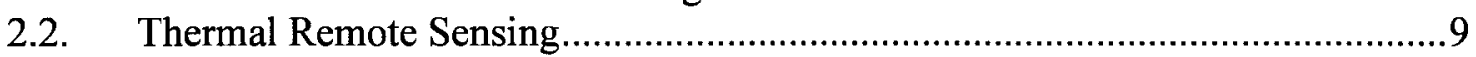

2.2.1. Estimating Land Surface Temperatures ...................................................

2.2.2. Thermal Remote Sensing of Urban Landscapes ........................................11

2.2.3. Thermal Anisotropy …………………………..................................... 13

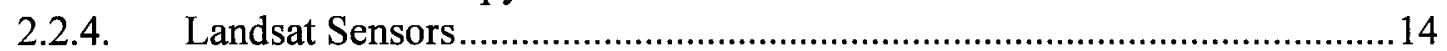

2.3. Urban Heat and Human Health..................................................................15

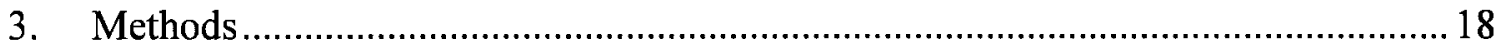

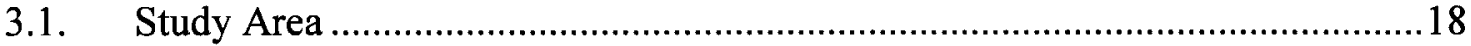

3.2. Surface and Air Temperature Monitoring Sites...............................................20

3.2.1. Measurement Validation ..........................................................................22

3.3. Remotely Sensed Surface Temperature Measurements ......................................23

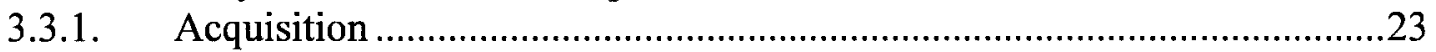

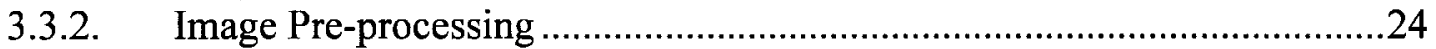

3.3.3. Land Surface Temperature Estimation.....................................................25

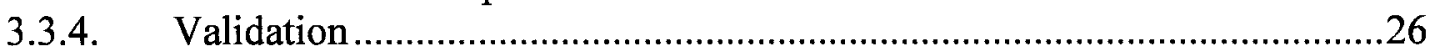

3.3.5. Source Area Averaging …………………………................................28

3.4. Urban Geometry and Urban Canyon Mapping...................................................31

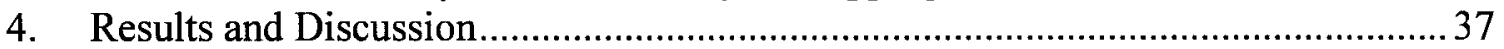

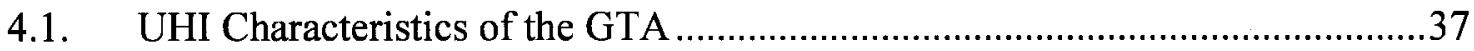

4.1.1. Regional Heat Islands............................................................................42

4.2. Air and Surface Temperature Relationships...................................................43

4.2.1. Green Roofs..................................................................................47

4.3. Remotely Sensed Surface Temperatures ..........................................................49

4.3.1. Urban Heat Island Mapping ......................................................................51

4.3.2. Source Areas and Air Temperature ........................................................52

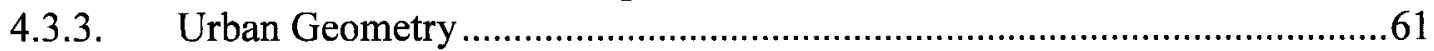

4.3.4. Modelling night-time temperatures ...........................................................65

4.4. UHI Modelling with LST, Upwind Source Areas and Urban Geometry ...........67

4.5. Implications for Health and Urban Planning ……................................................

5. Conclusions and Recommendations ............................................................... 72

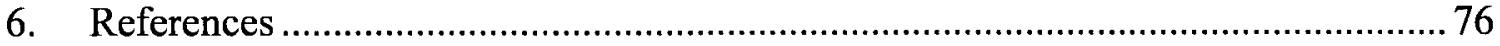

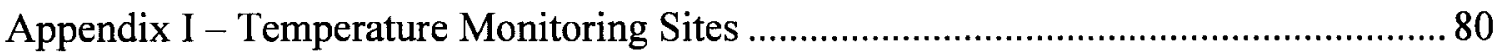

Appendix II - Land Surface Temperature Maps.......................................................... 82 


\section{List of Tables}

Table 1. Landsat imagery acquisitions and meteorological conditions at the time of acquisition. Air temperature, relative humidity and wind speed for 10:00 Local Standard Time from Lester B. Pearson Airport meteorological station (Environment Canada). .....24 Table 2. In situ surface monitoring sites with sensor temperatures and Landsat LST measurements from July 1, 2008 28

Table.3. Single factor ANOVA statistics, $a=0.05$ to test differences between urban, suburban and rural, noon and midnight air temperatures for August 2008.

Table.4. Regional mean differences between urban and rural temperatures $\left(\Delta \mathrm{T}_{\mathrm{u}-\mathrm{r}}\right)$, with standard deviations $(\sigma)$, for June 8, 2008; July 1, 2008; July 7, 2008.

Table.5. Single factor ANOVA statistics, with significance denoted by italics $(a=0.05)$, to test the temperature differences between sites of common cover types.

Table.6. The linear regression models, coefficient of determination $\left(\mathrm{r}^{2}\right)$ and standard error of the regression $(\sigma)$ for 10:00 and 23:00 air temperatures using 120 m Land Surface Temperatures (LST), $480 \mathrm{~m} \mathrm{LST}, \lambda \mathrm{F}$, and $480 \mathrm{~m}$ LST and $\lambda \mathrm{F}$ on each of the four LST dates. 


\section{List of Figures}

Figure 1. Night-time thermal image of downtown Vancouver....................................... 14

Figure 2. Study area with temperature monitoring site locations. .................................. 19

Figure 3. TMC-HD air temperature sensor and surface temperature sensor .....................22

Figure 4. Southern Ontario with Landsat TM scene extents.............................23

Figure 5. ArcGIS block statistical calculation method for source area............................2 29

Figure 6. Land surface temperature (LST) from $120 \mathrm{~m}$ pixels (above) averaged over a

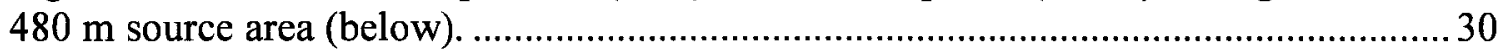

Figure 7. Sample building footprints and site area polygons............................................34

Figure 8. Sample building footprint with parallel line intersections to calculate frontal

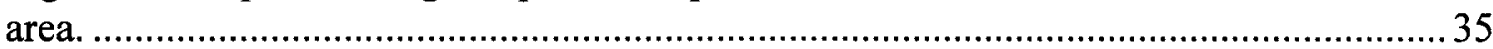

Figure 9. Hourly air temperature values for July 1, 2008 averaged by urban, suburban and rural classes. Standard deviations for urban and suburban measurements plotted as

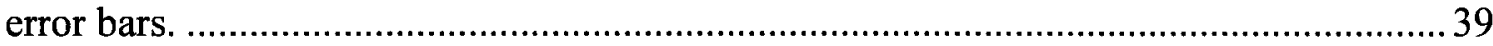

Figure 10. Noon air temperatures for August, 2008 averaged by urban, rural and

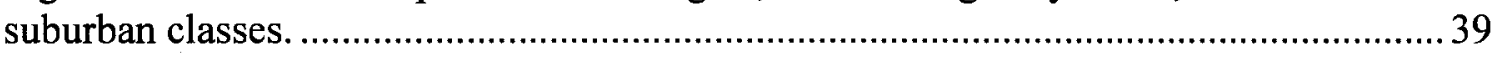

Figure 11. Midnight air temperatures for August, 2008 averaged by urban, rural and

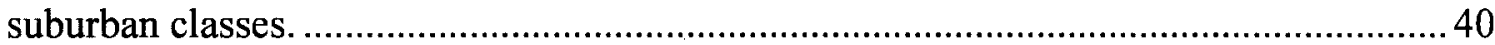
Figure 12. Surface and air temperatures for 4 different GTA measurement sites on a calm (June 6) and windy day (July 9) in 2008.

Figure 13. Roof surface temperatures and air temperatures measured on common cover

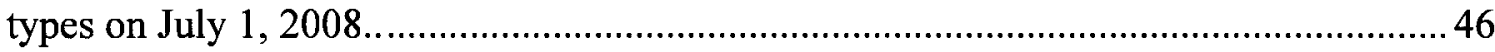

Figure 14. MEC asphalt tile roof and green roof. ........................................................ 48 Figure 15. MEC green roof and asphalt tile roof air and surface temperature measurements for August 1-3, 2007.

Figure 16. a) Suburban (Brampton) and b) Urban (Downtown Toronto) subsets of July 1, 2008 Land Surface Temperature map........................................................................5 50

Figure 17. 10:00 Land Surface Temperature $(120 \mathrm{~m})$ and 10:00 air temperature plots....52 Figure 18. 10:00 Land Surface Temperature and hourly air temperature correlations (r) for various source areas (upwind pixels)..................................................................... 54 Figure 19. 10:00 Land Surface Temperature $(480 \mathrm{~m})$ and 23:00 air temperature correlations for a) August 1, 2007, b) July 1, 2008, c) August 25, 2008 and d) September

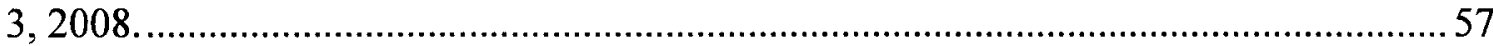
Figure 20. The correlation (r) between 10:00 Land Surface Temperature from the $480 \mathrm{~m}$ upwind source area and air temperature correlations (r) and UHI intensities for July 1, 2008.

Figure 21. Frontal area density $\left(\lambda_{F}\right)$ for site areas with monitoring sites and hydrology overlain.

Figure 22. Correlations (r) between frontal area density $\left(\lambda_{F}\right)$ and hourly air temperature for August 1, 2007, July 1, 2008, August 25, 2008 and September 3, 2008.....................63

Figure 23. Air temperatures from 4 urban sites for August 1, 2007. 65

Figure 24. Residuals from $480 \mathrm{~m}$ Land Surface Temperature (LST) and air temperature regressions plotted against Frontal Area Density $\left(\lambda_{F}\right)$ for August 1, 2007. 


\section{Introduction}

Urban Heat Islands (UHI), a common characteristic of urban microclimates where temperatures are warmer than in neighbouring rural areas, are typically modelled with in situ meteorological measurements. But our cities are heterogeneous and continuously evolving landscapes that require repeated spatially extensive measurements, which are both costly and impractical for in situ networks. Satellite and airborne thermal infrared sensors have presented the ability to map surface temperatures of urban regions with spatially extensive per-pixel estimates of radiated energy. Over the past 20 years, several dozen peer reviewed studies have used thermal remote sensing to map heat islands.

However, these studies make assumptions these surface temperatures directly relate to near surface air temperatures (i.e. $1.5 \mathrm{~m}$ above ground) (Roth et al., 1989, Voogt and Oke, 2003), a central variable in UHI microclimate and urban health studies (Smargiassi et al., 2005).

Many studies tend to miss the inherent problem of estimating surface temperatures over three dimensional urban environments with two dimensional imagery acquired from a single look angle, instead focussing on emissivity and atmospheric correction components of surface temperature estimation (e.g. Sobrino and Jimenez-Munoza, 2004). Preliminary research (Oke and Voogt, 1998) has found that the capacity for heat storage and subsequent release from walls of multi-storey structures can exceed that of rooftops, accounting for a significant portion of the heat flux budget in urban areas. 
Many of these studies either focus entirely on the surface heat island, ignoring any air temperature component, or assume that the relationship between surface temperature and air temperature is direct. Voogt and Oke (2003) discuss the problems with this assumption in complex urban environments that have significant variations in heat fluxes. Although microclimatology studies have illustrated the impact of horizontal flow and source areas contributing to the near surface air temperature of a particular location (e.g. Schmid, 2002), this information is rarely considered in thermal remote sensing studies. Urban geometry also plays a role in the UHI effect, where large structures in close proximity can also trap stored heat by limiting exposure of surfaces to the cool night-time sky (Oke, 1982). By knowing the height and density of buildings, in addition to the surface temperatures, it should be possible to parameterize the diurnal differences in urban and rural air temperatures and determine UHI intensities.

This thesis investigated the suitability of thermal remote sensing for UHI modelling, by comparing in situ air temperatures with Landsat TM thermal band surface temperatures over the Greater Toronto Area (GTA) for the summers of 2007 and 2008. The Landsat TM sensor was selected for this study as it is the most widely used and readily available thermal sensor. Building footprint and height information were also used to investigate the influence of urban geometry on the surface and air temperature relationships. 
Objectives

This research had the following objectives:

i. to investigate the spatial and temporal relationships between surface temperatures and air temperatures over various urban covers in heat event conditions;

ii. to investigate the effects of urban geometry on these surface and air temperature relationships; and

iii. to test the ability to model air temperatures with surface temperature and urban structural information.

Hypotheses

The objectives were approached by testing the following hypotheses:

i. The GTA will exhibit typical UHI characteristics, with warmer air temperatures in urban areas than those in rural areas. These temperature differences are expected to be most pronounced at night.

ii. Air temperatures will not be highly correlated with co-located surface temperature estimates.

iii. The correlation between surface and air temperature will improve when considering surface temperatures averaged over source areas up-wind of the air temperature measurement.

iv. Accounting for urban geometry will improve empirical relationships between air and up-wind surface temperatures. 


\section{Background}

\subsection{Urban Heat Islands}

Urban centres tend to have higher air temperatures than surrounding rural areas as a result of vegetated cover being replaced by non-porous, non-evaporating, highly thermal conductive surfaces such as concrete and asphalt. Another contributing factor to the UHI is the urban canyon effect, where walls of multi-storey buildings release heat that has been stored from daytime heating at lower rates during periods of night-time cooling than non-urban features (Oke, 1982). Urban canyons also tend to alter wind flow, where urban structures increase drag and turbulence, creating zones where wind speeds are reduced in comparison to those at the same height in rural areas (Oke, 1982).

The UHI is commonly described by UHI intensity $\left(\Delta \mathrm{T}_{\mathrm{u}-\mathrm{r}}\right)$, which is measured as the difference in air temperature between an urban area $(u)$ and its rural surrounds $(r)$. The UHI is normally measured within the urban canopy layer (UCL), which extends from the ground to the mean roof or treetop height. The UHI can also influence the urban boundary layer (UBL), a mesoscale layer which combines the cumulative effect of the energy budget from the city beneath and the atmosphere, and is measured above rooftop and canopy height. These layers are not closed systems and are linked by the same processes, particularly heat fluxes. In both systems, the rural areas are assumed to be the control site. The influence of urbanization on near surface air temperature is difficult to establish as both the urban and its 'control' rural sites would need to have similar macroclimatic conditions (e.g. total incoming radiation, prevailing winds, lake effects), 
topography, elevation, etc. and yet be distant enough from each other to limit advective interactions. Typically the spatial distribution of UHI intensity shows maximum differences at the urban centre with a large temperature gradient at the urban-rural edge (Oke, 1997). Previous work has also shown that the minimum daily temperatures (i.e. night time) are associated with the highest UHI intensities (Oke and Maxwell, 1975). The main reason for this observation is that the radiation exchanges for urban and rural surfaces are not solely determined by thermal conductivities (Oke and Maxwell, 1975). This also suggests that the $\mathrm{UHI}$ is not solely controlled by impervious cover, but instead related to urban canyon (Oke, 1981). This effect is exemplified in Peña (2008) where Santiago, Chile acts as an urban heat sink in the daytime due to the extreme surface temperatures from the dry and exposed rural surrounds and relatively cool city. Yet a nocturnal heat island is still observed and attributed to urban canyon effects, where longwave radiation is effectively trapped by canyons of dense multi-storey structures .

Heat islands are not limited to summer, and can often be pronounced in winter, where albedo from snowcover and anthropogenic heating play a stronger role (Oke, 1997). However, heat island intensities are at their maximum during nights in summer heatevent conditions, where areas of high pressure with little or no rain or clouds allow the urban surface to heat to excess in the day and see limited cooling at night. Definitions of heat-waves or heat event conditions vary, however temperatures above $25^{\circ} \mathrm{C}$ with wind speeds under $20 \mathrm{~km} / \mathrm{h}$ and low cloud cover have been associated with maximum UHI intensities as well as increases in heat-stress (Curriero et al., 2002). 
Numerous studies have attempted to characterize UHIs in the GTA with in situ temperature measurements, all detecting increases in air temperature associated with urban land covers (Munn, 1969; Koren, 1998; Mohsin and Gough, 2009). Both Munn (1969) and Mohsin and Gough (2009) employed less than 10 stations to characterize the GTA, and were unable to draw conclusions on the spatial distribution of UHI intensity, however they were able to link the changes in urbanization over past decades with increases in air temperatures. Koren (1998) presented unique observations of a northsouth transect of air temperatures by mobile measurements along Yonge street, a major arterial street running from the centre of Toronto through its periphery. That study found distinct decreases in daytime air temperature as the transect progressed from the urban centre to suburban-rural fringes. This study did not consider surface temperature measurements nor land cover mapping.

\subsubsection{Urban Heat Island Modelling}

In order to characterize and model variations in UHI intensity, the system is typically considered in terms of the surface energy balance equation so as to characterize the fluxes of both urban and rural environments. Oke (1982) produced a modified model of the net surface radiative flux density $\left(\mathrm{Q}^{*}\right)$ applicable to the UCL (Eq. 1). $\mathrm{Q}^{*}$ is primarily driven by short-wave radiation fluxes by day and long-wave radiation loss at night.

Anthropogenic heat flux (Qf) is included to account for heat produced by structures or vehicles. The surface radiant heat energy is balanced by several fluxes. ( $\Delta Q$ s) surface heat storage is heat transported by the conduction into the ground or buildings. (Qe) turbulent latent heat is flux of heat released or absorbed during a change of state of water. 
(Qh) turbulent sensible heat is the flux of heat absorbed or transmitted by surface to the atmosphere during a change of temperature.

$$
\mathrm{Q}^{*+} \mathrm{Qf}=\Delta \mathrm{Qs}+\mathrm{Qe}+\mathrm{Qh}
$$

Oke (1982) was able to determine the dominant terms in Eq 1 responsible for the UHI. As expected, increased $\Delta \mathrm{Q}$ s was found in some urban environments as a result of differences in thermal admittance. Increased thermal admittance of urban structures (e.g. concrete, asphalt) would promote the daytime uptake of heat and nighttime cooling. Despite expected differences in latent heat, due to loss of vegetation in urban areas, it was not found to significantly influence urban-rural $Q^{*}$. It was found that urban areas were not entirely vegetation free and that surface moisture availability was highly variable. Instead, the other critical parameter was decreased long-wave radiation loss in urban environments. Oke $(1981,1982)$ argued that at night, net longwave radiative flux $\left(L^{*}\right)$ was proportional to $\Delta$ Qs under calm, cloudless conditions that are conducive to the UHI. At night, with no shortwave radiation, $\mathrm{Q}^{*}=\mathrm{L}^{*}$ and in near calm and cloudless conditions when the surface layer is stably stratified, the turbulent terms Qh and Qe become negligible so that to a reasonable approximation Eq 1 becomes $L^{*}=\Delta$ Qs. Based on these approximations and by testing scale models of urban and rural surfaces, Oke (1981) effectively demonstrated the influence of canyon geometry on $\mathrm{L}^{*}$. It was determined that Sky View Factor (SVF), a measure of the degree to which the sky is obscured by the surroundings for a given point, is related to long-wave radiative heat loss. Urban canyons with increased building heights have a low SVF, where a greater proportion of the night 
sky is replaced with the sides of buildings which intercept outgoing long-wave radiation, leading to a decreased rate of night time cooling compared to rural areas with high SVF.

While these UHI models assume cloudless conditions, it is rare to find such conditions for the complete diurnal cycle. Studies have shown that cloud cover contributes the largest sources of uncertainty in air temperature modelling by affecting longwave radiation exchanges (Offerle et al., 2003). In the case of UHI intensity modelling, it is assumed that cloud cover would not favour any land use more than another and any uncertainties would be more or less uniform over a given urban area. That said, studies have shown that urban surface temperatures are correlated with increases in photochemical smog mechanisms and decreases in air quality (Lo and Quattrochi, 2003).

Under typical North American heat event conditions, which are rarely entirely absent of wind flow, Qh and Qe are not negligible as proposed in Oke's (1981) early scale model. In order to model heat fluxes or air temperature at a given location within the urban canopy layer, the flux footprint or source area must be considered. Most of the heat flux contribution at $1 \mathrm{~m}$ heights typically comes from not just immediate surfaces, but from surfaces several hundreds of meters downwind of the measurement (Schmid 2002; Leclerc et al., 1990). Wind speed, wind direction and atmospheric stability factor determine the shape and extent of the source area. The more uniform the surface, the more uniform the source area and the easier it is to predict air temperatures. However, urban environments are typically quite heterogeneous due to the mixes of covers, which will have significantly different thermal properties (e.g. lawns, roads, roofs). Determining 
the surface covers, and their ability to store and release heat, over a given flux footprint would likely improve the ability to predict air temperatures.

Although measuring all parameters of Eq. 1 can help predict UHI intensity, the collection of these measurements is expensive and unrealistic for extensive urban environments. However, information on canyon geometry, the wind direction and thermal properties of the surfaces can be collected through remote sensing techniques and may be suitable for predicting $\mathrm{UHI}$ intensities.

The influence of anthropogenic heating has been largely ignored in most UHI studies. Preliminary research has found that the $Q^{*}$ for typical large urban centres range from 400 to $800 \mathrm{Wm}^{-2}$ and Qf has been found to range considerably between 20 and $200 \mathrm{Wm}^{-2}$ in urban environments during summer months (Rigo and Parlow, 2007; Ichinose et al., 1999). Although Qf can be considerably higher in winter months due to heating of urban dwellings and transportation, there is considerable debate on its contribution to summer UHI (Ichinose et al, 1999).

\subsection{Thermal Remote Sensing}

\subsubsection{Estimating Land Surface Temperatures}

Thermal remote sensors (e.g. Landsat TM, ASTER, MODIS) capture spatially extensive per-pixel estimates of radiated energy in the 10.4-12.5 $\mu \mathrm{m}$ spectrum. Effectively, the energy radiated in this spectral range can be directly related to radiant temperature of the 
earth's surface. To estimate land surface temperature (LST) from satellite thermal data, the digital number (DN) of each image pixel is converted into Top of Atmosphere (TOA) spectral radiance using the sensor calibration data for Landsat (e.g. Markham and Barker, 1986).

Before the TOA spectral radiance can be converted to represent surface temperature, some potential sources of error need to be considered. First, the measurement may include other fractions of energy, which may introduce error into the estimate. These include radiation emitted from the ground as well as upwelling radiance from the atmosphere. These other sources of radiation can introduce error into the estimation of surface temperature. Typically atmospheric effects can be corrected by determining atmospheric transmission estimates coinciding with the thermal acquisition.

Numerous algorithms have been tested to convert the calibrated thermal radiance to LST (Schott and Volchol, 1985; Goetz et al., 1995, Sobrino and Jimenez-Munoza, 2004). The majority of these methods perform well, with errors less than $\pm 2.0^{\circ} \mathrm{C}$, but require not only atmospheric corrections but spatially explicit information on surface emissivity. Effectively, to obtain surface temperatures to an accuracy of $0.1^{\circ} \mathrm{C}$, the emissivity must be known to within $0.1 \%$ (Stroeve et al., 1996). Under uniform land cover with small variations in emissivity, this level of accuracy is possible. However, emissivity can vary considerably over urban cover (0.96-0.99) (Snyder et al., 1998), and estimating emissivity is difficult even with extensive land cover information. Axelsson and Lunden (1988) present the difficulties in estimating emissivity for heterogeneous urban areas 
surfaces, such as lawns $(\varepsilon=0.92-0.96)$, painted roofs $(\varepsilon=0.90-0.94)$ and roadways $(\varepsilon=$ 0.94-0.97), that may be in a given urban pixel. Even among vegetated rural areas, the leaf cover of broadleaf trees could have emissivities varying from 0.89-0.94 (Crowley and Da Luz, 2007). However, despite these difficulties, Sobrino and Jimenez-Munoza (2004) were able to demonstrate improved accuracies in LST estimation in non-urban areas using variable emissivity information.

\subsubsection{Thermal Remote Sensing of Urban Landscapes}

In the first years of thermal remote sensing studies applied to urban areas, Roth et al. (1989) discussed implications for UHI modelling in a series of questions posed to the research community. The authors describe a "veritable bonanza" of thermal remote sensing data, in 1989 limited to AVHRR $1 \mathrm{~km}$ imagery, and a series of UHI studies employing these new data sources. The authors investigated the popular new tool and found a common misuse or overemphasis on thermal imagery, particularly what is actually being observed in a $1 \mathrm{~km}$ AVHRR pixel. In urban areas, this could include a variety of structures and land covers. In the analysis of spatial and temporal variations in surface temperatures, the authors found observations which were not consistent with the common characteristics of UHIs. Although highest surface temperatures were found in industrial-commercial zones, which are traditionally "hot" zones, the central business districts did not have the expected high temperatures. Based on these observations, the authors posed questions to the community about the accuracy of the surface temperature measurements themselves, particularly the range of temperatures being observed in a 1 
$\mathrm{km}$ urban pixel, as well as the notion of characterizing UHIs with surface temperatures alone.

Voogt and Oke (2003) followed up these questions to see how the remote sensing research community had responded. The authors propose that the bulk of thermal remote sensing studies are no closer to mapping actual heat islands. They list several dozen studies that had effectively addressed surface temperature accuracies (i.e. atmospheric corrections) but ignored the issues of modelling air temperatures outlined by Roth et al. (1989). Many studies produced an incredible wealth of surface temperature samples from various angles, resolutions and times of day for large North American cities such as Atlanta (Lo et al., 1997) and Dallas (Gallo and Owen, 1998) as well as large Asian cities such as Shanghai (Zhu et al., 2009) and Tokyo (Sugawara and Takamura, 2006). These studies report similar findings, with elevated surface temperatures in urban centres relative to cool temperatures in rural fringes. These studies also report similar high correlations between cooler surface temperatures and vegetation cover. Yet most of these studies did not address air temperature in any capacity and provided no practical links to urban climatology. Although many studies reviewed did attempt to model air temperature with thermal remote sensing measurements (e.g. Rigo and Parlow, 2007), results are over small extents and do not provide uncertainty estimates for extensive modelling of UHI intensities. In revisiting Roth et al (1989)'s questions Voogt and Oke (2003) show the influence of thermal anisotropy, or scene geometry, and the potential underestimation of the 3D urban surface using 2D imagery. Despite these largely unaddressed limitations, Voogt and Oke (2003) conclude that thermal remote sensing still provides a valuable 
estimate of surface temperatures and has a role in urban atmospheric models, most likely partnered with in situ meteorological measurements.

\subsubsection{Thermal Anisotropy}

A factor that must be considered in the estimation of surface temperatures of urban areas from satellite imagery, is to determine what surface is actually being "seen" by the sensor (Roth et al.1989; Voogt and Oke, 2003). Complex 3D urban structures have a directional component to both how walls and roofs heat up or are shaded from solar radiation, as well as how these surfaces are observed by a satellite sensor at a given view angle. Voogt and Oke (1998) effectively demonstrate this by measuring apparent surface temperature over the diurnal cycle for north and south facing walls with an array of vehicle-mounted infrared thermometers for comparison with remotely sensed rooftop temperatures. It was observed that south facets had higher daytime surface temperatures than the north facets and rooftops. Not until several hours after sunset did the temperature differences begin to decrease. These results suggest that a nadir thermal remote sensing observation would not only omit a large portion of radiated surface area by only detecting the rooftops, but also underestimate the maximum surface temperature in a single pixel. This bias in surface temperature measurement varies with land use, as building geometries tend to become more complex in central business districts or dense residential areas. Figure 1 provides an example of this effect from a night-time thermal image with an off-nadir viewing angle that shows rooftops are cool relative to building walls and streets. Studies have shown that while rooftops and walls have different night-time surface temperatures, opposing walls within a canyon typically have insignificant surface temperature 
differences (Santamouris et al., 1996). This is due to the canyon effect, with rooftops receiving less longwave radiation from the cool night sky while opposing walls receive radiative emissions from each other (Oke, 1982). Rigo and Parlow (2007) calculate the enlargement of the thermal surface due to the 3-D structure of the city of Basel, Switzerland, estimating the potential surface for heat fluxes to almost double those of the 2-D surface.

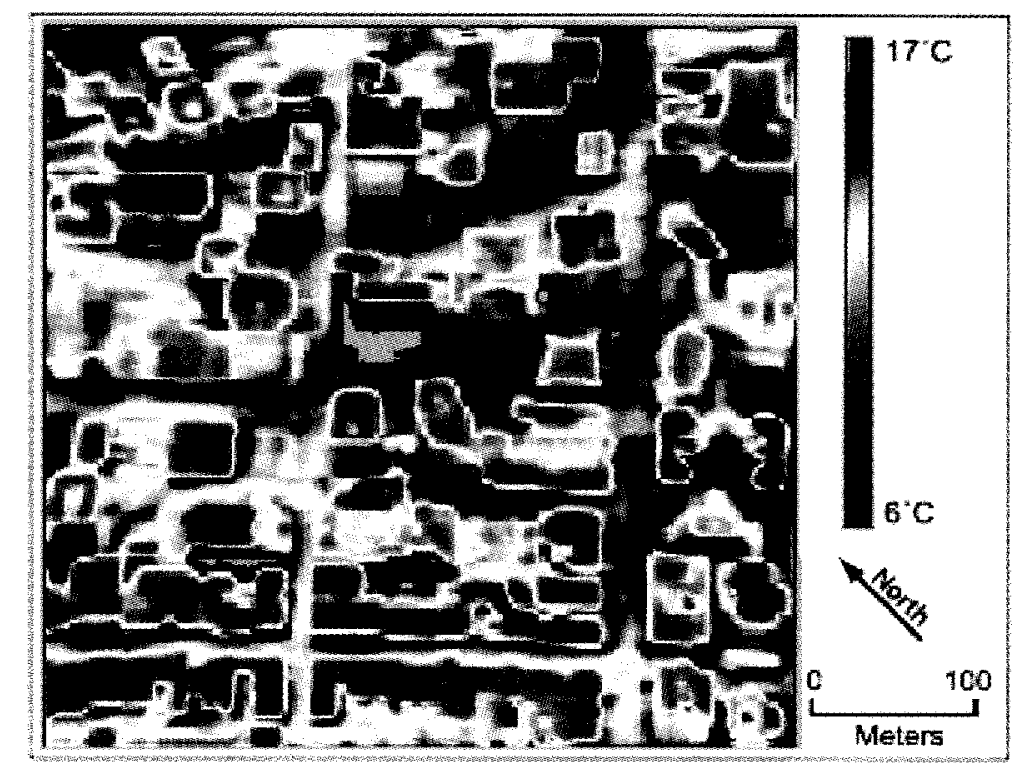

Figure 1. Night-time thermal image of downtown Vancouver, off-nadir viewing angle (Voogt et al., 2003).

\subsubsection{Landsat Sensors}

The Landsat Thematic Mapper (TM) and Enhanced Thematic Mapper (ETM) thermal sensors have a relatively fine nominal ground pixel size (120 m for TM and $60 \mathrm{~m}$ for ETM), capturing swaths of $185 \mathrm{~km}$ with 16 day repeat cycles at approximately 10:00 local time. Landsat TM has been operational since March 1, 1984 and now has 25 years 
of imagery. Landsat ETM+ has been operational since April 15, 1999, however on May 31, 2003 the Scan Line Corrector (SLC) instrument failed. The SLC failure results in linear gaps of missing data within the acquired image (i.e. 5 pixel gaps every 15 pixels).

The Landsat thermal sensors have been calibrated extensively by NASA and USGS with regular updates for the radiometric calibration parameters (gain and offset) that are necessary to properly calculate radiance (Barsi et al., 2003). Both TM and ETM+ sensors have on-board thermal calibration systems consisting of blackbody and low emissivity shutters. Tests have also been carried out using both the on board calibration systems and surface targets with known temperatures and emissivities to validate these sensor calibrations (Barsi et al., 2003). Many recent remote sensing based studies of UHIs have used Landsat sensors (e.g. Lo et al., 1997; Sobrino and Jimenez-Munoza, 2004; Peña, 2008) and share similar limitations in terms of 10:00 acquisition time and $120 \mathrm{~m}$ pixel resolution.

\subsection{Urban Heat and Human Health}

Heat related morbidity and mortality are central drivers for monitoring and modelling UHIs (e.g. Smargiassi et al., 2007). As urban centres tend to have higher air temperatures than surrounding rural areas, these areas are more susceptible to extreme heat events. With extreme heat, there is often significant mortality and morbidity, particularly for vulnerable populations, such as were recently recorded in France in 2003 (Fouillet et al., 2006). The impact on human health is not static; as an urban centre expands, the climate 
co-evolves, compounding the effect of increased air temperatures and increased population at risk.

With a projected increase in the number and intensity of extreme heat events resulting from climate change (Natural Resources Canada, 2007), and $80 \%$ of Canadians living in urban areas, there is a clear requirement for UHI mapping and monitoring despite Canada's reputation for cooler temperatures. In a study of 11 North American cities Curriero et al. (2002) found that heat related mortality increases with latitude. The likely explanation for this observation is the lack of preparedness in northern cities for heat events, such as a lack of air conditioning in low-income apartments or community cooling centres.

Given that preparedness for heat waves, as well as urban cooling methods such as "green roofs", rely on knowing the extent and intensity of the UHI, mapping of surface and air temperatures is required by public health agencies. A number of recent studies (e.g. Smoyer 1998) have begun integrating neighbourhood-level remotely sensed surface temperatures with socio-economic vulnerability (e.g. derived from census data) in order to determine risk for heat wave morbidity or mortality.

While technology permits extensive measurements of surface temperature, they are not well suited for human health applications. It is the air temperature which not only affects comfort, but in extreme heat events, determines mortality and morbidity (Smargiassi et al., 2007). Surface heating is clearly linked to air temperatures in the urban atmosphere 
through the transport of sensible and latent heat from the surface into the air of the urban canopy layer. However, surface and air temperatures are not directly correlated, particularly over the diurnal temperature cycle, and their relationship can vary considerably with winds and humidity (e.g. Roth et al., 1989). 


\section{Methods}

The following chapter describes the study area, methods to measure surface and air temperature using in situ and remote sensing techniques, as well as methods to model urban structure. UHI intensities will only be characterized using temperature $\left({ }^{\circ} \mathrm{C}\right)$ as described above. All times listed in the study refer to Local Standard Time.

\subsection{Study Area}

With the majority of Canadians living in urban centres throughout the St. Lawrence River Valley (Quebec City to Windsor), the GTA was selected as a study site that would represent the climatological conditions of this region and also because of its extensive urban cover and previously observed heat island effect (e.g. Munn, 1969). The urban study site may also be representative of other North American metropolitan areas, with its distinct central business district and substantial residential periphery. However, considerations should be made for the city's proximity to Lake Ontario (Gough and Rozanov, 2001), which has been shown to contribute to cooling effects caused by onshore breezes. The study area includes the GTA, comprising extensive suburban areas such as Oakville, Ajax, and Brampton, as well as the rural fringe as far north as the Oak Ridge Moraine. The GTA is one of the fastest growing urban areas in North America with a population of 5.53 million and an area of $641 \mathrm{~km}^{2}$ (Statistics Canada, 2008). The study area extent and in situ monitoring locations are shown in Figure 2. 


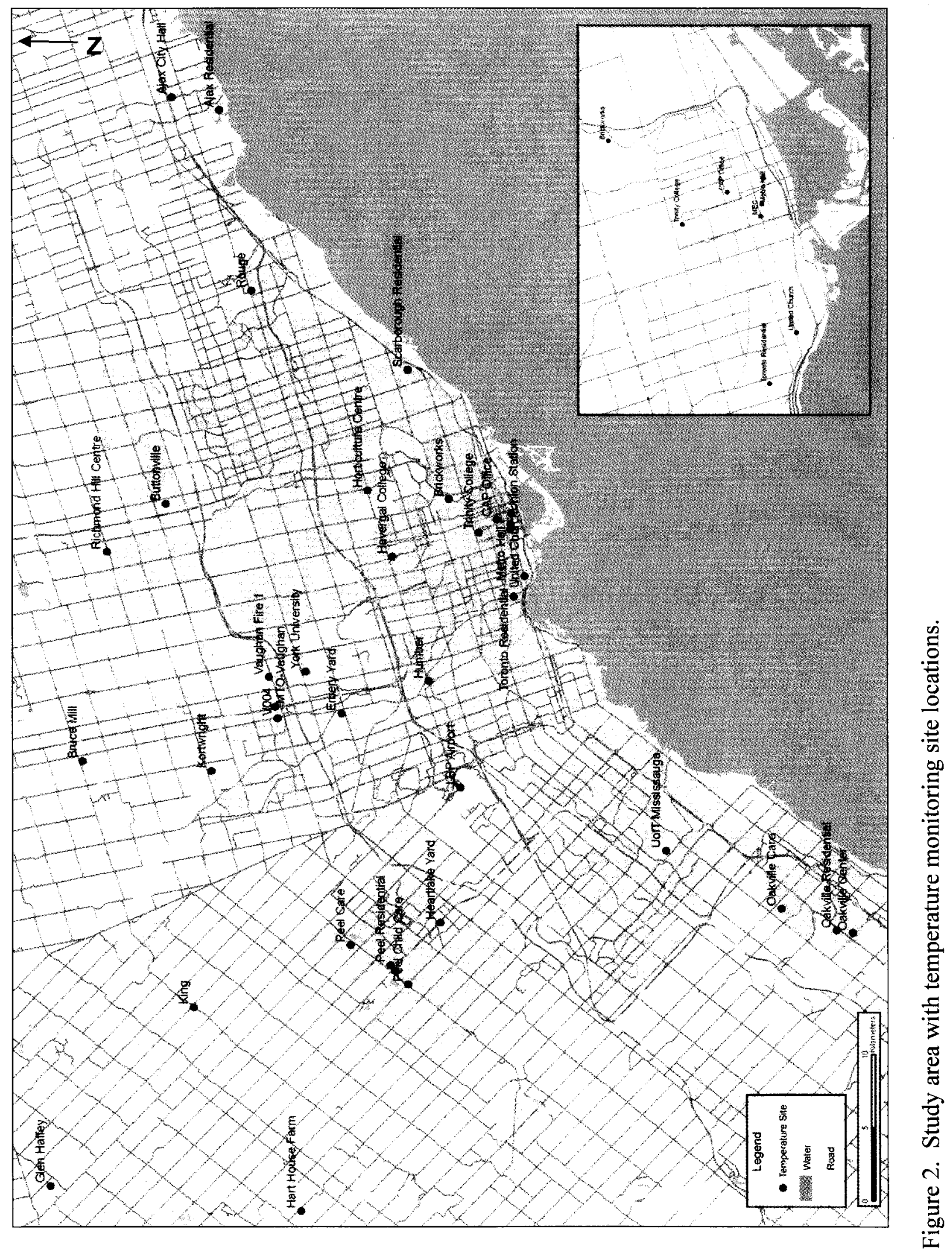




\subsection{Surface and Air Temperature Monitoring Sites}

In order to characterize air temperatures across the study area, in situ measurements were collected at 40 monitoring sites covering a wide range of urban and rural covers during the summers of 2007 and 2008. For the purpose of this study, 26 sites were installed for this study and the remaining sites were from other monitoring programs (monitoring site details can be found in Appendix I). In many cases monitoring sites were installed on rooftops, while others were at "street" or ground level, but all measurements are assumed to be within the UCL.

The monitoring site specifications varied among many of the sites due to individual site properties and the equipment employed, however some minimum specifications were met for each site. At every monitoring station, air temperature was measured at a minimum interval of every hour at approximately $1.5 \mathrm{~m}$ above the surface (approximately "screen" level). Each of the 26 installed monitoring sites, had HOBO TMC-HD air temperature sensors, and in many cases co-located customized surface temperature sensors installed on and over the dominant surface covers.

Other monitoring sites included meteorological stations from Environment Canada, Toronto Regional Conservation Authority (TRCA) and Ontario Ministry of Transportation. At these sites, a wide range of measurements, including wind speed, precipitation and solar radiation, were collected during the study. Additional meteorological data were acquired from weather stations at the University of Toronto and York University. While the 40 sites provided data for many of the dominant urban 
surface covers, there were large spatial gaps between sites (up to $10 \mathrm{~km}$ ) and certain surface cover types were not included due to access or security reasons (e.g. private businesses).

The distribution of stations by land use was as follows; 26 urban, 8 rural, and 6 suburban. The urban and suburban stations are considered to be an accurate representation of the diverse covers of the GTA. Included are recreation centres, churches, fire stations, residential homes and commercial high-rises. Two of the rooftop urban sites were also classified as "green roofs" with drought resistant vegetation. The 8 rural sites, consisting of both unmanaged pastures and forested covers, are believed to accurately represent the baseline natural conditions outside of the GTA. Photos of typical monitoring installations for surface and air temperatures sensors can be seen in Figure 3. All temperature measurements were averaged to hourly data points based on the coarsest recording frequency. Analysis indicated that there was little temperature variability that was omitted by using hourly averages.

Access to many of the monitoring stations was extremely difficult and ultimately resulted in a number of sensor outages due to battery failures or damage over long periods. Based on the outages and varied site specifications, there were only a few time periods during which all stations were operating. 


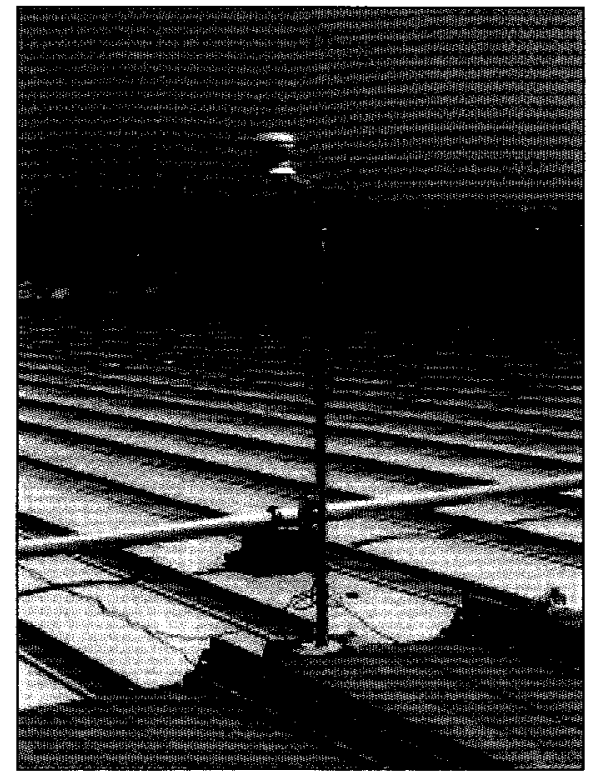

Figure 3a. TMC-HD air temperature sensor mounted on a 1.5 meter mast with radiation shield.

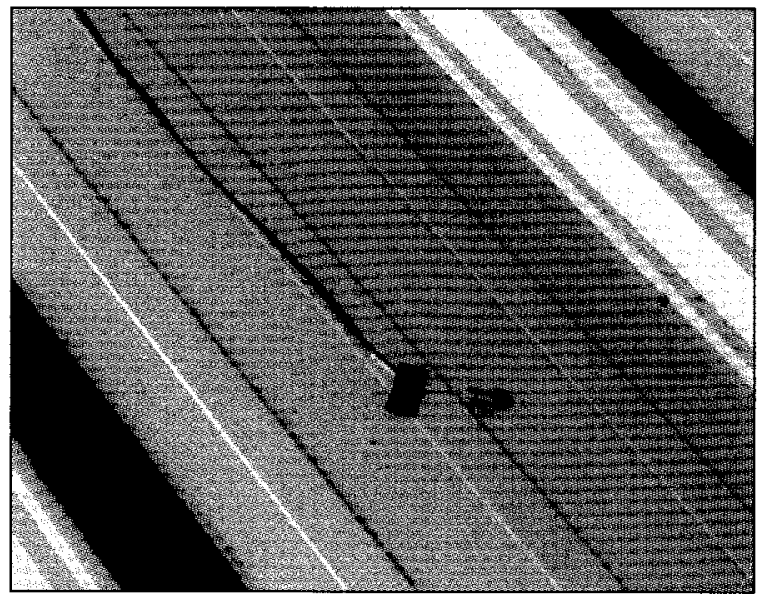

Figure 3b. Custom surface temperature sensor. Secured to surface with silicone gel.

\subsubsection{Measurement Validation}

The HOBO TMC-HD air temperature sensors were tested but not cross-calibrated prior to installation at the monitoring sites. Instead, during installation, the sensor readings were compared over a 15 minute period to readings from a portable temperature sensor (DiGi-

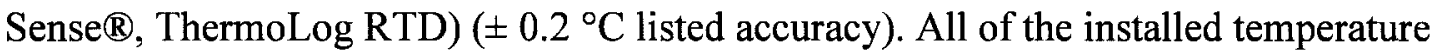
sensors recorded differences no greater than $\pm 0.5^{\circ} \mathrm{C}$ from the portable standard. Quality control of the air temperature data collected at the monitoring sites was also assured by checking hourly values against concurrent measurements at the Environment Canada Lester B. Pearson Airport station. For quality assurance testing, temperature differences exceeding an arbitrary threshold of $10{ }^{\circ} \mathrm{C}$ were checked as they would likely indicate an erroneous measurement as opposed to actual site difference such as UHI effect. No 
stations reported differences greater than $4.8^{\circ} \mathrm{C}$ over the comparison period of August 2008 and all measurements were deemed valid.

As the surface temperature sensors were custom thermistors, stripped of any protective casing for point contact measurements, a pre-deployment validation procedure was used. Two custom sensors were immersed in a bucket of "room temperature" water. The temperature of the water was also recorded by one of the unmodified HOBO TMC-HD air temperature sensors. The sensors were allowed to record at 1 minute intervals for a minimum of 1 hour. All of the modified sensors recorded temperatures within $\pm 1.0^{\circ} \mathrm{C}$ of each other and the TMC-HD sensor, which was determined to be within an acceptable accuracy range. Consequently, differences in air temperature among monitoring sites were considered real when greater than $0.5^{\circ} \mathrm{C}$, while differences in surface temperatures had to be greater than $1.0^{\circ} \mathrm{C}$.

\subsection{Remotely Sensed Surface Temperature Measurements}

\subsubsection{Acquisition}

Four Landsat TM images from scene path 18, row 30 , which covers the GTA and rural surrounds (Figure 4), were acquired. Other images were available for the summer periods of 2007-2008, however these either had substantial cloud cover or were on relatively cool days (maximum air temperatures of less than $25^{\circ} \mathrm{C}$ ). A small portion of the eastern GTA, including most of Ajax, was not acquired in these scenes. Table 1 lists the acquisition dates and meteorological conditions for the imagery that was used in the analysis. 


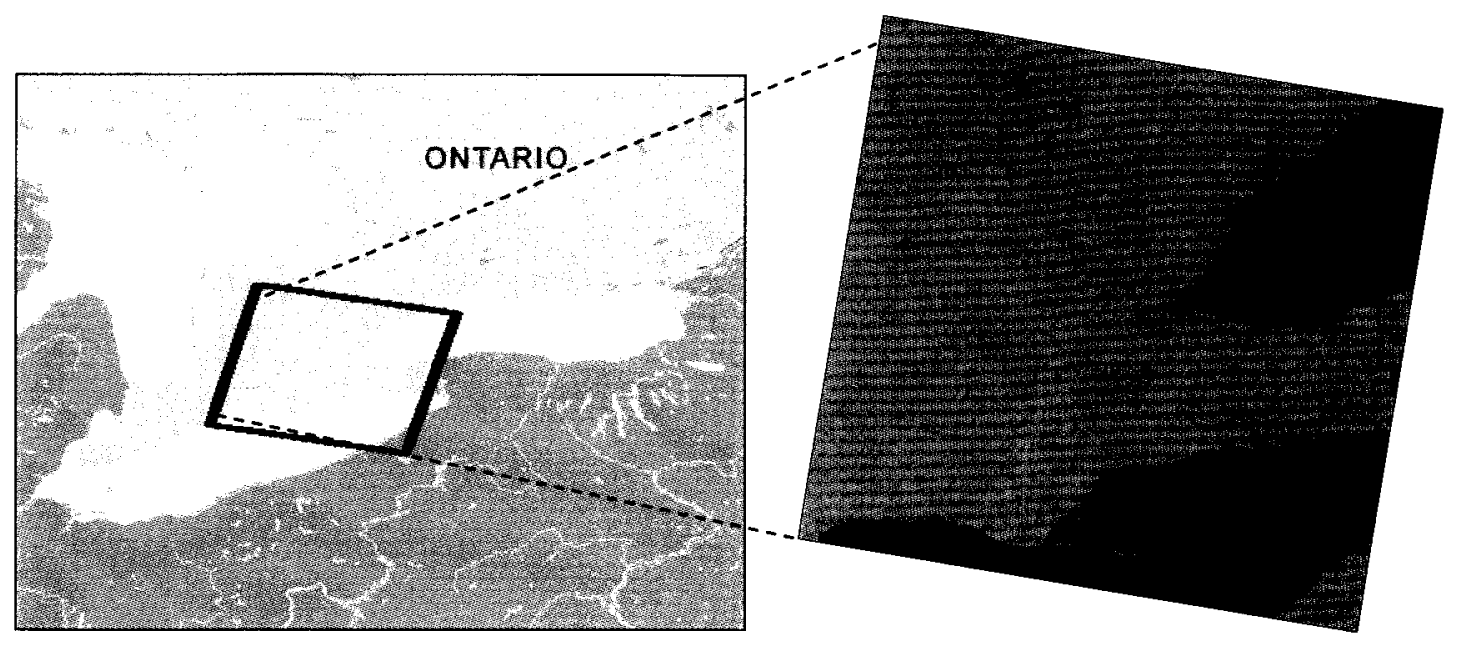

Figure 4. Southern Ontario with Landsat scene extents (path 18, row 30) covering GTA study area.

Table 1. Landsat imagery acquisitions and meteorological conditions at the time of acquisition. Air temperature, relative humidity and wind speed for 10:00 Local Standard Time from Lester B. Pearson Airport meteorological station (Environment Canada). Atmospheric transmission estimated from National Center for Environmental Prediction.

\begin{tabular}{|c|c|c|c|c|}
\hline 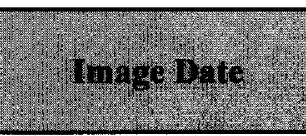 & $\begin{array}{l}\text { Air Temperatine } \\
\text { (o) }\end{array}$ & $\begin{array}{l}\text { Rel humidity } \\
(1 \%)\end{array}$ & $\begin{array}{l}\text { Whide } \\
(\mathrm{kin} / \mathrm{h})\end{array}$ & $\begin{array}{l}\text { Atmospheric } \\
\text { Transmission }\end{array}$ \\
\hline August 1,2007 & 30.7 & 48 & 4 & 0.62 \\
\hline July 1, 2008 & 23.1 & 43 & 15 & 0.78 \\
\hline August 25, 2008 & 17.3 & 37 & 20 & 0.80 \\
\hline September 3, 2008 & 26.3 & 48 & 7 & 0.76 \\
\hline
\end{tabular}

\subsubsection{Image Pre-processing}

In order to establish actual surface temperatures at specific locations for precise comparison with air temperatures or other parameters, the images needed to be geometrically corrected to a reliable source in order to minimize the positional error. The 
images were corrected with 1:50,000 Geobase road networks as reference using a firstorder polynomial transformation with PCI Orthoengine software (PCI Geomatics, 2003). A minimum registration accuracy of $\pm 120 \mathrm{~m}$ (1 pixel) for TM imagery was achieved using 25 ground control points for each image.

\subsubsection{Land Surface Temperature Estimation}

The LST conversion was carried out by first converting the TM imagery digital numbers (sensor values scaled from 0 to 255 ) to Top-Of-Atmosphere radiance values $\left(\mathrm{TOA}_{\mathrm{R}}\right.$ ) using gain and offset calibration values included with the Landsat image products. The conversion of $\left(\mathrm{TOA}_{\mathrm{R}}\right)$ to surface radiance $\left(\mathrm{S}_{\mathrm{R}}\right)$ was calculated using Eq. 2 with atmospheric transmission $(\tau)$ and upwelling estimates $\left(\mathrm{L}_{\mathrm{U}}\right)$ for the 10.4-12.5 $\mu \mathrm{m}$ range from the NCEP (National Center for Environmental Prediction) attained using the online tool developed by developed by Barsi et al. (2005).

$$
\mathrm{TOA}_{\mathrm{R}}=\tau \mathrm{S}_{\mathrm{R}}+\mathrm{L}_{\mathrm{U}}
$$

Eq. 2

The atmospheric correction of Landsat TM TOA $\mathrm{T}_{\mathrm{R}}$ using the NCEP measurements has been shown to produce LST estimates within $2.0^{\circ} \mathrm{C}$ (Barsi et al. 2005). Once $S_{R}$ is determined, LST is calculated using an inverse Planck function (Schott and Volchol, 1985). This method, shown in Eq 3, where LST is degrees Kelvin, where $K_{1}(607.76)$ and $\mathrm{K}_{2}(1260.56)$ are the calibration constants applied for the $10.4-12.5 \mu \mathrm{m}$ range. 


$$
\mathrm{LST}=\frac{\mathrm{K}_{2}}{\ln \left(\frac{\mathrm{K}_{1}}{\mathrm{SR}_{\mathrm{R}}}+1\right)}
$$

LST estimation processing was carried out using PCI Geomatica software (PCI

Geomatics, 2003). Although this method can use emissivity estimates, for the purposes of this study an emissivity of 1.00 was assumed for each pixel. Although precise emissivity could be estimated for uniform land covers, such as extensive rural areas, other land covers were too heterogeneous to estimate a precise emissivity, particularly residential areas. The error associated with using a uniform emissivity of 1.0 on LST is not expected to increase the error range beyond the $2.0^{\circ} \mathrm{C}$ range. For the purposes of this study, all LST measurements will refer to 10:00 local time only, based on the timing of the Landsat acquisitions.

\subsubsection{Validation}

In order to test the accuracy of the LST maps, estimated LST was compared to roof top in situ surface temperature measurements. Numerous studies have similarly assessed the accuracy of Landsat based LST (e.g. Schneider and Mauser, 1996) and a rigorous validation was not deemed necessary. However, a limited test of the map accuracies indicated that the method was implemented correctly and error ranges from previous studies may be applicable. Surface temperatures were collected at 10 sites from various urban covers over the study area for dates coincidental with the 2008 imagery. The LST maps derived from July 1, 2008 and September 3, 2008 were selected along with in situ 
measurements from 10:00 on the acquisition dates were selected as ground reference. Although none of the in situ sensors was measuring entirely homogeneous $120 \mathrm{~m}$ surfaces to match the satellite based minimum mapping unit, they were on surfaces representative of the dominant cover of city blocks or neighbourhoods. In some cases, multiple sensors were used at the same site to assess heterogeneity in surface temperatures. Table 2 shows a sample of the monitoring sites and lists the in situ and collocated Landsat estimated surface temperature for July 1, 2008. Although some LST estimates differ from the in situ measurements by as much as $6.2{ }^{\circ} \mathrm{C}$, the average difference is approximately $2.5^{\circ} \mathrm{C}$. There appears to be no systematic bias of the LST estimates on the whole or associated with any particular surface type and it is possible that the differences are a result of insufficient coverage by the in situ sensors to account for $120 \mathrm{~m}$ pixels. For example, when considering the Oakville Recreation Centre site, the municipal building covers roughly $30 \mathrm{~m} \times 30 \mathrm{~m}$ but is surrounded by an extensive grass recreation area. Based on these results, which were in agreement with other studies comparing in situ and Landsat LST estimates (i.e. Rigo et al. 2006), the LST maps are deemed accurate to within the $2.5^{\circ} \mathrm{C}$ range. It should be noted that this validation did not take into account walls or other facets that would not be apparent in the nadir acquisition. 
Table 2. In situ surface monitoring sites with sensor temperatures and Landsat LST measurements from July 1, 2008.

\begin{tabular}{|l|l|r|r|r|}
\hline $\begin{array}{l}\text { Monitoring Site } \\
\text { Location }\end{array}$ & $\begin{array}{l}\text { Dominant Surface } \\
\text { Description }\end{array}$ & $\begin{array}{l}\text { In Situ LST } \\
\left.\text { ( }{ }^{\circ} \mathbf{C}\right)\end{array}$ & $\begin{array}{l}\text { Landsat } \\
\left.\text { LST ( }{ }^{\circ} \mathbf{C}\right)\end{array}$ \\
\hline Ajax City Hall & gravel & & $\begin{array}{l}\text { Difference } \\
\left({ }^{\circ} \mathbf{C}\right)\end{array}$ \\
\hline Ajax Rec. Park & grass & 28.8 & 26.2 & 2.6 \\
\hline Oakville Rec.Centre & aluminum /grass & 33.5 & 27.3 & 0.6 \\
\hline Mississauga Fire & asphalt & 21.5 & 26.2 & 5.2 \\
\hline Toronto Metro Hall & large stone & 18.5 & 22.0 & -3.5 \\
\hline Toronto CAP Office & large stone & 23.6 & 24.2 & -0.6 \\
\hline Toronto MEC & grass & 24.0 & 27.6 & -3.6 \\
\hline Emery Yard & aluminum & 34.0 & 36.2 & -2.2 \\
\hline Horticultural Centre & grass & 23.3 & 26.7 & -3.4 \\
\hline Vaughan Fire Station 1 & gravel & 31.5 & 31.0 & 0.5 \\
\hline
\end{tabular}

\subsubsection{Source Area Averaging}

Initial research on flux footprints (Schmid 2002; Leclerc et al., 1990) demonstrates that most of the heat flux contribution at $1.5 \mathrm{~m}$ height typically comes from not just the immediate surface, but several hundreds of meters of surface upwind of the measurement. In order to test the impact of the upwind sources on air temperatures, the LST pixels upwind of each monitoring site were averaged from distances of $240,360,480,600,900$ and $1200 \mathrm{~m}$ and correlated with the $1.5 \mathrm{~m}$ air temperatures. The prevailing winds for each day were taken from the Lester B. Pearson Airport and Buttonville Airport weather stations (Environment Canada) on July 1, 2008 ( $280^{\circ}$ wind direction) and August 1, 2007 $\left(160^{\circ}\right.$ wind direction). The pixels were averaged using a wedge shaped block statistics algorithm in ArcGIS software (Environmental Systems Research Institute, 2004). The 
wedge averaging was selected to include pixels within a $60^{\circ}$ angle of the wind direction originating from the monitoring sites (Figure 5). The wedge shape was selected based on Schmid (2002), which describes highly variable elliptical shaped source areas upwind of a measurement site that contribute to the atmospheric characteristics, such as air temperature, at that site. The relatively wide radius was selected assuming that there would be some variation in wind direction over the measurement period and across the study area. At many of the measurement sites winds may be affected by the urban canyon, effectively channelling winds along street directions. A sample of the original LST pixels and source area averaged is shown in Figure 6.

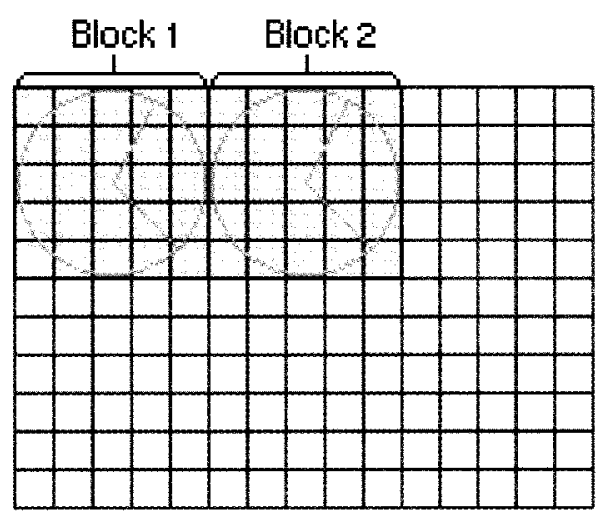

Shaded cells define the blocks on the output grid

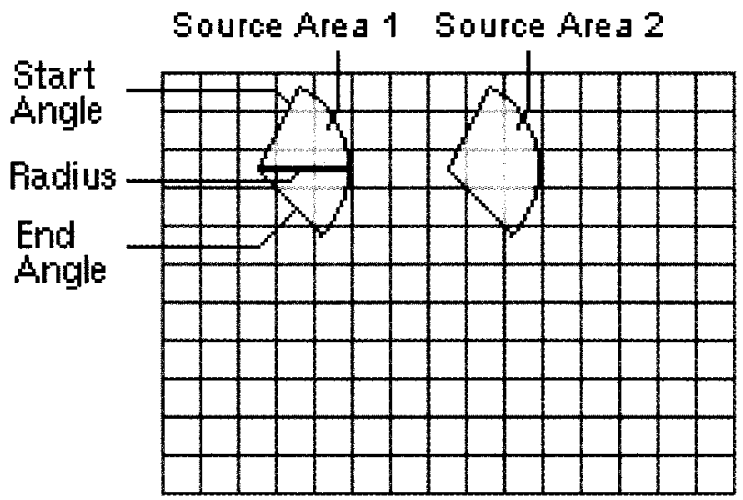

Shaded cells included in the Source Area calculations

Figure 5. ArcGIS block statistical calculation method for pixels within a wedge shape. The start and end angle were defined based on the wind direction and a $60^{\circ}$ angle. 

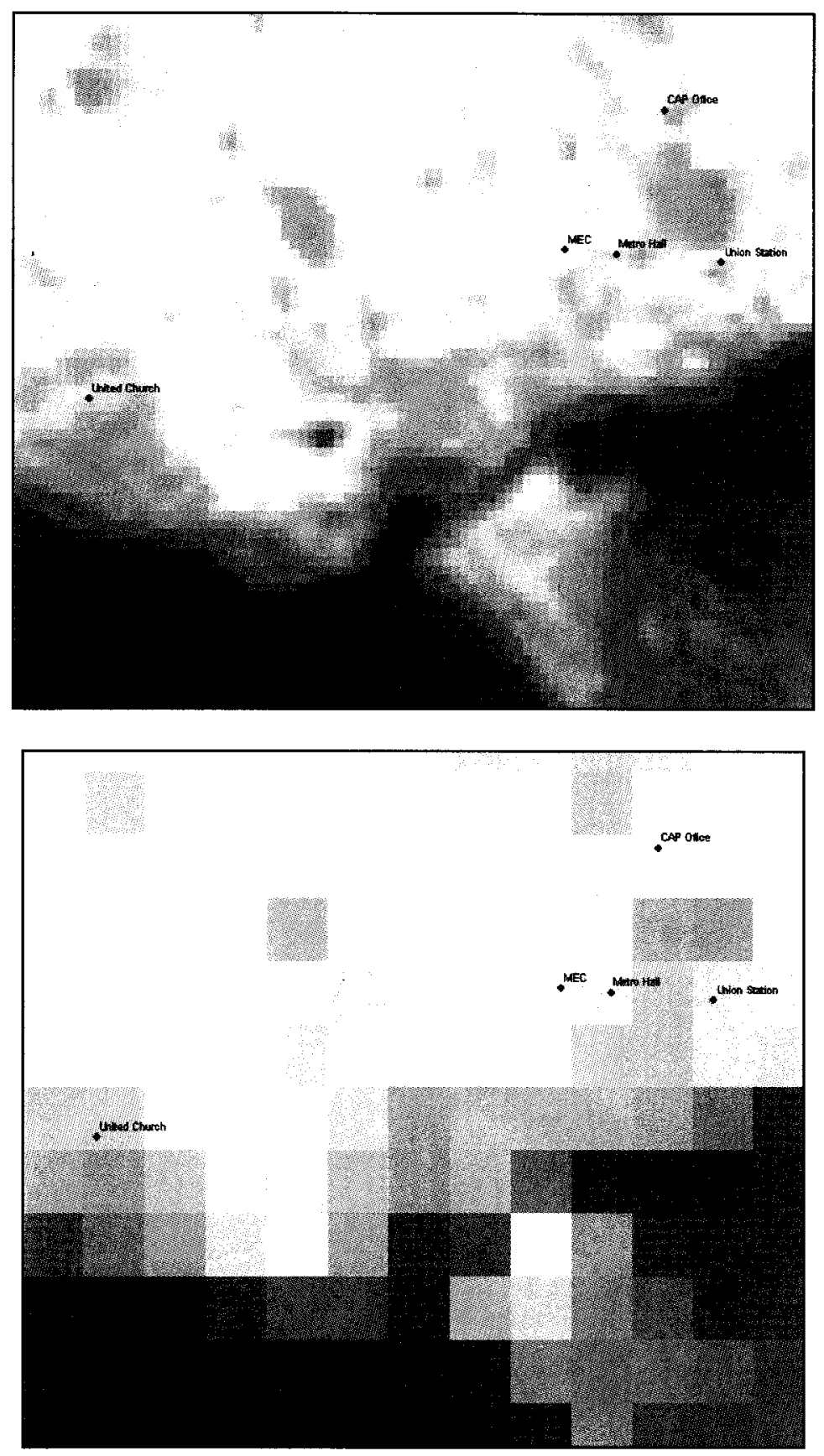

Figure 6. Land surface temperature (LST) from $120 \mathrm{~m}$ pixels (above) averaged over a $480 \mathrm{~m}$ source area (below). 


\subsection{Urban Geometry and Urban Canyon Mapping}

Urban geometry plays a role in not just the urban canyon effect, the trapping of heat and rate at which air temperatures cool at night, but also in thermal anisotropy with thermal remote sensing limited in its ability to observe 3D heated surfaces (Oke, 1982; Voogt and Oke, 2003). The urban canyon effect has been characterized by building height-to-width ratios as well as Sky-View Factor estimates (Oke, 1982) or simple averages of building height or densities (Bottema, 1997). The influence of heated walls omitted from nadir Landsat observations has not been extensively quantified, although suggestions have been made to employ solar aspect models (Voogt and Oke, 2003).

This study proposes that frontal area density $\left(\lambda_{\mathrm{F}}\right)$, a common parameter for quantifying the urban roughness, can serve as an indicator of both the urban canyon effect and proportion of horizontal surfaces omitted by the Landsat acquisitions. Bottema and Mestayer (1998) present an approach to calculate $\lambda_{\mathrm{F}}$ values using irregular building footprints based on building height $(\mathrm{h})$ and width $(\mathrm{w})$ measurements for the purpose of wind flow modelling. This approach, with some modifications, was used to produce $\lambda_{F}$ for a given site area (A). $\theta$ represents the peak solar radiation angle, south to match the acquisition time (i.e. 10:00) insolation, as frontal area $\left(\mathrm{h}^{*} \mathrm{w}\right)$ is a function of building orientation:

$$
\lambda_{\mathrm{F}}(\theta)=\left(\mathrm{h}^{*} \mathrm{~W}(\theta)\right) /(\mathrm{A})
$$


There is an inherent complexity in attempting to parameterize the proportion of walls which are heated and those which are shaded, particularly when considering the scene geometry as the sun angle changes throughout the day. Although solar aspect models exist for smaller scenes (e.g. building block) they would not be applicable to large areas. In this study, frontal area was calculated only for south facing walls, with the assumption that the majority and peak insolation will occur on these facets. Voogt and Oke (1998) demonstrated that southern facets had surface temperatures exceeding those of rooftops, whereas the northern facets had surface temperatures approximating those of the rooftops.

In order to calculate $\lambda_{\mathrm{F}}$, building perimeters and heights were required. Highly detailed stereographic vector data containing building polygons (e.g. residences, industrial buildings, sheds) were acquired from the City of Toronto planning division. The stereographic vector data was photogrammetrically constructed from aerial photos at a 1:5000 scale. In order to use the building polygons to estimate $\lambda_{\mathrm{F}}$, considerable preprocessing was required. The data were provided as CAD files in $250 \mathrm{~m} \times 250 \mathrm{~m}$ subsections which required translation to merged ArcGIS shapefiles. The merged dataset did not include elevations $(h)$ for the entire GTA. Although this information was collected for most of the City of Toronto, it was not collected for many of the peripheral regions. In order to build a complete 3D building database, the building elevations for some regions were estimated from off-nadir aerial photography. Comparisons of these estimates to actual building heights (field data) ensured the validity of the estimated heights (e.g. $+-3 \mathrm{~m})$. In all cases a singular $h$ value was given to each structure; the 
angular properties of many residential roofs were ignored as this may introduce bias in suburban areas dominated by irregular rooftops.

Building polygons that were less than $1.5 \mathrm{~m}$ apart were aggregated, as it was assumed that no significant insolation would occur between structures with this proximity. This was also done to minimize processing time. After aggregation, the number of individual structures in the GTA was 581,700 . In order to calculate any urban geometric parameters, perimeter and area values were derived for each polygon.

The site area (A) estimation presented a challenge, as buildings were rarely of similar size or regularly spaced apart. Many of the studies that calculated $\lambda_{\mathrm{F}}$ had slightly different interpretations of "site area". Burian et al. (2004) used uniform grids (e.g. 100m pixels) to determine A, however, this led to splitting of building footprints. Based on the irregular arrangement of structures across the GTA, it was decided that uniform grids would not be appropriate for site areas. Euclidean distance between building polygons was calculated to create site area polygons which were then linked to the building polygons for the $\lambda_{\mathrm{F}}$ calculations. Figure 7 shows a sample of the building footprints and the site areas. 


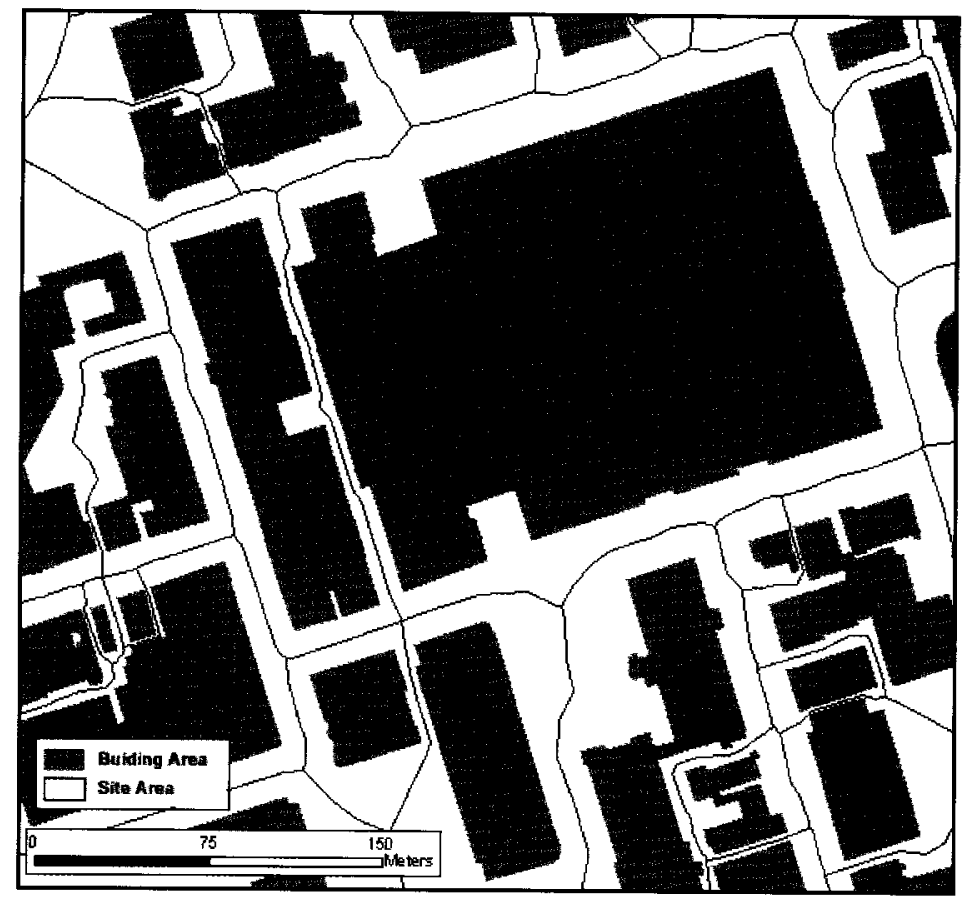

Figure 7. Sample building footprints and site area polygons.

Gal and Hunger (2009) present a sophisticated method to calculate frontal area from a given wind direction, which was applied to this study to calculate south facing frontal area. A vector layer was created containing lines parallel with the given radial direction $\theta$ and covering each site area polygon (Figure 8). The distance between the neighbouring lines is $5 \mathrm{~m}$. Each line intersection with each building footprint polygon was then counted and based on the $5 \mathrm{~m}$ line spacing, number of line intersections ( $\mathrm{n}$ ) per building and the building height (h) and width (w) used to calculate frontal area. The frontal area was then divided by the area of the site to determine the density. As this method incorporates solar radiation angle, the orientation of the structure will affect the frontal area estimate.

Whether structures are oriented directly north-south or not, likely determined by grids of street networks, will have an impact on solar loading. Although it is assumed that various 
regions of the GTA have different average orientations, no quantitative analysis of these differences was carried out.

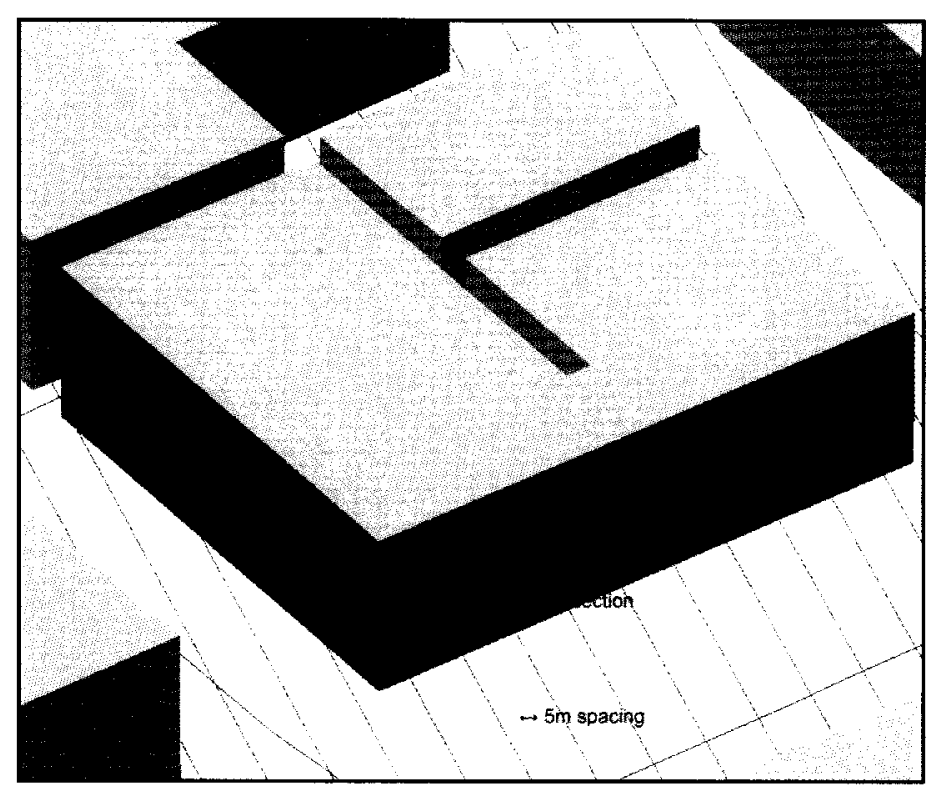

Figure 8. Sample building footprint with parallel line intersections to calculate frontal area.

Several statistical tests, carried out in Microsoft Excel (Microsoft Corporation, 2003) and ArcGIS (Environmental Systems Research Institute, 2004), are used to determine the strength of the relationships between variables. To first determine air temperatures and surface temperature difference from urban and suburban sites and rural baseline, a series of single factor ANOVA tests were carried out. The results of the ANOVA provide insight into the strength of the UHI, which can later be used to assess the suitability of variables, such as surface temperature, to model these air temperature differences. In order to establish significance of the ANOVA, Tukey tests (Zar, 2006) are carried out. The Tukey tests statistic establishes the absolute mean difference by dividing the difference between the means by the square root of the ratio of the within group variation 
and the sample size. The null hypothesis is rejected if the test statistic value is greater than the critical range. Prior to all ANOVA tests, all data sets were also tested for normality (Kolmogorov-Smirnov test). When monthly time series were analyzed, data sets were tested for temporal autocorrelation using a Mantel test (Mantel, 1967). The Mantel test is commonly used for correlations between spatial distances but can be used for temporal "distances" as well. In this case, the actual temperatures and random permutations of actual temperatures are correlated with day of month. Autocorrelation between repeated measurements would mean that ANOVA would not be a suitable test for the dataset.

In order to test the relationships between surface temperature and frontal area density with air temperature, both Pearson $(r)$ correlations and coefficient of determination $\left(r^{2}\right)$ were calculated. The $r$ values serve to indicate strength of correlations with air temperatures, where the $r^{2}$ are used to test the goodness of fit within a linear regression model, or the ability to predict measured air temperatures. Multiple regressions were also attempted with both surface temperature and frontal area density. All regressions tested assume linearity between variables based on normal distributions of the diurnal temperature variations for the heat event conditions observed. Surface temperatures and frontal area densities are tested for independence prior to employing multiple regressions, and no multicollinearity was found. Frontal area estimates are not scaled to match the surface or air temperatures $\left({ }^{\circ} \mathrm{C}\right)$ in the regression analysis. The implications are that it will not be possible to determine the relative strength of each predictor variable in the regression. 


\section{Results and Discussion}

This chapter reports on the study results, first summarizing the heat island characteristics for the GTA as observed by the monitoring stations. It also summarizes the relationships between surface and air temperatures as observed across various urban covers. Finally, remotely sensed surface temperatures and $\lambda_{\mathrm{F}}$ estimates are compared to air temperatures for a range of spatial and temporal conditions. Based on these results, models to estimate air temperature are proposed, but not tested due to the small sample size of 4 image dates.

\subsection{UHI Characteristics of the GTA}

The in situ air temperature measurements suggest several microclimates within the GTA, however, a generalized air temperature UHI trend is evident. Six rural sites (Ajax Conservation, Brock, Glen Haffey, Hart House Farm, Kortright, Rouge), six urban sites (United Church, CAP Office, Metro Hall, Union Station, Brickworks, Emery Yard) and six suburban (Ajax City Hall, Ajax Residential, Oakville Center, Oakville Residential, Peel Residential, Mississauga Fire) sites were used in the analysis. Although additional site measurements were available, these sites became the focus of further analysis to include an equal number of sites per land use class, and to omit anomalous measurements. Air temperature differences between sites for each land use class were compared on August 1, 2007, July 1, 2008, August 25, 2008 and September 3, 2008. Differences in air temperatures within urban and suburban class sites were quite small, with standard deviations for each class less than $1.2^{\circ} \mathrm{C}$. Based on the low variation among sites from the same class, sites across the GTA were aggregated to urban, suburban and 
rural sites for comparison. The rural sites, which were to act as the baseline for determining UHI intensities, had a mean noon air temperature of $23.9^{\circ} \mathrm{C}$ with a standard deviation of $\pm 1.2^{\circ} \mathrm{C}$ for July 1,2008 . This was considerably lower variation than found in other studies that observed significant differences among rural sites and complicated the determination of heat islands extents and intensities (e.g. Hawkins et al., 2004). Given the distribution of rural sites throughout the GTA and the good variety of rural site locations including both unmanaged pastures and forested areas, the rural baseline was judged to be an accurate control for calculating UHI intensities.

Figure 9 shows hourly air temperature values for July 1, 2008 averaged by land use class. These results present a weak daytime UHI, with less than $1.8^{\circ} \mathrm{C}$ difference between urban and rural sites during the daytime from 8:00 until 20:00. The suburban sites had slightly greater differences from the rural baseline, but still no pronounced daytime heat island. However, both urban and suburban sites had a pronounced night-time heat island (21:00 - 7:00), with 1.9 and $5.3{ }^{\circ} \mathrm{C}$ differences, respectively, from the rural baseline. To test the persistence of these intensities, the average noon and midnight air temperatures by land use class were compared for each day over the month of August 2008 (Figures 10 and 11). A clear and consistent night-time UHI is present, with negligible daytime heating differences. The night-time $\Delta \mathrm{T}_{\mathrm{u}-\mathrm{r}}$ varies across the month, with the lowest $\Delta \mathrm{T}_{\mathrm{u}-\mathrm{r}}$ coinciding with periods of precipitation, however despite the variation, the night-time urban temperatures appear to be at least $2.0^{\circ} \mathrm{C}$ warmer than the rural baseline. 


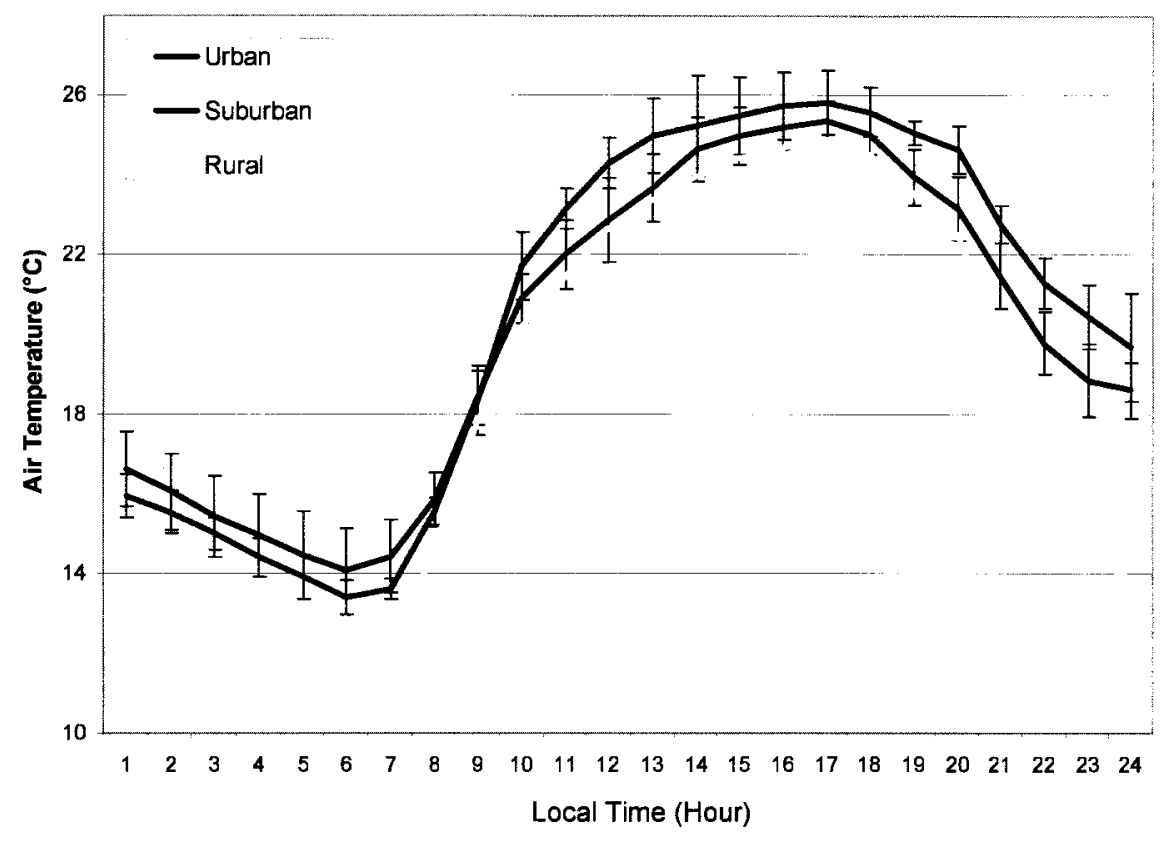

Figure 9. Hourly air temperature values for July 1, 2008 averaged by urban, suburban and rural classes. Standard deviations for urban and suburban measurements plotted as error bars.

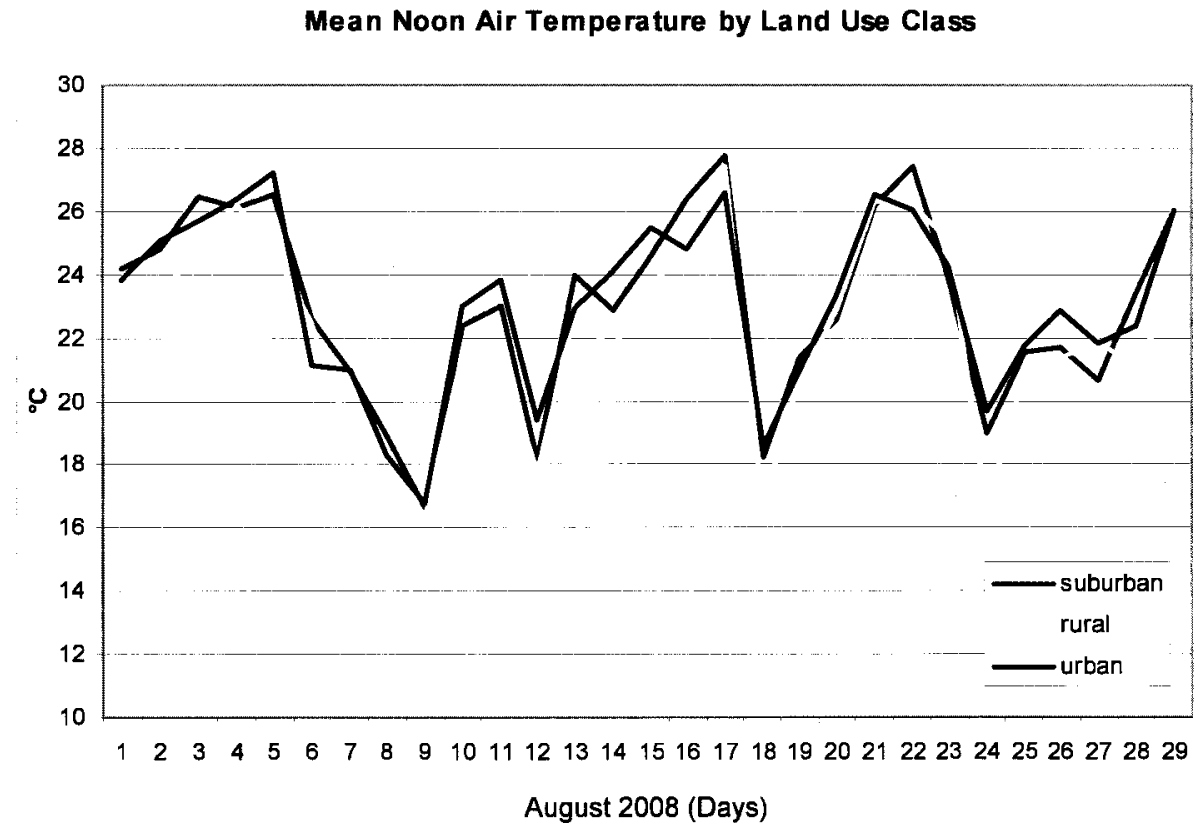

Figure 10. Noon air temperatures for August, 2008 averaged by urban, rural and suburban classes. 


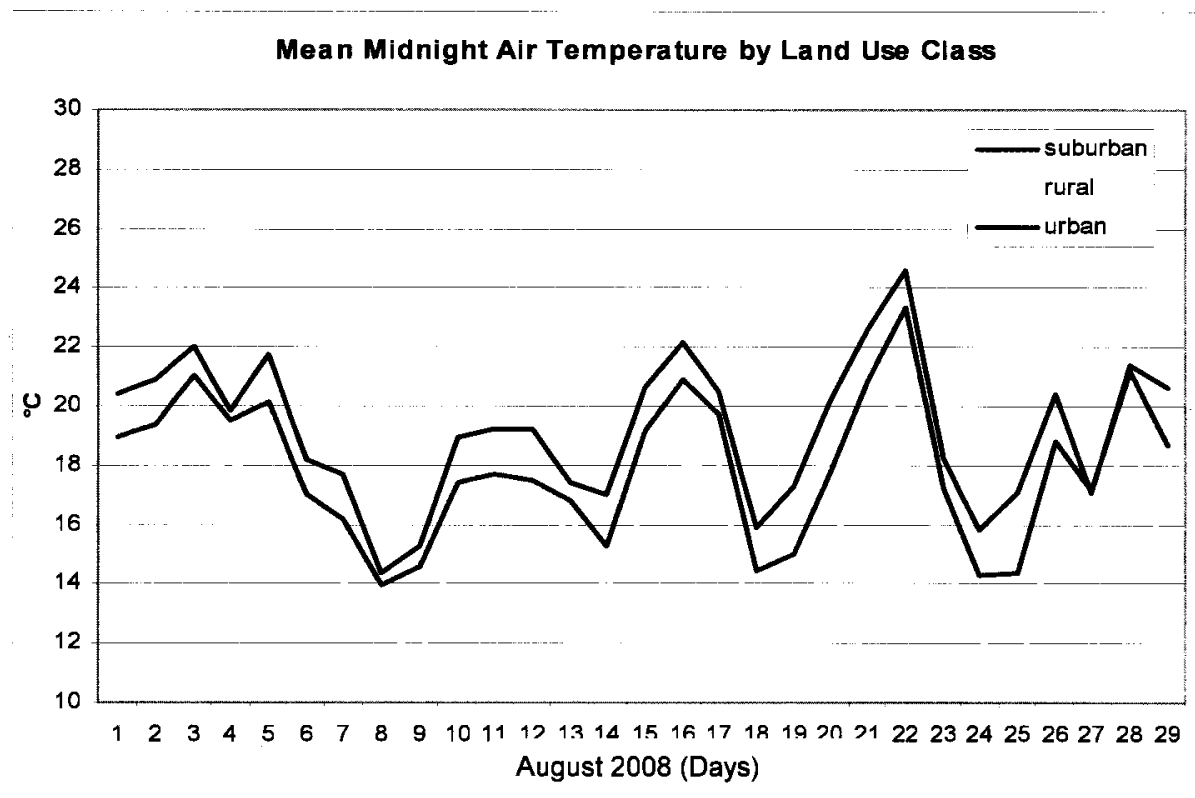

Figure 11. Midnight air temperatures for August, 2008 averaged by urban, rural and suburban classes.

ANOVA tests were used to determine if August 2008 noon and midnight air temperatures were significantly different between urban and suburban sites and the rural baseline (Table 3). August 2008 was selected to provide a large sample size of typical summer days as well as numerous heat event condition days. Prior to ANOVA tests, the August 2008 noon and midnight temperatures were tested for temporal autocorrelation using a Mantel test (Mantel, 1967). The Mantel tests, revealed no significant temporal autocorrelations (Mantel's $r<0.001$ ) for either the noon or midnight temperatures. This can also be interpreted as an absence of temperature trends within the month. The air temperatures over 30 day samples were also found to have normal distributions using Kolmogorov-Smirnov tests $(\mathrm{D}<0.15)$ and similar variances were found for each land use class. Based on the ANOVA results, the Tukey method was used to assess land use air 
temperature differences and revealed no significant differences between the noon air temperatures for the urban or suburban classes and the rural baseline. In contrast, the midnight air temperatures for the rural baseline were deemed significantly different from both the urban and suburban classes. The suburban and urban classes were not found to have significantly different air temperatures. The observed diurnal range of UHI intensities match the expected ranges measurements in other Canadian urban centres (Oke and Maxwell, 1975; Mohsin and Gough, 2009), and follow the diverging rates of cooling between the urban and rural sites after sunset observed by Oke (1982).

Table.3. Single factor ANOVA statistics, $a=0.05$ to test differences between urban, suburban and rural, noon and midnight air temperatures for August 2008. Significant differences are indicated by ${ }^{*}$, where absolute mean difference is greater than Tukey test critical range (q).

\section{$\underline{\text { Noon Air Temperatures }}$}

$\begin{array}{lcl}\text { F } & \text { P-value } & \text { Critical Range }(\boldsymbol{q}) \\ 1.22 & 0.30 & 2.11 \\ \text { Absolute Mean Differences }\left({ }^{\circ} \mathrm{C}\right) & \\ \text { Urban - Rural } & 1.08 & \\ \text { Suburban - Rural } & 1.03 & \\ \text { Urban - Suburban } & 0.05 & \end{array}$

Midnight Air Temperatures

$\begin{array}{lll}\text { F } & \text { P-value } & \text { Critical Range (q) } \\ 17.04 & 0.001 & 1.78\end{array}$

$\begin{array}{lc}\text { Absolute Mean Differences }\left({ }^{\circ} \mathrm{C}\right) \\ \text { Urban - Rural } & 3.77^{*} \\ \text { Suburban - Rural } & 2.43^{*} \\ \text { Urban - Suburban } & 1.33\end{array}$


It should be noted that the least difference between air temperatures for all land use classes occurs at approximately 10:00 (Figure 9), likely due to a mix of antecedent cooling and 1-2 hours of solar loading. From the UHI monitoring perspective, this would be the least effective time for air temperature measurements, but unfortunately coincides with Landsat thermal measurements. Based on the diurnal air temperature differences shown in Figure 9, it appears that measurements between 21:00 and 24:00 would be optimal for characterizing peak $\Delta \mathrm{T}_{\mathrm{u}-\mathrm{r}}$.

\subsubsection{Regional Heat Islands}

Although there were generalized temperature trends for all urban and suburban sites, there were also differences between some of the included regions. The $\Delta \mathbf{T}_{\mathbf{u}-\mathrm{r}}$ for Toronto, Peel, Oakville and Ajax were investigated. Three heat event days were considered for the regional analysis (June 8, 2008; July 1, 2008; July 7, 2008), with all urban and suburban sites for each region included. The average $\Delta \mathbf{T}_{\mathbf{u}-\mathbf{r}}$ and standard deviation for noon and midnight for each region are shown in Table 4. The Toronto sites had some of the largest $\Delta \mathbf{T}_{\mathbf{u}-\mathrm{r}}$ within the GTA, but also had the most variation, potentially from land use and structural heterogeneity across the region as well as proximity to Lake Ontario, a potentially cool source area. The Oakville sites had the highest $\Delta \mathbf{T}_{\mathbf{u}-\mathrm{r}}$, although a bias is suspected as these sites were mostly in dense commercial areas. Ajax sites have the lowest $\Delta \mathbf{T}_{\mathbf{u}-\mathbf{r}}$ of the four regions. Finally, the Peel sites that had a good mix of land use classes had higher $\Delta \mathbf{T}_{\mathbf{u}-\mathbf{r}}$ than the Toronto region sites. These results suggest that the suburban dominated peripheral regions may act as localized heat islands within the overall study area. 
Table.4. Regional mean differences between urban and rural temperatures $\left(\Delta \mathbf{T}_{\mathbf{u}-\mathrm{r}}\right)$, with standard deviations $(\sigma)$, for June 8, 2008; July 1, 2008; July 7, 2008.

\begin{tabular}{|l|r|r|r|r|}
\hline & Noon & & Midnight & \\
\cline { 2 - 5 } & $\Delta \mathbf{T}_{\mathbf{u}-\mathbf{r}}$ & \multicolumn{1}{|c|}{$\boldsymbol{\sigma}$} & $\Delta \mathbf{T}_{\mathbf{u}-\mathbf{r}}$ & \multicolumn{1}{c|}{$\boldsymbol{\sigma}$} \\
\hline Ajax & 0.5 & 2.2 & 2.2 & 1.6 \\
\hline Peel & 2.5 & 0.6 & 4.1 & 0.6 \\
\hline Oakville & 2.8 & 1.1 & 4.9 & 1.1 \\
\hline Toronto & 1.9 & 2.6 & 2.7 & 1.6 \\
\hline
\end{tabular}

\subsection{Air and Surface Temperature Relationships}

If wind flow and subsequent advective heat fluxes are negligible, surface and nearsurface air temperatures should be directly related. However, the in situ observations over the GTA during heat event conditions (i.e. low wind speeds) indicate a more complicated relationship between the two variables. Figure 12 shows air and surface temperatures for two 2008 summer dates from 4 GTA sites, each selected as representative of a land use type. June 6 had clear skies with low winds (max speed $26 \mathrm{~km} / \mathrm{h}$ ) and July 9 had clear skies but with slightly higher winds (max speed $35 \mathrm{~km} / \mathrm{h}$ ). Relationships between air and surface temperatures are different for each monitoring site, with Emery Yard (industrial area) and Oakville Recreation Centre (dense suburban) showing significant increases in surface temperatures throughout the day but comparatively weak increases in air temperatures. In contrast, we see closer agreement between surface and air temperatures at the Horticultural Centre (green roof) and the Ajax Recreational Park. In the Ajax location, the agreement was best on the calm day (June 6) while on the windier day, this was the only site where surface temperatures remained relatively constant while air 
temperatures varied to a greater extent. For the other three sites, there was less hysteresis in surface air temperatures on the windier day possibly due to increased turbulent mixing. In general, Figure 12 highlights that air temperature at $1.5 \mathrm{~m}$, even under relatively calm conditions, is being influenced by more than the heating of the immediate surface below. The Emery Yard and Oakville Recreation Centre sites indicate that low albedo, nonvegetated surfaces are not resulting in dramatically different air temperatures than the stations with vegetated surfaces.
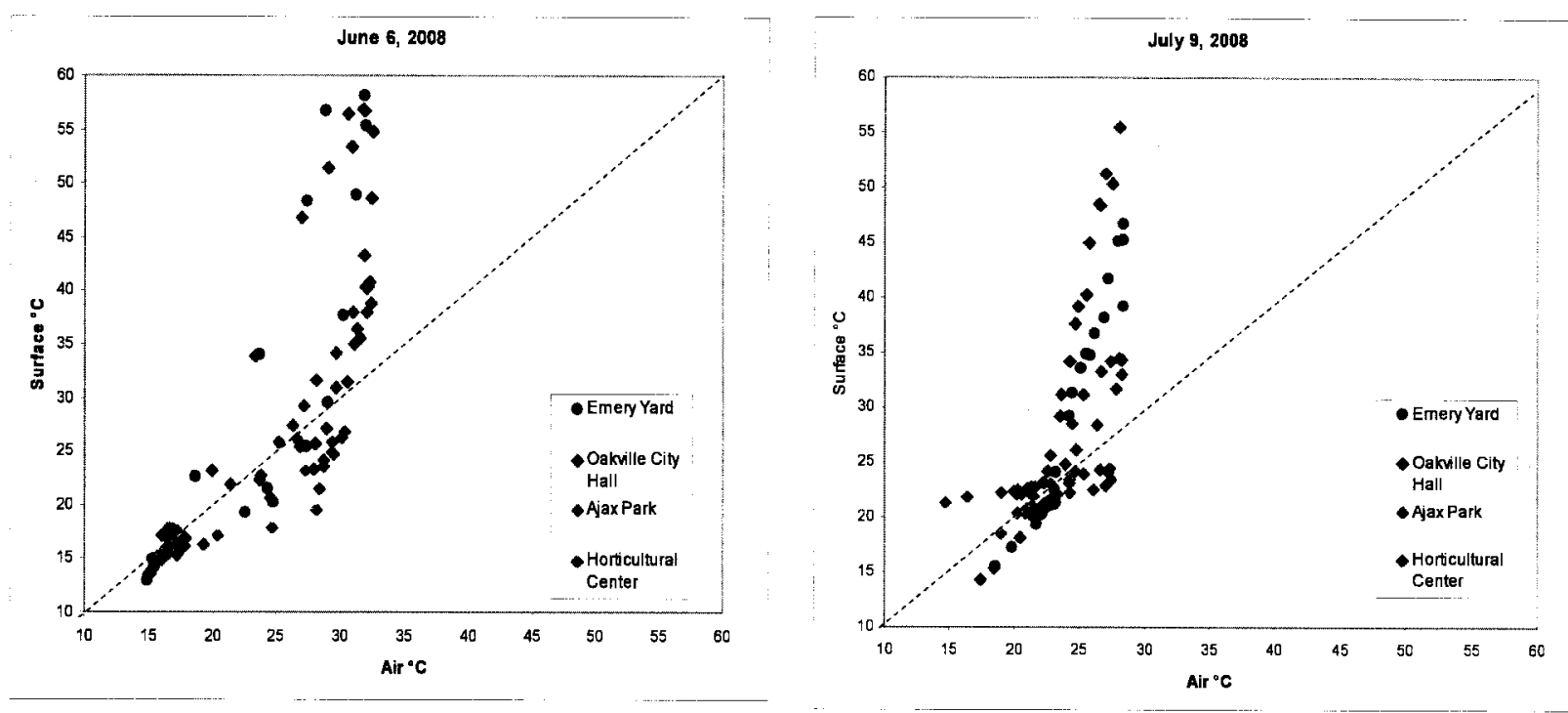

Figure 12. Surface and air temperatures for 4 different GTA measurement sites on a calm (June 6) and windy day (July 9) in 2008.

The next step of the analysis was to determine the variability of surface and air temperatures among common surface covers across the GTA. For a given surface cover, solar loading (i.e. aspect and cloud cover) and thermal characteristics of the surfaces are effectively the same, so it was hypothesized that the surface temperatures should be very similar regardless of location. However, it is hypothesized that the air temperatures 
above these similar cover types will differ, due in part to differences in surrounding surface covers. Figure 13 demonstrates that diurnal surface temperatures measured in heat event conditions (July 1,2008) across common covers were similar, while air temperatures above these common covers showed more variance. The hourly air and surface temperature measurements for July 1, 2008 show very similar temperature responses to solar radiation among the similarly surfaced roofs. Despite the large range in diurnal surface temperatures $\left(30^{\circ} \mathrm{C}\right)$, differences between sites rarely exceeded $5^{\circ} \mathrm{C}$ at any given time. This is particularly informative given that these monitoring sites are up to $50 \mathrm{~km}$ apart. In contrast, the air temperatures for the same date over these common surfaces had diurnal ranges of only $10^{\circ} \mathrm{C}$ yet up to $4{ }^{\circ} \mathrm{C}$ differences between sites. ANOVA tests on mean daytime (6:00 - 18:00) and mean night-time (19:00 - 5:00) temperatures from the common surface covers demonstrate the significance of the between site differences (Table 5). For night-time air temperatures for both rock/gravel roofs and asphalt roofs, a significant difference was found between sites. However, no significant differences were found for the night-time surface temperatures. 

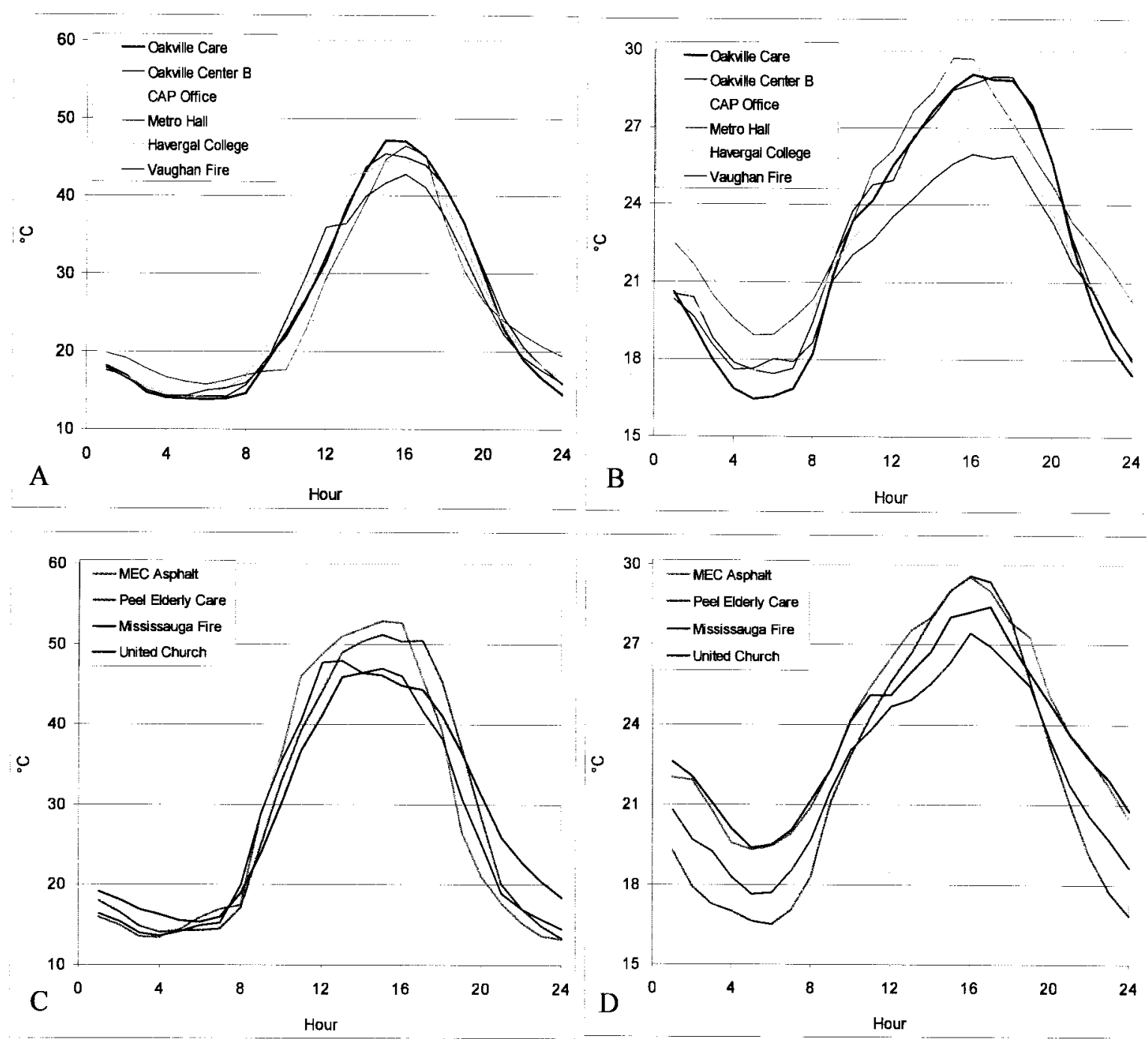

Figure 13. Roof surface temperatures and air temperatures measured on common cover types on July 1, 2008. a) Surface temperatures for rock and gravel covered roofs b) Air temperatures for rock and gravel covered roofs c) Surface temperatures for asphalt and concrete roofs d) Air temperatures for asphalt and concrete roofs. 
Table.5. Single factor ANOVA statistics, with significance denoted by italics $(a=0.05)$, to test the temperature differences between sites of common cover types.

\begin{tabular}{|l|r|r|}
\hline & F & P-value \\
\hline Rock and Gravel Roofs & & \\
\hline Air temperature, daytime & 0.99 & 0.43 \\
\hline Air temperature, night-time & 2.34 & 0.05 \\
\hline Surface temperature, daytime & 0.16 & 0.98 \\
\hline Surface temperature, night-time & 0.39 & 0.85 \\
\hline Asphalt Roofs & & \\
\hline Air temperature, day & 0.11 & 0.96 \\
\hline Air temperature, night-time & 2.76 & 0.04 \\
\hline Surface temperature, day & 0.79 & 0.50 \\
\hline Surface temperature, night-time & 1.48 & 0.23 \\
\hline
\end{tabular}

These results demonstrate that solar loading is relatively uniform across the study area and that common cover types may be grouped when examining air and surface temperature relationships. These observed limitations also question the suitability of remotely sensed surface temperatures, no matter how spatially extensive, to support air temperature modelling. Recent thermal remote sensing studies (e.g. Voogt and Oke, 2003) also raise these concerns for effective UHI mapping.

\subsubsection{Green Roofs}

This study also presented an opportunity to compare air and surface temperatures on two "green roofs" in relation to adjacent asphalt roofs. The Mountain Equipment Co-op (MEC) building in Toronto had a portion of the asphalt roof covered with prairie grasses (Figure 14a-b) with the uncovered portion of the asphalt MEC roof as the control site. 
The Toronto Horticultural Centre roof had various grasses as cover. The Havergal College site, (1.2 km west) was used as an asphalt control for the Horticultural Centre. Hourly surface and air temperatures were compared from various heat event days, with results for August 1-3, 2007 at the MEC site plotted in Figure 15. The large differences in surface temperatures between the two roof covers are apparent, with hourly differences as large as $30^{\circ} \mathrm{C}$ and an average difference of $9^{\circ} \mathrm{C}$ over the full 3 days. However, the effect on air temperatures at $1.2 \mathrm{~m}$ for both roofs is considerably smaller, with an average difference of only $0.6^{\circ} \mathrm{C}$. Another observation of note was that the asphalt surfaces with lower heat capacity, due to lower water content, cooled as quickly as they heated up, and actually became cooler than the green roofs after 21:00 local time. The frequency for irrigating the green roofs was not known, but the soil moisture content plays a role in the differences in rates of cooling. Both sets of results are typical of high heat, low wind and cloud free days and suggest that a greater number of green roofs within an area would be required to cool the near surface air.

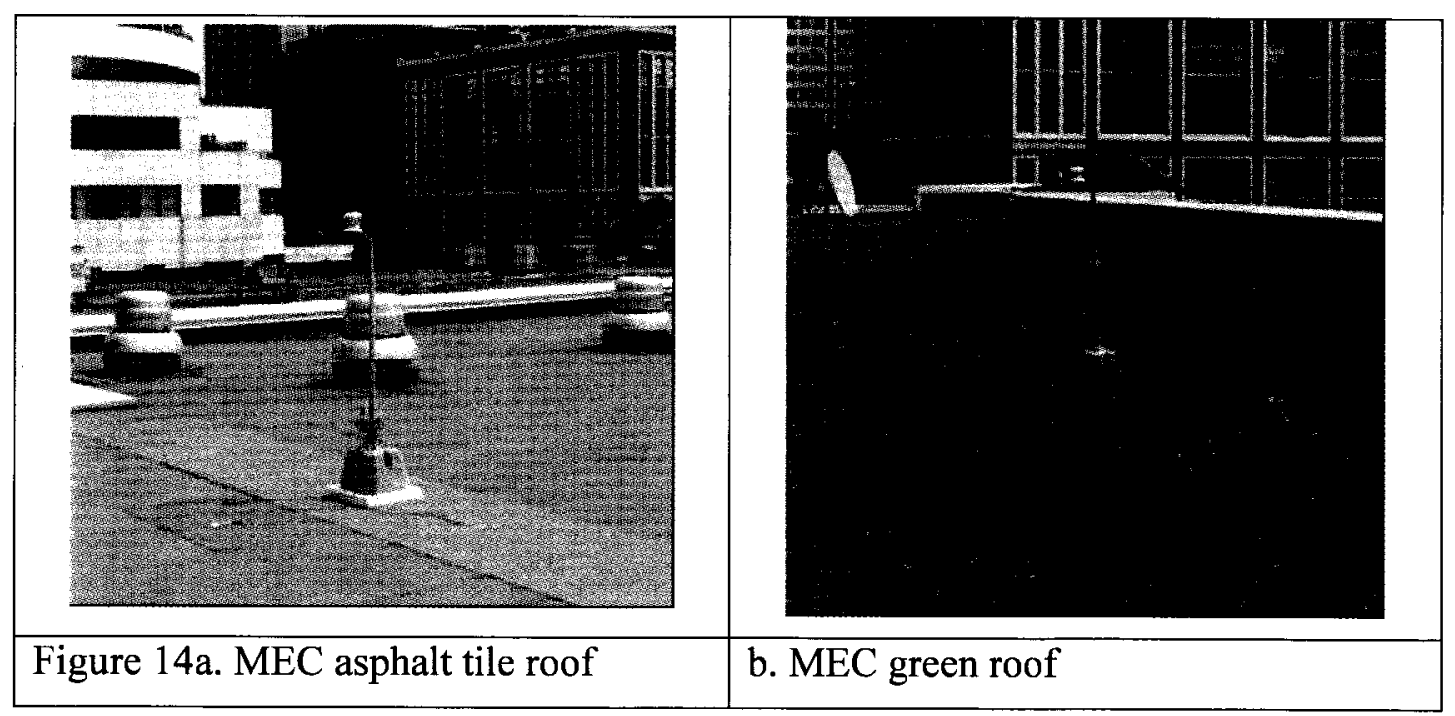




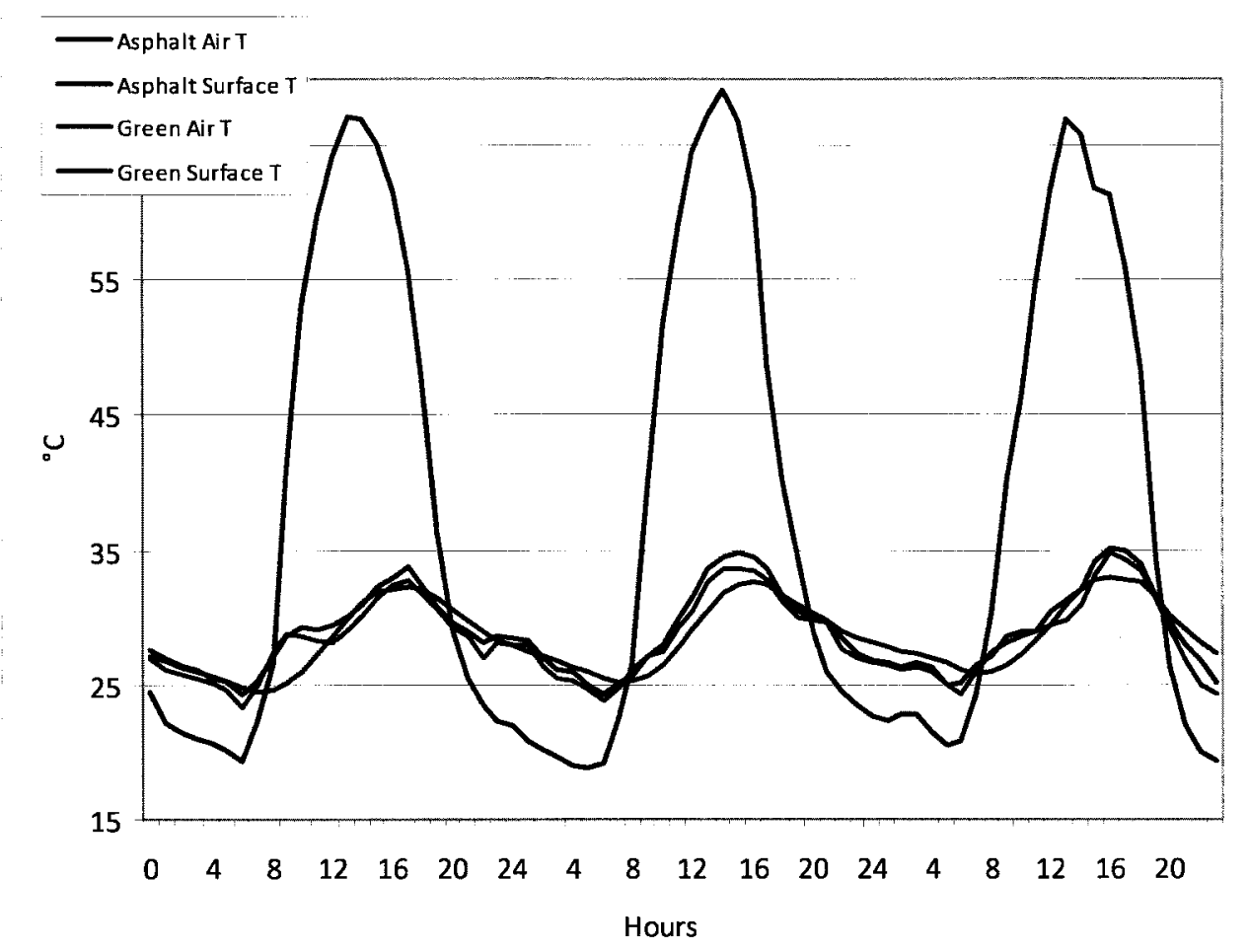

Figure 15. MEC green roof and asphalt tile roof air and surface temperature measurements for August 1-3, 2007.

\subsection{Remotely Sensed Surface Temperatures}

The production of 4 heat event LST maps from Landsat TM imagery allowed the analysis of spatial variations for daytime surface and air temperatures across the GTA (LST maps in Appendix II). The LST maps were deemed valid to approximately $\pm 2.5^{\circ} \mathrm{C}$ based on in situ measurements and previous assessments of Landsat TM imagery. As with most heat event LST maps for urban areas (e.g. Gallo and Owen, 1998; Lo et al., 1997), the maps for the GTA present a pronounced surface UHI with $15^{\circ} \mathrm{C}$ differences between urban and rural areas. For the 4 images over 2007 and 2008 there are several common observations. There are some small variations in rural surface temperatures $\left(\sim 5^{\circ} \mathrm{C}\right)$, likely due to albedo differences from bare fields and various stages of crop development. The 
downtown core has lower surface temperatures than much of the peripheral suburban and urban cover. Figure 16 shows higher resolution subsets of suburban Brampton and the downtown Toronto core. With perhaps the greatest amount of impervious cover and highest density of multi-storey structures, one would expect the downtown core to have the highest surface temperatures. The relatively low surface temperatures in the core suggest thermal anisotropic effects, where the sensor is observing some shaded roofs but omitting heated walls of multi-storey structures that are causing the shading. As Voogt and Oke (1998) observed, there can be an underestimation of surface temperature because of the limited observations and complex scene geometry. For July 1, 2008 at 10:00 during the time of acquisition, the solar elevation angle is $52.3^{\circ}$ with shadows extending a length of $77 \%$ of structure height (i.e. calculated as Tan(structure angle solar elevation angle)). As many structures in the Toronto downtown are spaced with less distance than their heights, there is substantial shadowing between structures in the LST maps.

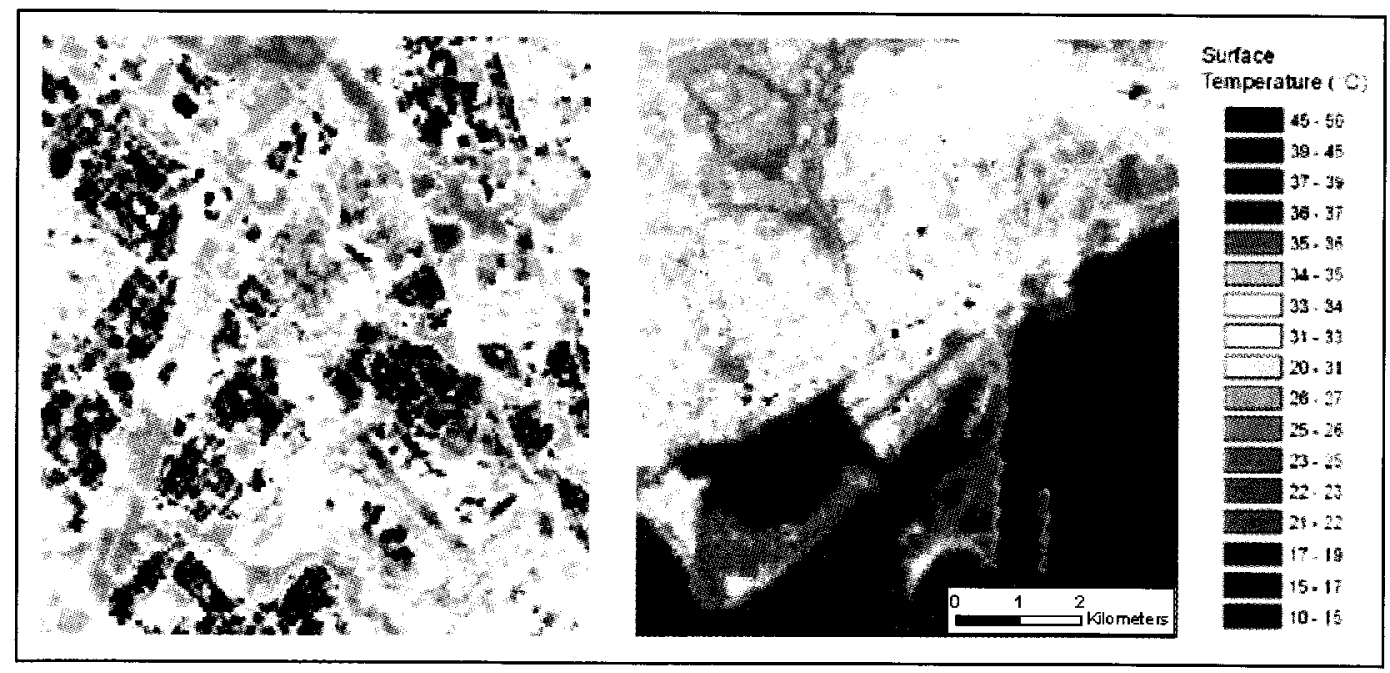

Figure 16. a) Suburban (Brampton) and b) Urban (Downtown Toronto) subsets of July 1, 2008 Land Surface Temperature map. 


\subsubsection{Urban Heat Island Mapping}

While the noon air temperature measurements show no daytime UHI, with no significant differences between urban air temperatures and the rural baseline, the LST maps show pronounced daytime heat island patterns. The LST maps appeal to our intuitive notion of heat islands (i.e. hot surface is proportional to hot air) but are inconsistent with, or actually contradict, near surface air temperatures. This contradiction can be represented through plotted 10:00 $120 \mathrm{~m}$ pixel LST and 10:00 air temperatures and coefficient of

determinations $\left(\mathrm{r}^{2}\right)$ between air and surface temperatures, shown in Figure 17. With $\mathrm{r}^{2}$ of less than 0.12 it is evident that 10:00 LST are not suitable for modelling air temperatures. The plots also show no consistent trend between air temperature and LST among the four dates. When considering these results with the diurnal variations of the surface and air temperature relationships for typical urban sites shown in Figure 12, it is evident that using LST for UHI intensity modelling is complex at any time of day. 

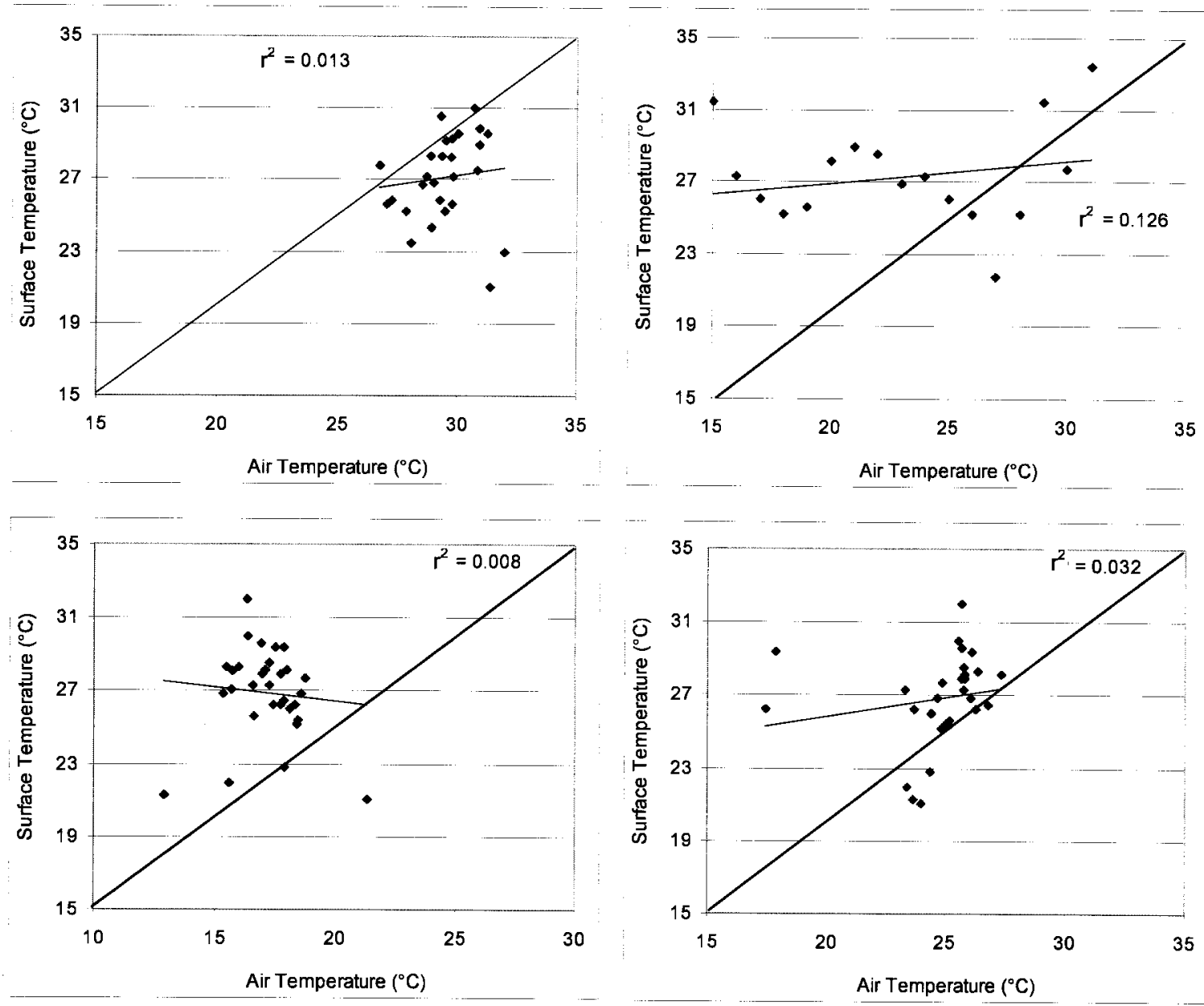

Figure 17. 10:00 Land Surface Temperature $(120 \mathrm{~m})$ and 10:00 air temperature plots for a) August 1, 2007, b) July 1, 2008, c) August 25, 2008 and d) September 3, 2008.

\subsubsection{Source Areas and Air Temperature}

The poor agreement between in situ or remotely sensed surface temperatures and air temperatures indicate that there are other spatial or temporal factors that need to be considered. At 10:00 surfaces have been exposed to incoming solar radiation for a number of hours and this energy may be partitioned (Eq. 1) into warming surface structures $(\Delta Q s)$, evaporating water $(\mathrm{Qe})$ or into fluxes of sensible heat $(\mathrm{Qh})$. 
Consequently there is often some lag time between warming of the surface and the air layer above. Also, as shown earlier, air temperature at $1.5 \mathrm{~m}$ is determined by heat sources that are not directly at that measurement location but potentially from larger source areas at distances in excess of the $120 \mathrm{~m}$ pixel.

In order to test the impact of the source area on the surface-air temperature relationship, the LST pixels upwind of each monitoring site were averaged for distances of $240 \mathrm{~m}$ up to $1200 \mathrm{~m}$ and correlated with the corresponding air temperatures for four image dates: August 1, 2007 ( $160^{\circ}$ wind direction), July 1, 2008 ( $280^{\circ}$ wind direction), August 25 , $2008\left(330^{\circ}\right.$ wind direction) and September 3, $2008\left(360^{\circ}\right.$ wind direction). Figure 18 shows the correlations (r) with the 10:00 LST averages over various source areas with air temperatures throughout the day, to assess if there is a delayed response from the heated surfaces. Correlations declined when computed for air temperature measured from $24 \mathrm{~h}$ to $6 \mathrm{~h}$ the following day and are not shown. 

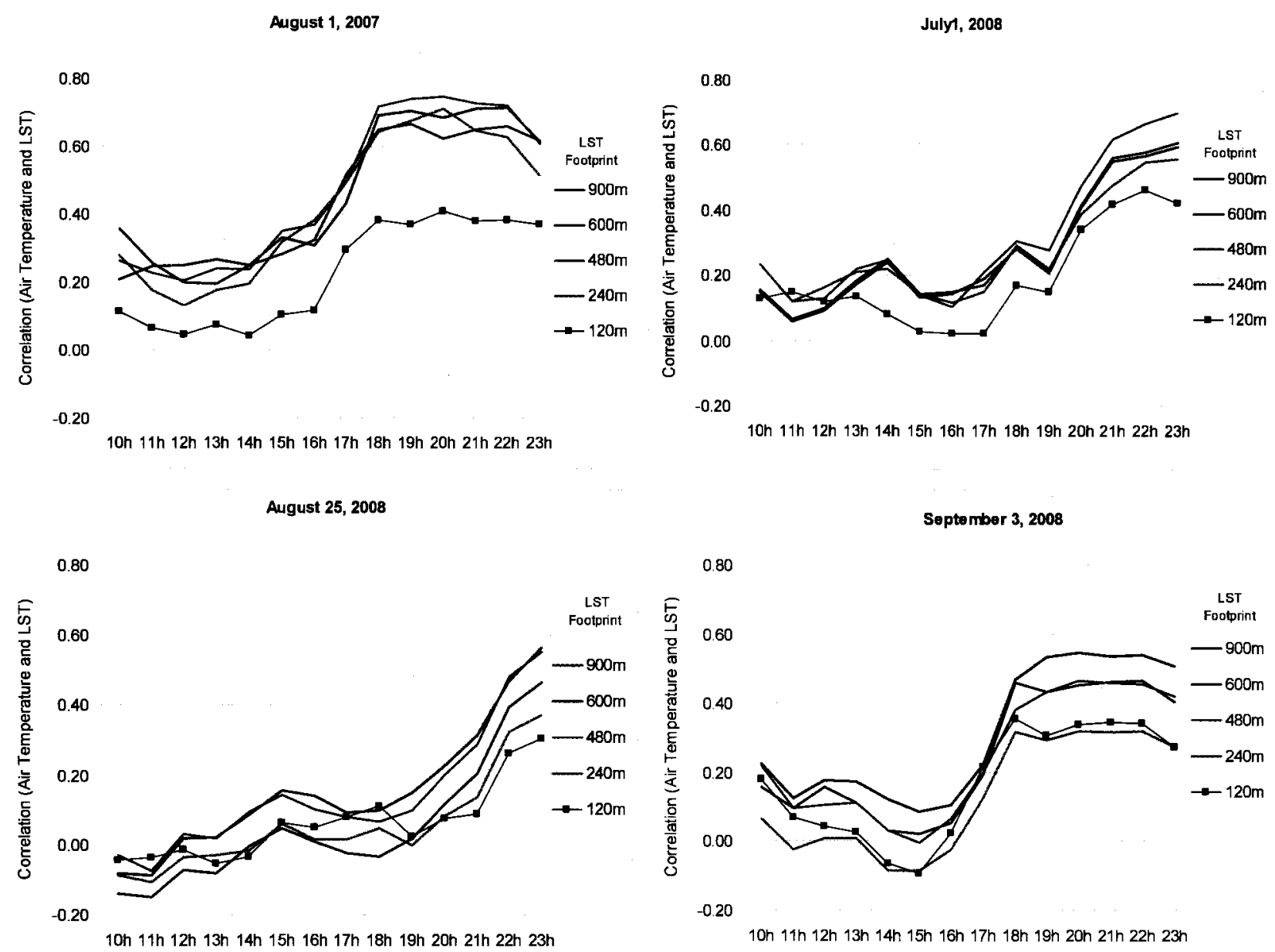

Figure 18. 10:00 Land Surface Temperature and hourly air temperature correlations (r) for various source areas (upwind pixels) for August 1, 2007, July 1, 2008, August 25, 2008 and September 3, 2008.

For all dates tested, several trends are apparent. First, correlations between 10:00 LST and hourly air temperature increase throughout the day, eventually peaking several hours after sunset. LST appears to best explain the proportion of variability in 23:00 air temperatures $(r=0.75)$ more than any other time of day.

These results depict an apparent lag effect for heat fluxes, where LST indicates how much heat is absorbed in the surfaces and gradually released. Based on this lag effect, 
10:00 LST may be considered most appropriate for predicting night-time air temperatures assuming cloud cover or wind speeds remain consistent throughout the day.

A second trend found in all of the dates analyzed was that as source area increased up to $600 \mathrm{~m}, \mathrm{r}$ values increased. According to the four image dates tested, LST best describes $1.5 \mathrm{~m}$ air temperature when averaged over a larger source area of $480-600 \mathrm{~m}$. The highest $\mathrm{r}$ values were typically for night-time air temperatures from LST pixels averaged over $480 \mathrm{~m}$ upwind of the monitoring sites.

Despite the similarity in the general patterns found for all dates analyzed in Figure 18, there were some specific differences among each date. The correlations for July 1 gradually increased from 10:00 until 23:00, however there were brief drops from approximately 14:00 to 18:00. According to meteorological conditions listed at the L.B.P. and Buttonville Airports, periods of partial cloud cover were observed, indicating localized differences in solar loading. After 20:00, partial cloud cover was consistently observed at both airports, although correlations between surface and air temperatures appeared to remain the same or increase until 23:00, with relatively high $r$ values of 0.60 .

The measurements from August 25, 2008 produced the lowest correlations, with values ranging from -0.10 to 0.20 from 10:00 until 20:00. The climatological conditions for this day were the least representative for heat event conditions out of the four dates used in the analysis. The low correlations were likely due to the relatively low air temperatures and higher wind speeds throughout the day. It should still be noted that even on a 
relatively cool summer day, there was still a nocturnal heat island, and high night-time surface to air temperature correlations.

August 1, 2007 had the highest air temperatures out of all dates compared, with the most pronounced "heat wave" conditions. Air temperatures remained above $30{ }^{\circ} \mathrm{C}$ from 10:00 until 19:00. The correlations also were higher than any of the other dates, with values above 0.65 for 16:00 until 23:00.

Based on the above findings, linear regressions were developed to predict the 23:00 air temperatures from $480 \mathrm{~m}$ source area LST, making it possible to assess the suitability of this data for modelling UHI. Figure 19 shows $\mathrm{r}^{2}$ results between $480 \mathrm{~m}$ source area LST and 23:00 air temperatures for the four dates tested. Although the LST to air temperature relationships shown in Figure 19 are not ideal, with considerable scatter, there is substantial improvement ( $\sim 0.20$ increases) when compared to the initial LST to air temperature results shown in Figure 17. 

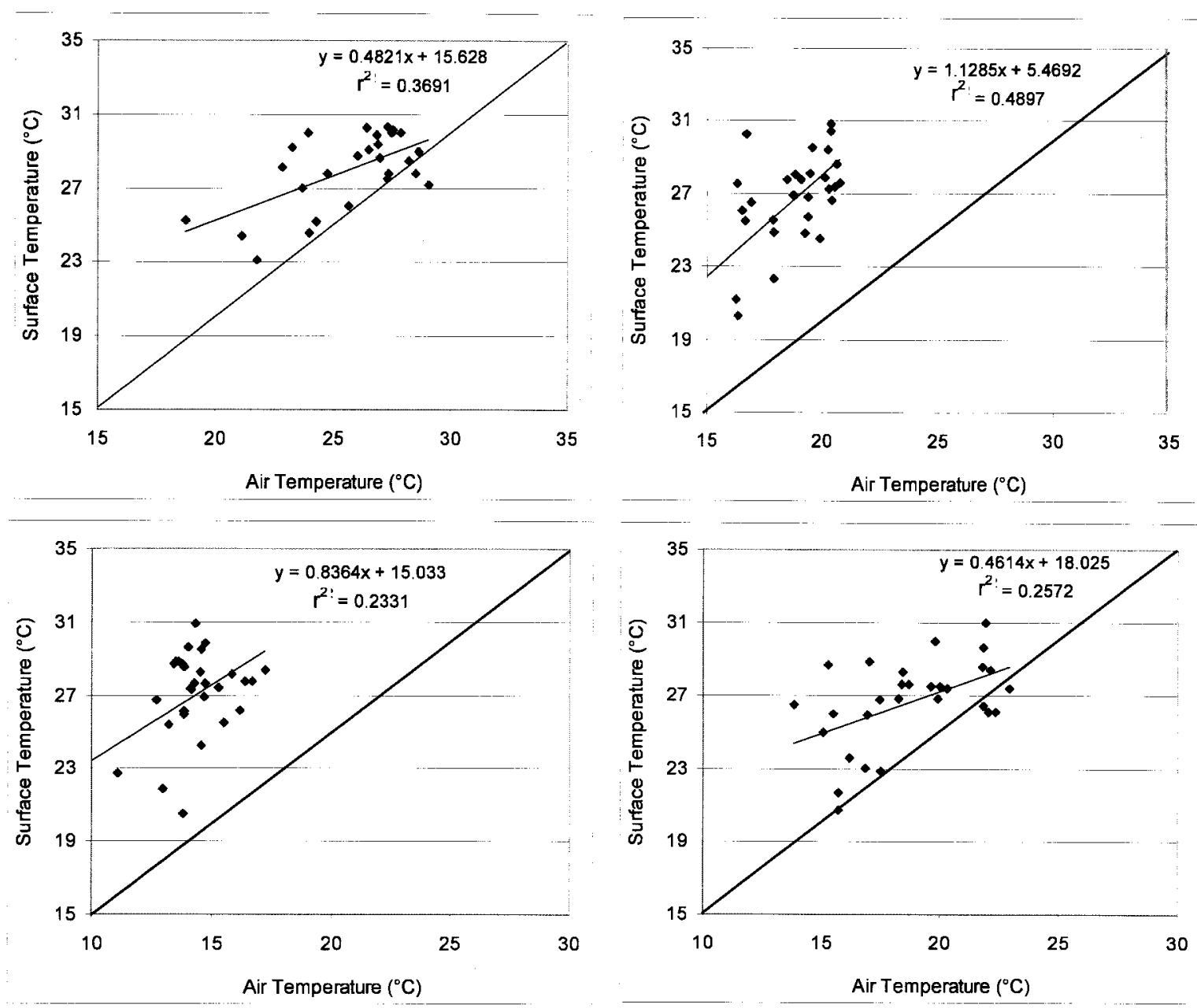

Figure 19. 10:00 Land Surface Temperature (480m) and 23:00 air temperature correlations for a) August 1, 2007, b) July 1, 2008, c) August 25, 2008 and d) September 3,2008 .

It would be interesting to compare and evaluate the impacts of source areas on the surface and air temperature relationships by separating the results by land use class, however many of the measurement sites did not fit into clear categories (e.g. green roofs, suburban recreation centres). Low confidence in land use classes of the measurement sites and surrounding source areas precluded such analysis. 
Table 6 shows the regression models, $\mathrm{r}^{2}$ and standard error of the regression $(\sigma)$ for 10:00 and 23:00 air temperatures using $120 \mathrm{~m} \mathrm{LST}, 480 \mathrm{~m} \mathrm{LST}, \lambda \mathrm{F}$, and $480 \mathrm{~m} \mathrm{LST}$ and $\lambda \mathrm{F}$ on each of the four LST dates. The variability in daytime air temperature was never well explained by any of the models with $r^{2}$ remaining below 0.10 . When regressing 23:00 air temperatures against either $120 \mathrm{~m}$ LST or $480 \mathrm{~m} \mathrm{LST}, \sigma$ are typically less than $2.50{ }^{\circ} \mathrm{C}$ and can be as low as $1.32{ }^{\circ} \mathrm{C}$ although using $480 \mathrm{~m} \mathrm{LST}$ as the independent variable resulted in greater $\mathrm{r}^{2}$ and lower $\sigma$. Considering typical night-time UHI intensities observed and absolute mean differences listed in Table 3 exceed these $\sigma, 10: 00$ LSTs could be used as indicators of UHI intensity. The diurnal relationships of the correlation between 10:00 LST from the $480 \mathrm{~m}$ upwind source area and air temperatures also appear to follow the trend of UHI intensities (Figure 20). As described in early studies (e.g. Oke, 1997), UHIs are not simply the solar loading of urban materials or the daytime maximum surface temperatures, but instead the rate at which the stored heat is released into the air. From these observations, 10:00 LST performs best as an indicator for night-time air temperatures, which also is when UHI intensities are at their highest. From a human health perspective, predicting UHI intensities at their peak time is ideal. 


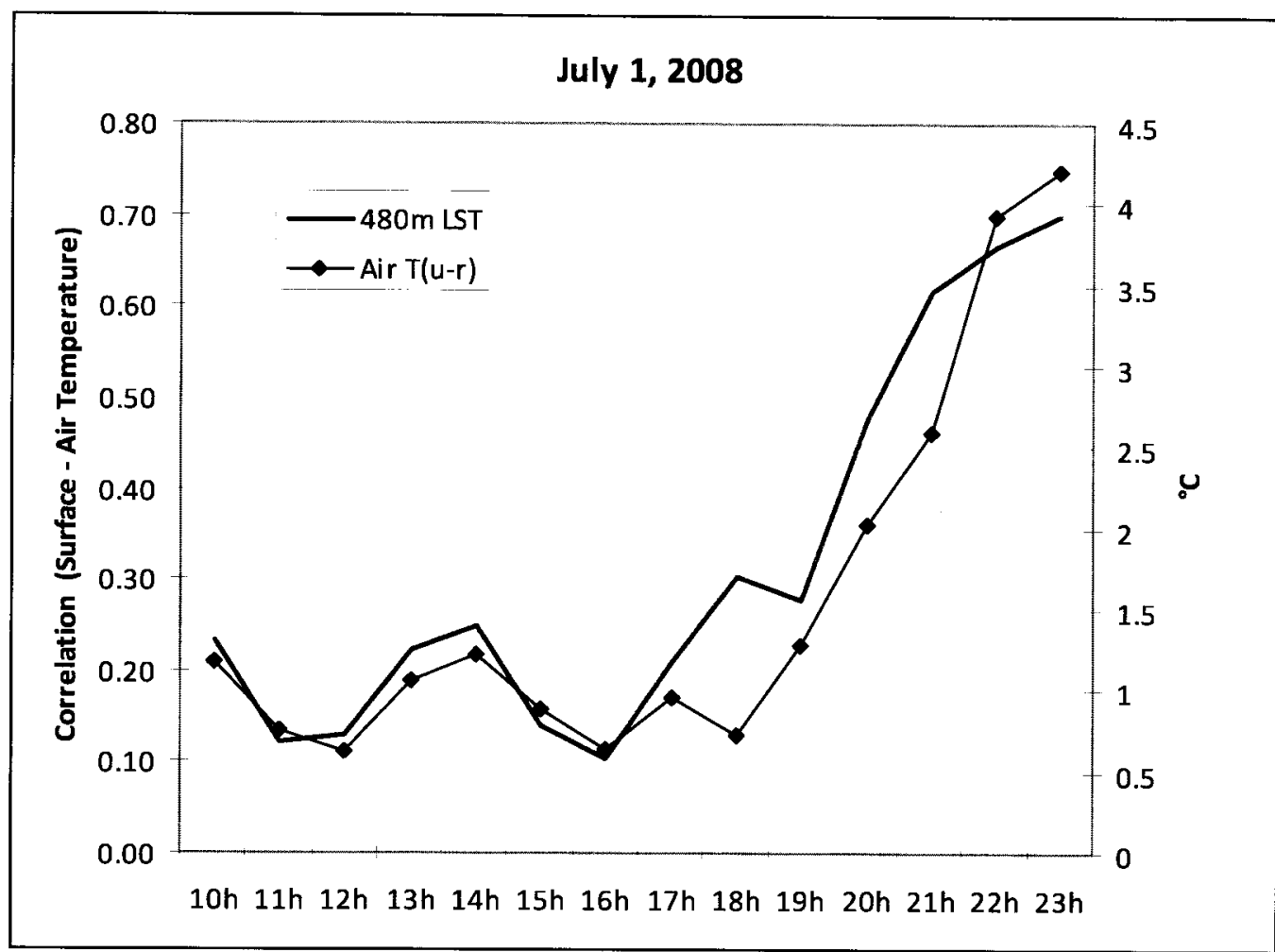

Figure 20. The correlation (r) between 10:00 Land Surface Temperature from the $480 \mathrm{~m}$ upwind source area and air temperature correlations (r) and UHI intensities for July 1, 2008. 

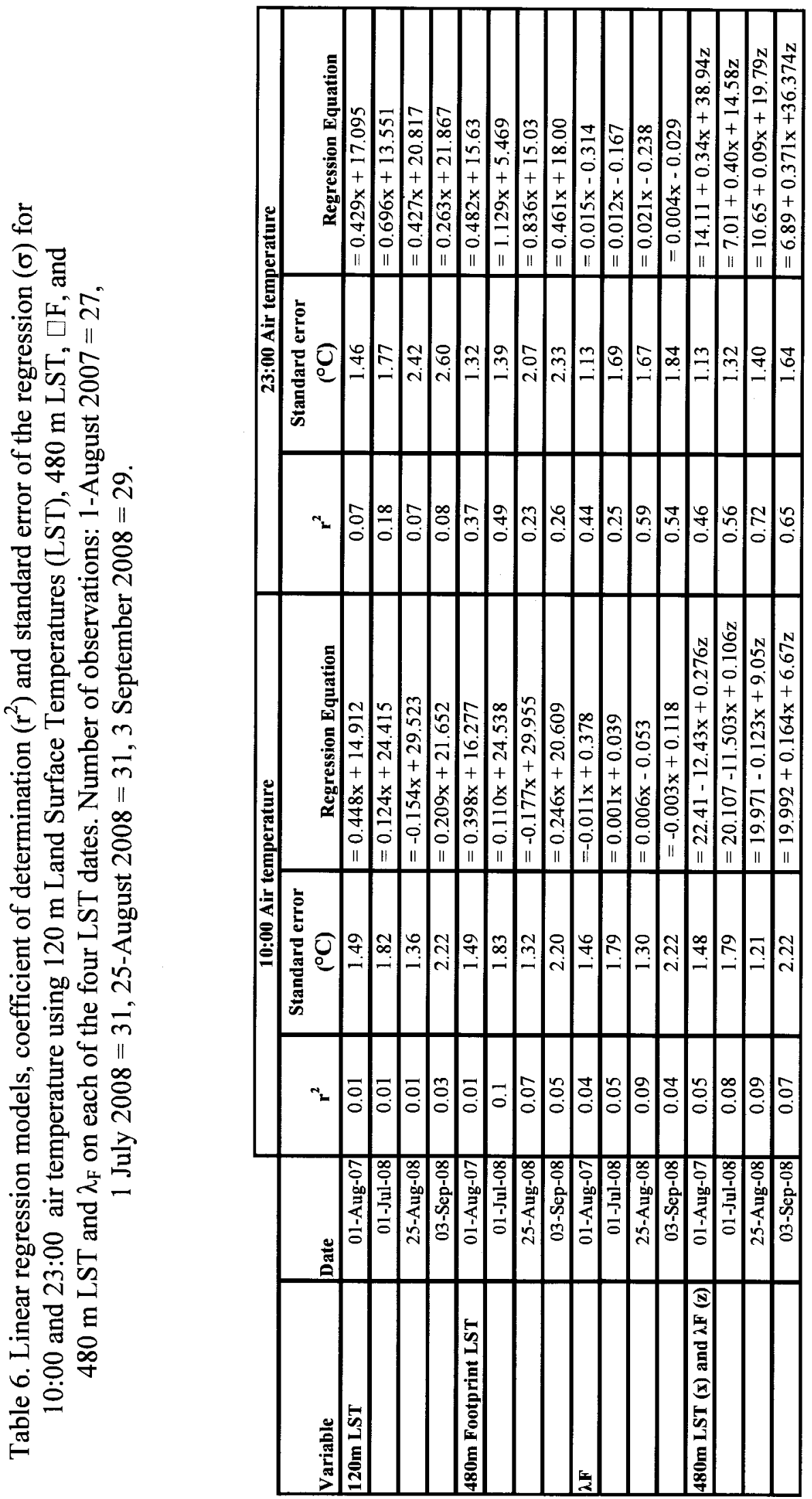


\subsubsection{Urban Geometry}

The influence of urban geometry on the discrepancy between LST and air temperature is also considered. Frontal area density $\left(\lambda_{\mathrm{F}}\right)$ was calculated to quantify the influence of urban geometry on air temperatures. Figure 21 shows a subset of the Toronto downtown core, with site area polygons showing calculated $\lambda_{\mathrm{F}}$. As one would expect, $\lambda_{\mathrm{F}}$ is relatively high in the Central Business District and is negligible in the natural corridors such as the Don River Valley (e.g. Brickworks site).

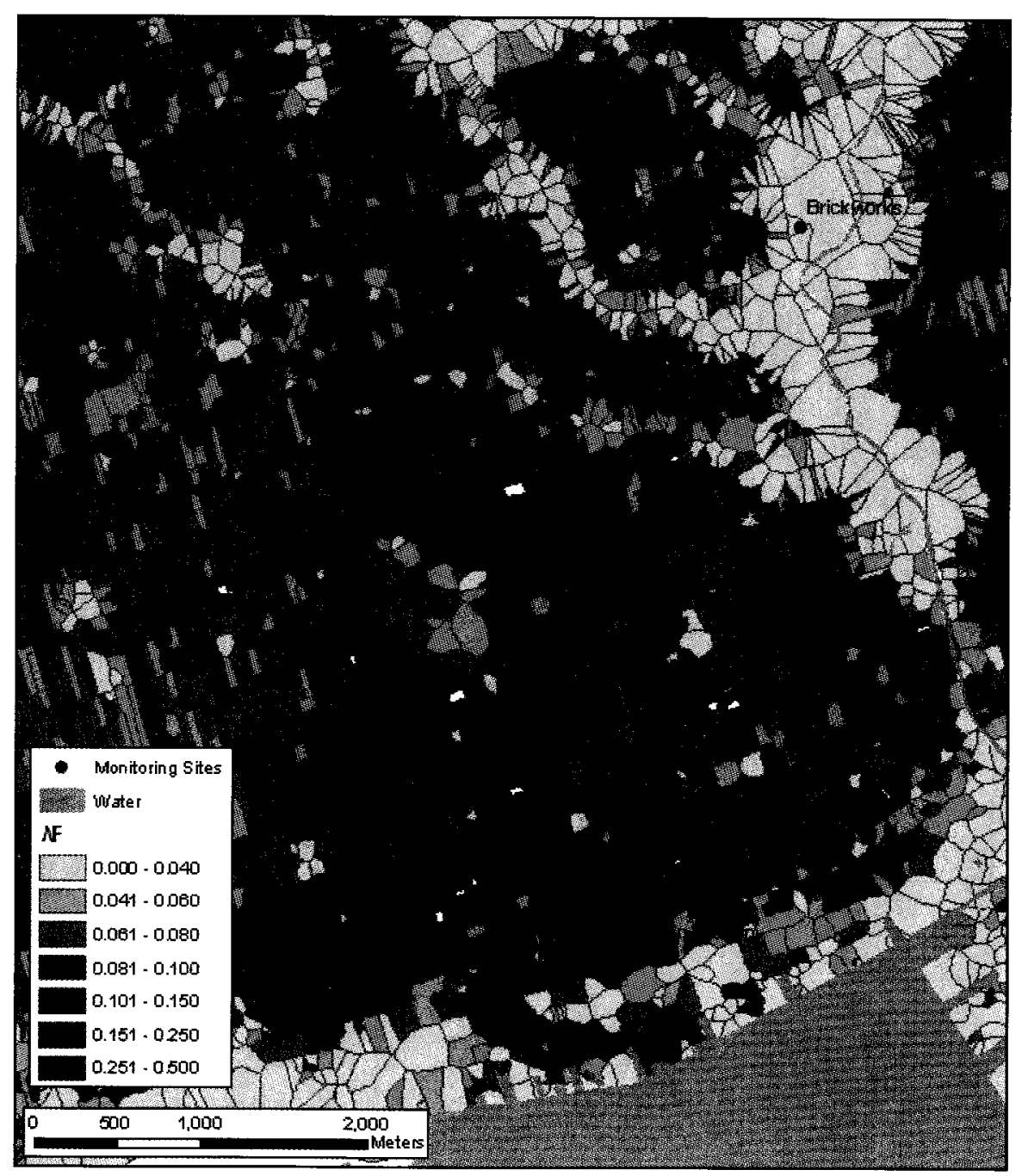

Figure 21. Frontal area density $\left(\lambda_{\mathrm{F}}\right)$ for site areas with monitoring sites and hydrology overlain. 
Figure 22 shows the correlations between $\lambda_{\mathrm{F}}$ and hourly air temperatures for four heat event days. A common trend among all dates compared, was low or negative correlations at 10:00 with a gradual increase towards high correlations $(>0.50)$ at midnight. As expected, the monitoring sites with highest $\lambda_{\mathrm{F}}$ are the ones with the highest night-time air temperatures, suggesting that rates of cooling decrease with increases in $\lambda_{\mathrm{F}}$.

While the correlations tend to follow a similar diurnal trend, there were some differences among the four dates analyzed. July 1, 2008 experienced periods of variable cloud cover across the GTA between 16:00 and 18:00. This cloud cover caused variation in surficial heating and subsequent heat fluxes. The result appears to be a temporary decrease in correlations between $\lambda_{\mathrm{F}}$ and air temperature. However, the correlations appear to continue the trend of gradual increase that was observed in the other three dates.

August 25, 2008 had relatively consistent correlations throughout the day. Wind measurements from the L.B.P. Airport site suggest that the peaks in wind speed correspond to the drops in correlations observed at 12:00 and 18:00.

The suitability for modelling night-time UHI was assessed by using the $\lambda_{\mathrm{F}}$ estimates in linear regressions to predict the 23:00 air temperatures on the four dates LST maps were available (Table 6). A similar or slightly greater proportion of variability in 23:00 air temperature was explained by $\lambda_{\mathrm{F}}$ than was explained by 10:00 LST from a $480 \mathrm{~m}$ upwind source area. In addition, the standard error of the regressions $(\sigma)$ ranged from 1.13 and 
$1.84^{\circ} \mathrm{C}$ and since night-time UHI intensities measured for the GTA (Table 4) exceeded this range, $\lambda_{\mathrm{F}}$ could be used as indicators of UHI intensity for these events. Similar to the situation for daytime air temperature and LST for $120 \mathrm{~m}$ and $480 \mathrm{~m}$ upwind source areas, $\mathrm{r}^{2}$ for daytime air temperature and $\lambda_{\mathrm{F}}$ were low.
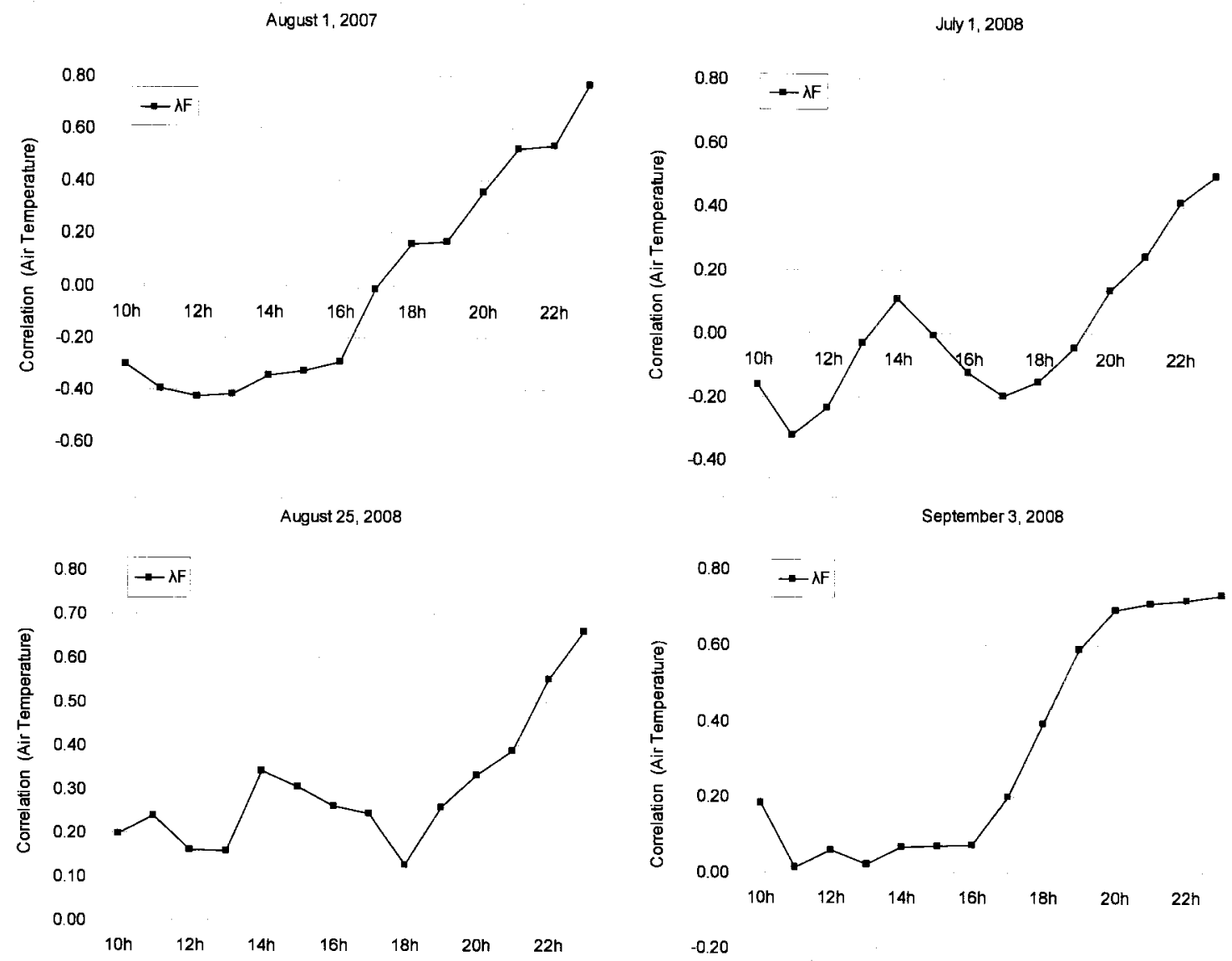

Figure 22. Correlations (r) between frontal area density $\left(\lambda_{\mathrm{F}}\right)$ and hourly air temperature for August 1, 2007, July 1, 2008, August 25, 2008 and September 3, 2008.

August 1, 2007, having the most pronounced heat event conditions, can serve as an example for qualitative comparison between monitoring sites. Four urban sites with different $\lambda_{\mathrm{F}}$ are compared in Figure 24. Both the CAP Office and MEC Asphalt Roof are 
located in the Toronto central business district with high $\lambda_{F}(0.13$ and 0.14$)$. Although these buildings are only 3 storeys high, they are directly adjacent to buildings with 10-20 storeys (e.g. Metro Hall). Conversely, the Brickworks and Heartlake sites are both in relatively flat and exposed industrial areas with no neighbouring structures above 3 storeys and subsequently are associated with low $\lambda_{F}(0.02$ and 0.03$)$. All of these sites are in areas composed mostly of impervious surfaces and relatively similar peak daytime air temperatures (at 16:00, 31.38 to $33.94{ }^{\circ} \mathrm{C}$ ). However, the 23:00 temperatures are significantly different, with the low $\lambda_{F}$ Brickworks and Heartlake sites having temperatures $5^{\circ} \mathrm{C}$ less than the structurally dense CAP Office and MEC Asphalt Roof sites. The Heartlake site exemplifies the significance of urban structure on UHI. It is located in the dense industrial yards in the Northwest of the GTA, with the highest 10:00 surface temperatures and highest peak air temperatures as there is little evaporation or shading here. However, this site is also the quickest to cool, with no neighbouring walls to effectively slow radiative cooling at night. 


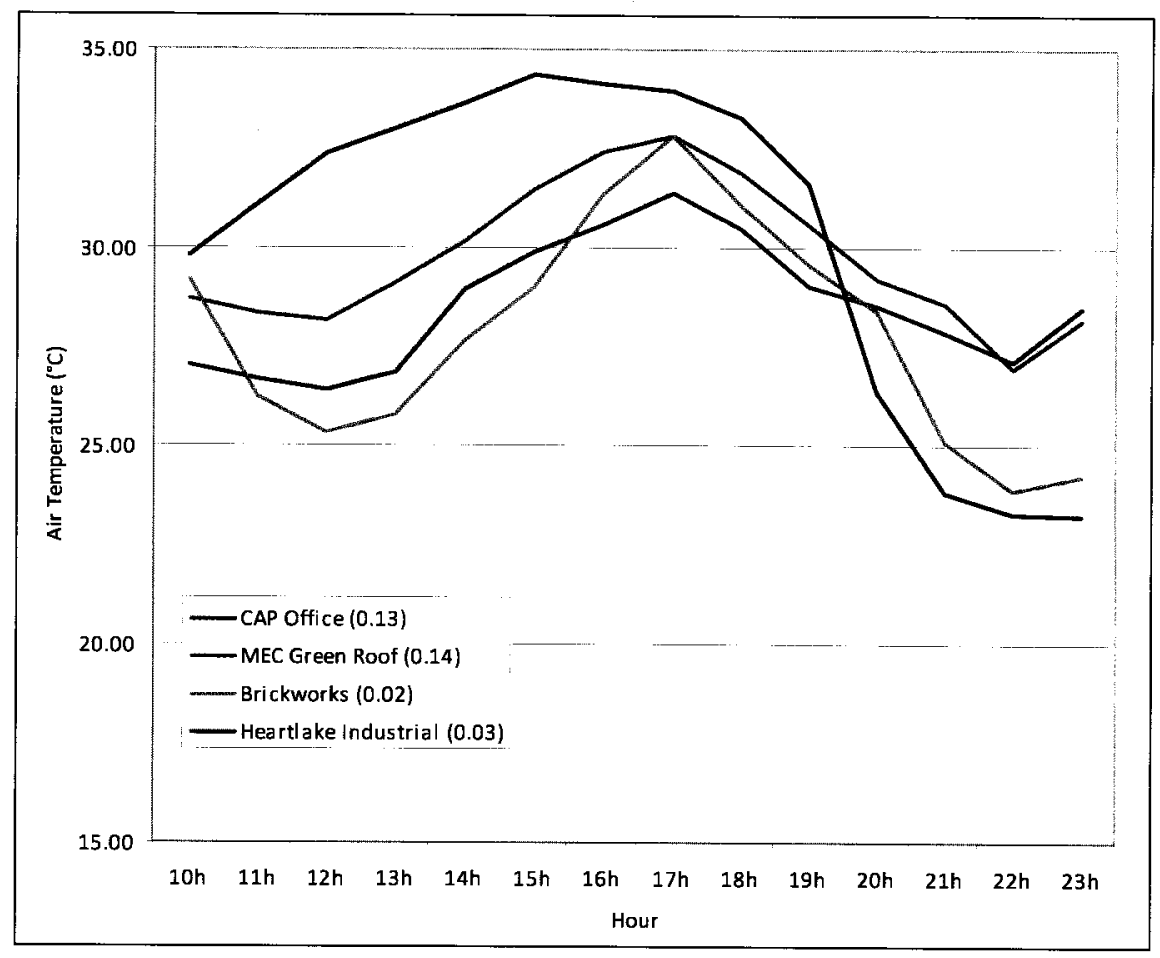

Figure 23. Air temperatures from 4 urban sites for August 1, 2007 with $\lambda_{\mathrm{F}}$ listed in brackets.

\subsubsection{Modelling night-time temperatures}

The potential for a multiple regression model to predict 23:00 air temperature using LST averaged over larger (i.e. $480 \mathrm{~m}$ ) source areas and building frontal areal density was explored. The residuals from the 23:00 air temperature regression from LST are plotted against $\lambda_{F}$ on August 1, 2007 (Figure 24). For sites with a $\lambda_{F}>0.04$ the models tend to underestimate night-time air temperatures. For relatively exposed sites, $\lambda_{\mathrm{F}}<0.04,23: 00$ air temperatures for some sites are well modelled while others are overestimated. 
6

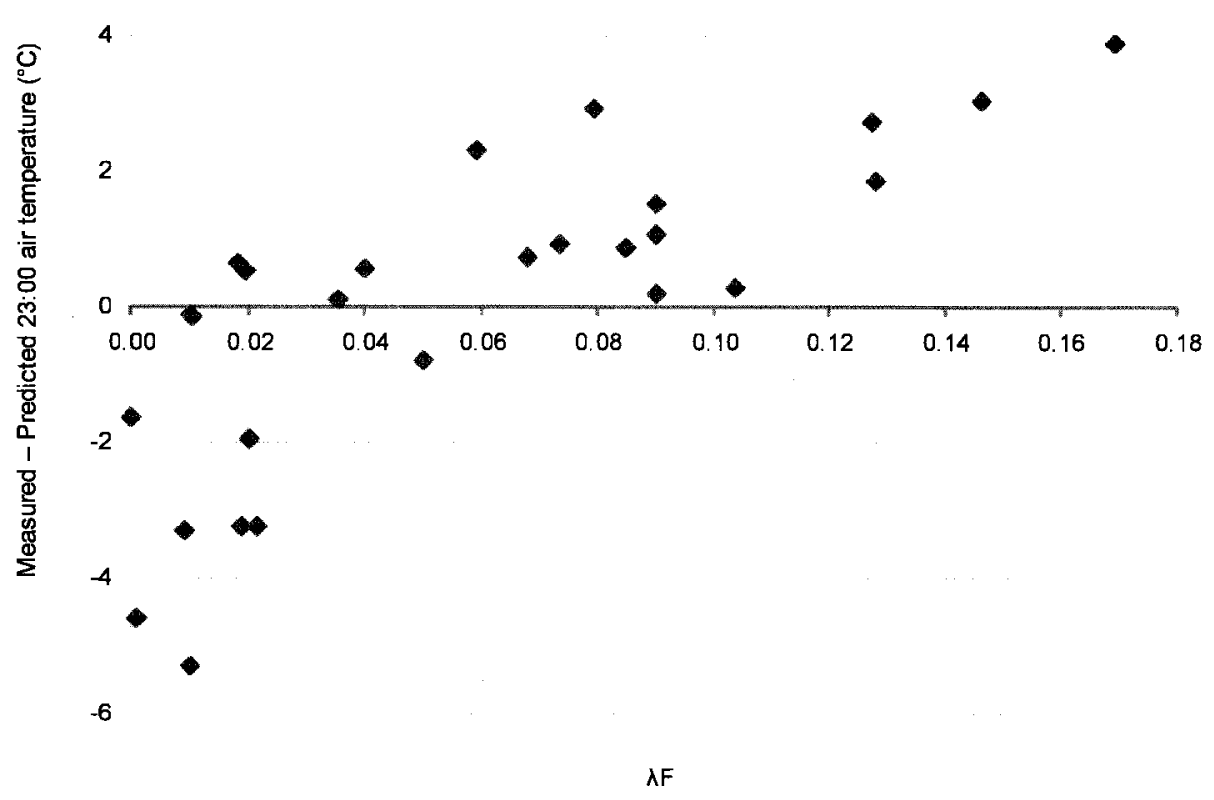

Figure 24. Residuals from $480 \mathrm{~m}$ Land Surface Temperature (LST) and air temperature regressions (Table 6) plotted against Frontal Area Density $\left(\lambda_{\mathrm{F}}\right)$ for August 1, 2007.

Multiple regression with $480 \mathrm{mLST}$ and $\lambda_{\mathrm{F}}$ as independent variables showed improvement over either variable alone (Table 6) with the highest $\mathrm{r}^{2}$ and lowest standard errors for both 23:00 and 10:00 air temperature estimation. Standard errors for 23:00 air temperatures were all lower than $1.64^{\circ} \mathrm{C}$, which is approximately half the expected UHI intensity for that time. Although only four dates were compared, these results demonstrate the strong linear relationship between LST and frontal area and night-time air temperatures. 


\subsection{UHI Modelling with LST, Upwind Source Areas and Urban Geometry}

A number of analyses here clearly show how air temperatures are not solely influenced by the immediate underlying surface. For example, the two green roof sites (MEC and Horticultural centre) were found to have similar air temperatures to surrounding impervious covered areas (Figure 15). The analysis of LST pixels upwind of the measurement sites suggested that the heat storage of the extensive source areas were important in determining night-time air temperatures. While most UHI studies employ the immediate surface cover or LST to characterize UHI intensities (e.g. Lo et al. 1997, Pena, 2008), it is shown here that thermal characteristics over source areas of several hundred meters may have been relevant. Many recent studies even suggest the need for higher resolution thermal imagery to further isolate heat islands (e.g. Voogt and Oke, 2003; Zhu et al., 2009). However, the Landsat thermal imagery may be already sufficient for UHI modelling, as air temperature doesn't appear to vary below the $120 \mathrm{~m}$ scale, and high resolution thermal imagery can be misleading as it implies that the air temperature would vary proportionally with surface temperature.

The complexity involved in accurately determining a source area for an atmospheric variable such as air temperature in an urban area is evident when one considers both the spatial arrangement of features with different thermal properties and the variability in turbulent transport. Factors which affect the size and shape of the upwind source areas, including surface roughness (Schmid, 2002), change dramatically across urban canyons, such as those found in the downtown core of Toronto. Additionally, wind direction and 
wind speeds across the GTA have been shown to be affected by proximity to Lake Ontario, which is susceptible to on-shore breezes (Gough and Rozanov, 2001). Unfortunately, wind measurements were not collected at the measurement sites and only central GTA airport wind speeds were used. Considerations should be made for the locations of the measurements which took place both at ground level and at rooftops of various heights. There would certainly be different, and likely larger, source areas for air temperatures at 3 storeys above the ground (but still $1.5 \mathrm{~m}$ above the surface) than those at street level. Unfortunately, there was not a sufficient sample size of measurement sites at different building heights to test the relation between source area size and height within the urban canyon.

The thermal properties of structures also have complex contributions within a source area, not just the differences in thermal conductivities for lawns or building, but also the potential underestimation of the surface area of a building with nadir Landsat acquisitions. A multi-storey structure may have greater contribution to a source area from its south-facing walls than its roof.

Despite these complexities, it may be that accurate wind direction is not critical to constraining footprints in air temperature modelling. For urban cover that is relatively homogeneous up to 500 meters in each direction, as was typically the case for the GTA, the correlations tended to increase when pixels were averaged to approximately $480 \mathrm{~m}$ with a wide $60^{\circ}$ footprint angle. 
This study also attempted to characterize the influence of urban geometry on UHI intensities by linking $\lambda_{\mathrm{F}}$ and surface temperatures to air temperatures. It is proposed that both canyon effects and thermal anisotropic effects can be explained by the relationships observed. The strong correlations between $\lambda_{\mathrm{F}}$ and night-time air temperatures, yet weak correlations with air temperatures between 10:00 and 17:00 (Figure 23), are in agreement with the canyon effect concept (Oke, 1981). As the literature suggests, as building heights increase (i.e. $\lambda_{\mathrm{F}}$ increases), sky-view factors decrease and rates of cooling decrease. However, it is difficult to determine any influence from thermal anisotropic effects, due to the apparent lag between solar loading of urban surfaces and air temperatures. While rooftop surface temperatures were measured and validated, no surface temperatures were taken for walls or facets to deduce the underestimation of total heated surface area in the Landsat LST. Conversely, no in situ longwave radiation measurements were taken, which could have been linked to $\lambda_{\mathrm{F}}$ and parameterized different rates of night-time cooling. Studies have linked urban geometry and longwave radiation to UHI intensities (e.g. Eliasson, 1990; Rigo and Parlow, 2007) and have also explored how urban geometry contributes to underestimation of surface temperatures of 3D structures (Voogt and Oke, 1998), however the two factors have not been extensively evaluated together in most studies employing LST for UHI mapping.

Voogt and Oke (2003) report on the state of thermal remote sensing of UHIs and note similar discrepancies in LST accuracies and overconfidence in using them to determine UHI intensity and extents. The overconfidence in LST data sets may stem from the 
readily accessible Landsat imagery while $3 \mathrm{D}$ urban geometry information may not exist for many urban areas. Computational limitations may be another factor determining the use of urban geometry in UHI modelling. For this study, building footprint and height information was available for the GTA, however this may not be the case for many urban areas. The processing of high resolution (1:5000) vectors was also computationally intensive and due to time and processing constraints, the $\lambda_{\mathrm{F}}$ calculations were limited to 5 $\mathrm{m}$ intersection counts and only for subsets around the measurement sites. The calculation of high resolution $\lambda_{\mathrm{F}}$ estimates for entire urban areas is not feasible with most desktop GIS software.

\subsection{Implications for Health and Urban Planning}

The basis for many UHI mapping studies is the link between excess mortality and exposure to high air temperatures. By mapping the spatial distribution of surface temperatures, it is expected to determine areas of risk for heat exposure (e.g. Lo et al. 1997). Based on these UHI risk maps, plans are also suggested or implemented to alter the thermal properties of urban structures (i.e. green roofs). As demonstrated in this study, the relationships between LST and air temperatures are indirect and suggest considerable uncertainty in any heat exposure risk maps based on LST alone. This study makes it clear that spatial information related to urban geometry and upwind source areas may be required to properly map heat exposure risk.

In terms of heat exposure, night-time air temperatures are just as significant as daytime temperatures (Curriero et al., 2002). Heat stress is associated with continued exposure to 
elevated temperatures, which can be alleviated in periods of night-time cooling. The in situ measurements from this study determined that for the GTA, the urban and rural daytime heat risk would be the same, however urban areas would see an nighttime elevated risk occurring. It was also observed that relatively flat suburban areas, which may have the highest 10:00 LST, are also the quickest to cool down after sunset and may interrupt periods of heat stress. Conversely, the dense downtown core of the GTA has similar high daytime LST, but higher night-time air temperatures and may sustain heat stress. By using LST alone, these two areas would be considered the same health risk. Both the source area scale (e.g. $480 \mathrm{~m}$ ) as well as urban geometry have an essential role in determining UHI intensities, and are particularly relevant in determining areas of high heat exposure risks. At-risk populations, such as the elderly or those without air conditioning, may not be in areas of extreme LST but may be in neighbourhoods with high frontal area density (i.e. low income high rises). Any efforts to change the form or distribution of heat islands, either to minimize energy consumption from air conditioning or in order to mitigate heat exposure risks, would also require consideration for source areas, urban geometry and wind direction. 


\section{Conclusions and Recommendations}

This study's objectives were to explore the temporal and spatial relationships between urban surface and air temperatures and test the influence of urban geometry on these relationships. With many recent studies employing solely remotely sensed LST to map UHI intensities, this study sought to demonstrate the complexity of surface-air temperature interactions and the importance of urban geometry in accurately quantifying UHI intensities. This study also attempted to address some of the limitations concerning thermal anisotropy and effective UHI mapping with thermal imagery discussed in Voogt and Oke (2003).

The GTA was found to have typical UHI characteristics with insignificant differences between urban and rural air temperatures during the daytime $\left(\sim 1.0^{\circ} \mathrm{C}\right)$ yet pronounced differences during the night-time $\left(\sim 3.5^{\circ} \mathrm{C}\right)$. Differences were also observed between suburban and urban sites, with suburban areas having higher noon air temperatures, but lower midnight air temperatures. In contrast, LST maps from four heat event days suggested a strong UHI with 10:00 LST in urban areas warmer than rural areas by more than $5^{\circ} \mathrm{C}$.

This study demonstrated that daytime surface and near-surface air temperatures over various urban and rural covers were significantly different. However, the correlation between air temperature and 10:00 surface temperatures gradually increased throughout the day. Relationships between these two variables over the diurnal cycle appeared 
strongest at 23:00, demonstrating an apparent lag between solar loading and warming of the air layer above.

Correlations with air temperature were found to increase when comparing not just the collocated LST estimates, but LST values that were averaged over several hundred metres upwind of the air temperature measurement. These LST averages are thought to represent a source area contributing to the mean status of the atmosphere at that location.

The ability to estimate night-time air temperatures increased when frontal area density was included in the linear model with 10:00 LST for a $480 \mathrm{~m}$ upwind area. It is theorized that frontal area is representing both urban canyon effects and thermal anisotropic effects. This study observed canyon effects, as urban sites in dense areas with high structural complexity were shown to cool down after sunset at lower rates than sites in relatively flat areas. In terms of thermal anisotropy, the results do not necessarily confirm that there are biases from nadir looking LST, nor that these potential biases are affecting the ability to predict air temperature. However, previous studies have shown the presence of this bias for different urban land covers (Voogt and Oke, 2003) and frontal area density does quantify the amount of area not visible versus that which was imaged by the nadir viewangle Landsat (i.e. walls vs. rooftops).

It is proposed that models using both LST averaged over large source areas and frontal area density could be suitable to estimate night-time air temperature and model UHI intensity in the GTA. Given the GTA's typical UHI intensities that were observed (i.e. 
significant night-time) and traditional urban form characteristics (central business district, periphery consisting of suburban to rural gradient), it is reasonable to assume the LST and frontal area density could be applied in models of other North American cities. However, other urban areas may not have similar wind patterns nor the presence of a major water body, such as Lake Ontario, which affects the climate of the GTA.

One of the major limitations of this study was the use of Landsat TM, where other satellite and airborne sensors are potentially available for use in UHI studies. For example MODIS thermal imagery is available for several time of day and night, although it is likely too coarse at $0.93 \mathrm{~km}$ pixels. Future studies should make considerations for LST measurements at different times of day, at different scales and different look angles. The timing of LST measurement and amount of solar loading (i.e. past 10:00) would likely lead to different relationships with air temperature.

Future work in this area might focus on exploring different estimates of urban geometry and further parameterizing thermal anisotropy by incorporating in situ surface temperature measurements on facets of buildings as well as rooftops. It is also recommended that the links between land use and urban geometry also be explored. If building footprint and height information is not available for many urban areas, other land use information could serve as an indicator of urban canyon effects. For example, typical residential areas are dominated by one or two storey structures, likely with a uniform frontal area density. Other data sets on urban form characteristics (e.g. census 
population density, age of neighbourhood) are readily available in most municipalities and would likely be linked to urban canyon effects and subsequent UHI intensities.

Finally, future UHI studies using thermal remote sensing should consider the uncertainties associated with the LST measurement. Although LST mapping can produce dramatic representations of surface UHIs, the actual air temperatures and UHI intensities for these surfaces may be considerably different as was observed in this study. Without considering these differences, LST maps can be misleading to health risk and urban planning measures. 


\section{References}

Axelsson, S., Lunden, B., 1988. Atmospheric Correction of Thermal Infrared Data from LANDSAT-5 for Surface Temperature Estimation, Proceedings of the Conference January, 1988, Spectral Signatures of Objects in Remote Sensing.

Barsi, J.A., Schott, J.R., Palluconi, F.D., Helder, D.L., Hook, S.J., Markham, B.L., Chander, G., O'Donnell, E.M., 2003. Landsat TM and ETM+ thermal band calibration. Canadian Journal of Remote Sensing, 29, 2.

Barsi, J.A., Schott J.R., Palluconi F.D, Hook S.J., 2005.Validation of a Web-Based Atmospheric Correction Tool for Single Thermal Band Instruments. Earth Observing Systems X, Proc. SPIE Vol. 5882, San Diego, CA.

Bottema, M., Mestayer, P.G., 1998: Urban roughness mapping - validation techniques and some first results. $J$. Wind Engineering and Industrial Aerodynamics 74-76.

Burian, S. J., 2004. Urban canopy parameter assessment for Houston, Texas. Research report prepared for Daewon Byun, Institute for Multidimensional Air Quality Studies, University of Houston, Houston, Texas.

Crowley, J., Da Luz, B., 2007. Spectral reflectance and emissivity features of broad leaf plants: Prospects for remote sensing in the thermal infrared $(8.0-14.0 \mu \mathrm{m})$. Remote Sensing of Environment, 109, 4, 393-405.

Curriero, F., Samet, J., Zeger S., 2002. Temperature and mortality in 11 cities of the eastern United States, American Journal of Epidemiology. 158, 1, 93-94.

Eliasson, I., 1990, Urban Geometry, surface temperature and air temperature. Energy and Buildings, 15, 141-145.

Environmental Systems Research Institute, 2004. Arc/Info for Windows XP. Version 9.0. ESRI Ltd., Redlands, CA, U.S.A.

Fouillet, A., Rey, G., Laurent, F., 2006. Excess mortality related to the August 2003 heat wave in France, Int. Arch. Occup. Environ. Health, 80, 16-24.

Gal, T., Unger, J., 2009. Detection of ventilation paths using high-resolution roughness parameter mapping in a large urban area. Building and Environment, 44, 198-206.

Gallo, K. P., Owen, T. W., 1998. Assessment of urban heat island: A multi-sensor perspective for the Dallas-Fort Worth, USA region. Geocarto International, 13.

Goetz, S. J., Halthore, R. N., Hall, F. G., Markham, B. L., 1995. Surface temperature retrieval in a temperate grassland with multi-resolution sensors. Journal of Geophysical Research. 100, 12. 
Gough, W.A. and Y. Rozanov, 2001. Aspects of Toronto's climate: heat island and lake breeze. Canadian Meteorological and Oceanographic Society Bulletin, 29.

Hawkins, T., Brazel. A., Stefanov, W., Bigler. W. and Saffell, E., 2004. The role of rural variability in urban heat island determinati 72 Meteorology, 43. , Arizona. Journal of Applied

Ichinose, T., K. Shimodozono, and K. Hanaki., 1999. Impact of anthropogenic heat on urban climate in Tokyo. Atmospheric Environment. 33.

Koren, O., 1998. Yonge Street Temperature Study Report. Environment Canada.

Leclerc, M.Y., Thurtell, G.W., 1990. Footprint prediction of scalar fluxes using a Markovian analysis, Boundary-Layer Meteorology 52.

Lillesand, T.M., Kiefer, R.W., 2000. Remote Sensing and Image Analysis, 4th Edition. John Wiley and Sons, New York

Lo, C.P., Quattrochi, D.A., Luval, J.C., 1997. Application of high-resolution thermal infrared remote sensing and GIS to assess the urban heat island effect. International Journal of Remote Sensing, 18, 2, 287-304

Mantel, N., 1967. The detection of disease clustering and a generalized regression approach. Cancer Research, 27, 209-220.

Markham, B. L., Barker, J. L., 1986. Landsat MSS and TM post-calibration dynamic rangers, exoatmospheric reflectance and at-satellite temperatures. EOSAT Landsat Tech. Notes (Aug.): 3-8.

Microsoft Corporation, 2003. Microsoft Office Excel 2003.

Mohsin, T., Gough, W.A., 2009. Trend analysis of long-term temperature time series in the Greater Toronto Area (GTA). Theoretical and Applied Climatology.

Munn, R.E., Hirt, M.S., Findlay, B.F., 1969. A Climatological Study of the Urban Temperature Anomaly in the Lakeshore Environment at Toronto. Journal of Applied Meteorology, 8, 411-422

Natural Resources Canada, 2007. From Impacts to Adaptation: Canada in a Changing Climate 2007.

Offerle, B., C.S.B. Grimmond, Oke, T.R., 2003. Parameterisation of net all-wave radiation for urban areas, Journal of Applied Meteorology, 42. 
Oke, T.R., 1997. Boundary Layer Climates. 2nd ed., Methuen, London Methuen: London and New York.

Oke, T. R., 1982. The energetic basis of the urban heat island. Quarterly Journal Royal Meteorological Society, 108.

Oke, T. R., 1981. Canyon geometry and the nocturnal heat island. Comparison of scale model and field observations, Journal of Climatology, 1.

Oke T.R., Maxwell G.B., 1975. Urban heat island dynamics in Montreal and Vancouver. Atmospheric Environment, 9.

PCI Geomatics, 2003. www.pcigeomatics.com.

Peña, M.A., 2008. Relationships between remotely sensed surface parameters associated with the urban heat sink formation in Santiago, Chile. International Journal of Remote Sensing. 29.

Rigo, G., Parlow, E., 2007. Modelling the ground heat flux in an urban area with remote sensing methods. Theoretical and Applied Climatology, 90.

Rigo, G., Parlow, E., Oesch, D., 2006. Validation of satellite observed thermal emission with in-situ measurements over an urban surface. Remote Sensing of Environment, 104.

Roth, M., Oke, T. R., Emery, W. J. 1989. Satellite-derived urban heat island from three coastal cities and the utilization of such data in urban climatology. International Journal of Remote Sensing 10, 11, 1699-1720

Schmid, H.P., 2002. Footprint modeling for vegetation atmosphere exchange studies: a review and perspective. Agricultural and Forest Meteorology, 113, 159-183.

Schott, J. R., Volchok, W. J., 1985. Thematic Mapper thermal infrared calibration. Photogrammetric Engineering and Remote Sensing, 51. 9.

Schneider K., Mauser W., 1996. Processing and accuracy of Landsat Thematic Mapper data for lake surface temperature measurement. International Journal of Remote Sensing, $17,11,2027$ - 2041

Smargiassi, A., Fournier, M., Griot, C., Baudoin, Y., Kozatzky, T., 2008. Prediction of the indoor temperatures of anurban area with an in-time regression mapping approach. Journal of Exposure Science and Environmental Epidemiology 18.

Smoyer, K.E., 1998. Putting risk in its place: methodological considerations for investigating extreme event health risk. Social Science and Medicine, 47. 
Snyder, W. C., Wan, Z., Feng, Y. Z., 1998. Classification-based emissivity for land surface temperature measurement from space. International Journal of Remote Sensing, 19,14 .

Sobrino, J.A., Jimenez-Munoza, P., 2004. Land surface temperature retrieval from LANDSAT TM 5. Remote Sensing of Environment, 90, 4.

Statistics Canada, 2008. Population of census metropolitan areas, http://www40.statcan.ca/101/cst01/.

Stroeve, J., Haefliger, M., Steffen, K., 1996. Surface temperature from ERS-1 ATSR infrared thermal satellite data in polar regions. Journal of Applied Meteorology, 35, 8.

Streutker, D. R., 2002. A remote sensing study of the urban heat island of Houston, Texas. International Journal of Remote Sensing, 23, 13.

Sugawara, H., Takamura, T., 2006. Longwave radiation flux from an urban canopy: Evaluation via measurements of directional radiometric temperature. Remote Sensing of Environment, 104, 226-237.

Voogt, J.A., Oke, T.R., 1998. Effects of urban surface geometry on remotely-sensed surface temperature. International Journal of Remote Sensing, 19, 5.

Voogt, J.A., T.R. Oke. 2003. Thermal remote sensing of urban areas. Remote Sensing of Environment, 86, 3.

Zar, J.H., 2006. Biostatistical Analysis (5 $5^{\text {th }}$ edition) Prentice-Hall, Upper Saddle River, New Jersey.

Zhu, S., Zhang, G., Chen, J., 2009. Study on urban heat island of Shanghai by using multi-temporal remote sensing data and air temperature data. Urban Remote Sensing Event IEEE, Shanghai. 


\section{Appendix I - Temperature Monitoring Sites}

\begin{tabular}{|c|c|c|c|c|c|c|}
\hline Site & Owner & Land Use Class & $\begin{array}{l}\text { Measurement } \\
\text { Surface }\end{array}$ & $\begin{array}{l}\text { Measurement } \\
\text { Frequency }\end{array}$ & Longitude & Latitude \\
\hline $\begin{array}{l}\text { Ajax City } \\
\text { Hall }\end{array}$ & NRCan & $\begin{array}{l}\text { Urban } \\
\text { (Municipal) }\end{array}$ & roof, stones & 15 minutes & -79.0201 & 43.8508 \\
\hline $\begin{array}{l}\text { Ajax } \\
\text { Conservation }\end{array}$ & NRCan & Rural & grass & 15 minutes & -79.0599 & 43.8995 \\
\hline $\begin{array}{l}\text { Ajax } \\
\text { Residential }\end{array}$ & NRCan & Suburban & grass & 15 minutes & -79.032 & 43.8216 \\
\hline Brickworks & NRCan & $\begin{array}{l}\text { Urban } \\
\text { (Industrial) }\end{array}$ & roof, asphalt & 15 minutes & -79.3662 & 43.6842 \\
\hline Brock & TRCA & Rural & grass & 15 minutes & -79.0992 & 43.8639 \\
\hline Kortright & TRCA & Rural & grass & 15 minutes & -79.7286 & 43.5833 \\
\hline $\begin{array}{l}\text { Buttonville } \\
\text { Airport }\end{array}$ & $\mathrm{EC}$ & $\begin{array}{l}\text { Urban } \\
\text { (Commercial) }\end{array}$ & grass & 1 hour & -79.3653 & 43.8602 \\
\hline CAP Office & NRCan & $\begin{array}{l}\text { Urban } \\
\text { (Commercial) }\end{array}$ & roof, stones & 15 minutes & -79.3845 & 43.6543 \\
\hline Emery Yard & NRCan & $\begin{array}{l}\text { Urban } \\
\text { (Industrial) } \\
\end{array}$ & roof, aluminium & 15 minutes & -79.5461 & 43.7533 \\
\hline Glen Haffey & TRCA & Rural & grass & 15 minutes & -79.9429 & 43.9385 \\
\hline Goodwood & TRCA & Rural & lot, asphalt & 15 minutes & -79.5928 & 43.8352 \\
\hline $\begin{array}{l}\text { Hart House } \\
\text { Farm }\end{array}$ & UofT & Rural & grass & 1 hour & -79.967 & 43.7831 \\
\hline $\begin{array}{l}\text { Havergal } \\
\text { College }\end{array}$ & NRCan & $\begin{array}{l}\text { Urban } \\
\text { (Commercial) }\end{array}$ & roof, asphalt & 15 minutes & -79.4144 & 43.7201 \\
\hline $\begin{array}{l}\text { Heartlake } \\
\text { Industrial }\end{array}$ & TRCA & Urban & asphalt & 5 minutes & -79.7242 & 43.6941 \\
\hline $\begin{array}{l}\text { Horticultural } \\
\text { Center }\end{array}$ & NRCan & $\begin{array}{l}\text { Urban (Green } \\
\text { Roof) }\end{array}$ & roof, grass & 15 minutes & -79.3577 & 43.7343 \\
\hline Humber & TRCA & Urban & grass & 5 minutes & -79.5201 & 43.6989 \\
\hline King & TRCA & Rural & grass & 15 minutes & -79.7928 & 43.8486 \\
\hline $\begin{array}{l}\text { L.B.P. } \\
\text { Airport }\end{array}$ & $\mathrm{EC}$ & $\begin{array}{l}\text { Urban } \\
\text { (Commercial) }\end{array}$ & grass & 1 hour & -79.6106 & 43.6803 \\
\hline MEC Asphalt & NRCan & $\begin{array}{l}\text { Urban } \\
\text { (Commercial) }\end{array}$ & roof, asphalt & 10 minutes & -79.3931 & 43.646 \\
\hline $\begin{array}{l}\text { MEC } \\
\text { Greenroof }\end{array}$ & NRCan & $\begin{array}{l}\text { Urban (Green } \\
\text { Roof) }\end{array}$ & roof, grass & 10 minutes & -79.3931 & 43.646 \\
\hline $\begin{array}{l}\text { Metro Hall - } \\
\text { North }\end{array}$ & NRCan & $\begin{array}{l}\text { Urban } \\
\text { (Commercial) }\end{array}$ & roof, stones & 15 minutes & -79.3888 & 43.6457 \\
\hline $\begin{array}{l}\text { Metro Hall - } \\
\text { South }\end{array}$ & NRCan & $\begin{array}{l}\text { Urban } \\
\text { (Commercial) }\end{array}$ & roof, stones & 15 minutes & -79.3888 & 43.6457 \\
\hline $\begin{array}{l}\text { MTO - } \\
\text { Vaughan }\end{array}$ & MTO & $\begin{array}{l}\text { Urban } \\
\text { (Industrial) }\end{array}$ & grass & 5 minutes & -79.5393 & 43.7946 \\
\hline $\begin{array}{l}\text { Mississauga } \\
\text { Campus }\end{array}$ & UofT & $\begin{array}{l}\text { Urban } \\
\text { (Commercial) }\end{array}$ & grass & 1 hour & -79.6671 & 43.5518 \\
\hline $\begin{array}{l}\text { Mississauga } \\
\text { Fire } \\
\end{array}$ & NRCan & $\begin{array}{l}\text { Urban } \\
\text { (Commercial) }\end{array}$ & roof, asphalt & 15 minutes & -79.7286 & 43.5833 \\
\hline $\begin{array}{l}\text { Oakville } \\
\text { Center A }\end{array}$ & NRCan & $\begin{array}{l}\text { Urban } \\
\text { (Municipal) }\end{array}$ & roof, aluminium & 15 minutes & -79.7171 & 43.4803 \\
\hline
\end{tabular}




\begin{tabular}{|c|c|c|c|c|c|c|}
\hline 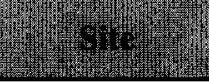 & Pat & 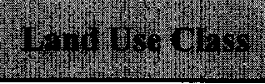 & 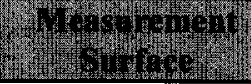 & 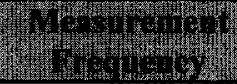 & (19) & Whine \\
\hline $\begin{array}{l}\text { Oakville } \\
\text { Center B }\end{array}$ & \multirow{3}{*}{$\begin{array}{l}\text { NRCan } \\
\text { NRCan } \\
\end{array}$} & \multirow{3}{*}{$\begin{array}{l}\text { Urban } \\
\text { (Municipal) } \\
\text { Suburban } \\
\end{array}$} & \multirow{3}{*}{$\begin{array}{l}\text { roof, stones } \\
\text { grass } \\
\end{array}$} & \multirow{3}{*}{$\begin{array}{l}15 \text { minutes } \\
15 \text { minutes } \\
\end{array}$} & \multirow{3}{*}{$\begin{array}{r}-79.7387 \\
-79.7364 \\
\end{array}$} & \multirow{3}{*}{$\begin{array}{r}43.4362 \\
43.4461\end{array}$} \\
\hline Oakville & & & & & & \\
\hline Residential & & & & & & \\
\hline $\begin{array}{l}\text { Peel Child } \\
\text { Care }\end{array}$ & NRCan & Suburban & roof, stones & 15 minutes & -79.7421 & 43.7503 \\
\hline $\begin{array}{l}\text { Peel Elderly } \\
\text { Care }\end{array}$ & NRCan & $\begin{array}{l}\text { Urban } \\
\text { (Commercial) }\end{array}$ & roof, asphalt & 15 minutes & -79.7765 & 43.7149 \\
\hline $\begin{array}{l}\text { Peel } \\
\text { Residential }\end{array}$ & NRCan & Suburban & grass & 15 minutes & -79.7648 & 43.7227 \\
\hline $\begin{array}{l}\mathrm{RH} \\
\text { Operations }\end{array}$ & NRCan & $\begin{array}{l}\text { Urban } \\
\text { (Municipal) }\end{array}$ & roof, concrete & 15 minutes & -79.4051 & 43.8974 \\
\hline Rouge & TRCA & Rural & grass & 5 minutes & -79.1857 & 43.804 \\
\hline $\begin{array}{l}\text { Scarborough } \\
\text { Residential }\end{array}$ & NRCan & Suburban & fence, wood & 30 minutes & -79.256 & 43.7079 \\
\hline $\begin{array}{l}\text { Toronto } \\
\text { Residential }\end{array}$ & NRCan & Suburban & grass & 30 minutes & -79.4502 & 43.6446 \\
\hline Downtown & $\mathrm{EC}$ & $\begin{array}{l}\text { Urban } \\
\text { (Commercial) }\end{array}$ & grass & 1 hour & -79.3953 & 43.6658 \\
\hline Union Station & NRCan & $\begin{array}{l}\text { Urban } \\
\text { (Industrial) }\end{array}$ & roof, asphalt & 15 minutes & -79.38 & 43.6451 \\
\hline $\begin{array}{l}\text { United } \\
\text { Church }\end{array}$ & NRCan & $\begin{array}{l}\text { Urban } \\
\text { (Commercial) }\end{array}$ & roof, concrete & 15 minutes & -79.4329 & 43.6376 \\
\hline $\begin{array}{l}\text { Vaughan Fire } \\
1\end{array}$ & NRCan & $\begin{array}{l}\text { Urban } \\
\text { (Industrial) }\end{array}$ & roof, gravel & 15 minutes & -79.5139 & 43.7983 \\
\hline $\begin{array}{l}\text { Vaughan Fire } \\
2\end{array}$ & NRCan & $\begin{array}{l}\text { Urban } \\
\text { (Industrial) }\end{array}$ & roof, gravel & 15 minutes & -79.5491 & 43.7934 \\
\hline $\begin{array}{l}\text { York } \\
\text { University } \\
\text { Campus }\end{array}$ & York U & $\begin{array}{l}\text { Urban } \\
\text { (Commercial) }\end{array}$ & grass & 5 minutes & -79.5099 & 43.7753 \\
\hline
\end{tabular}




\section{Appendix II - Land Surface Temperature Maps}

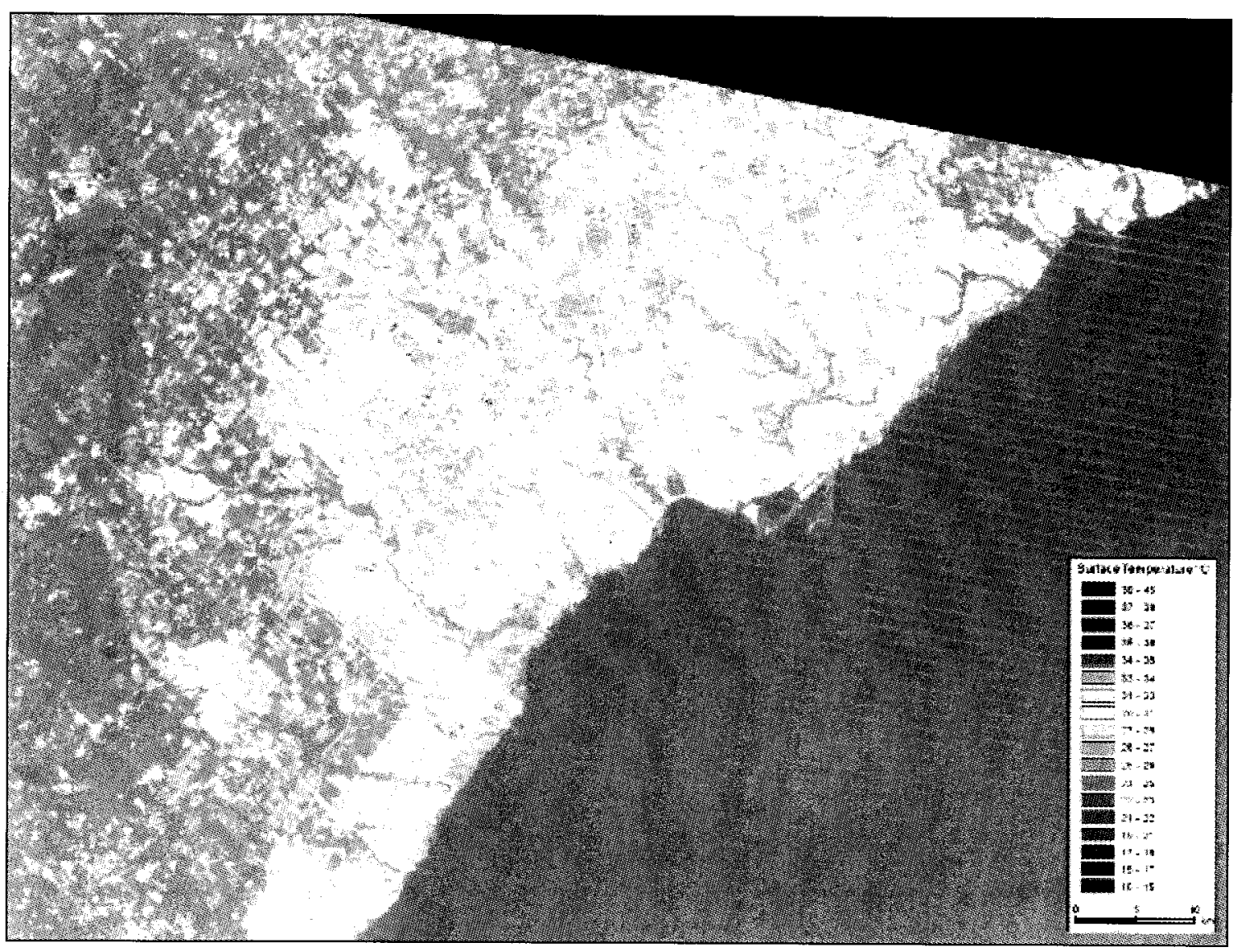

Figure I. Land Surface Temperature for August 1, 2007 


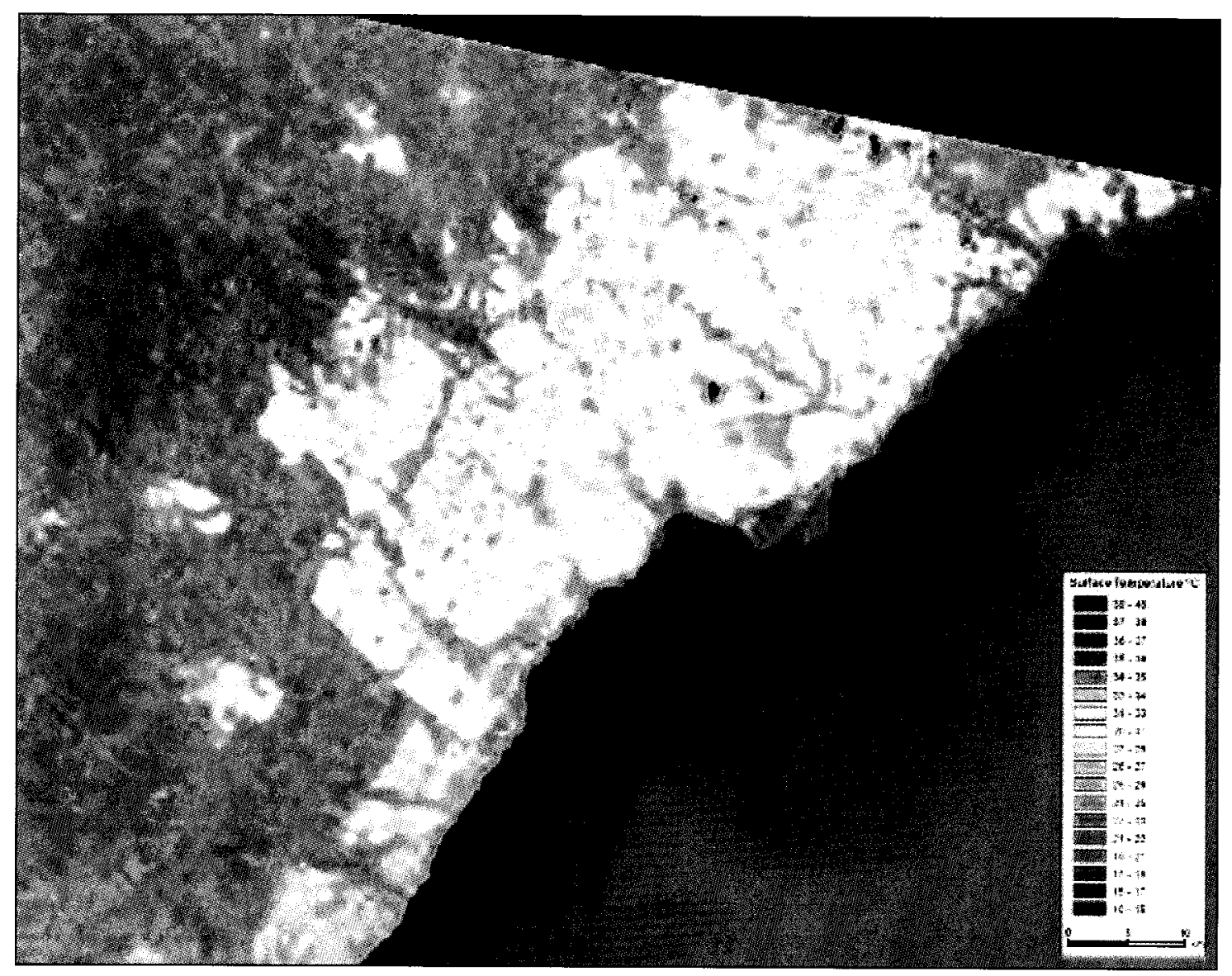

Figure III. Land Surface Temperature for July 1, 2008 


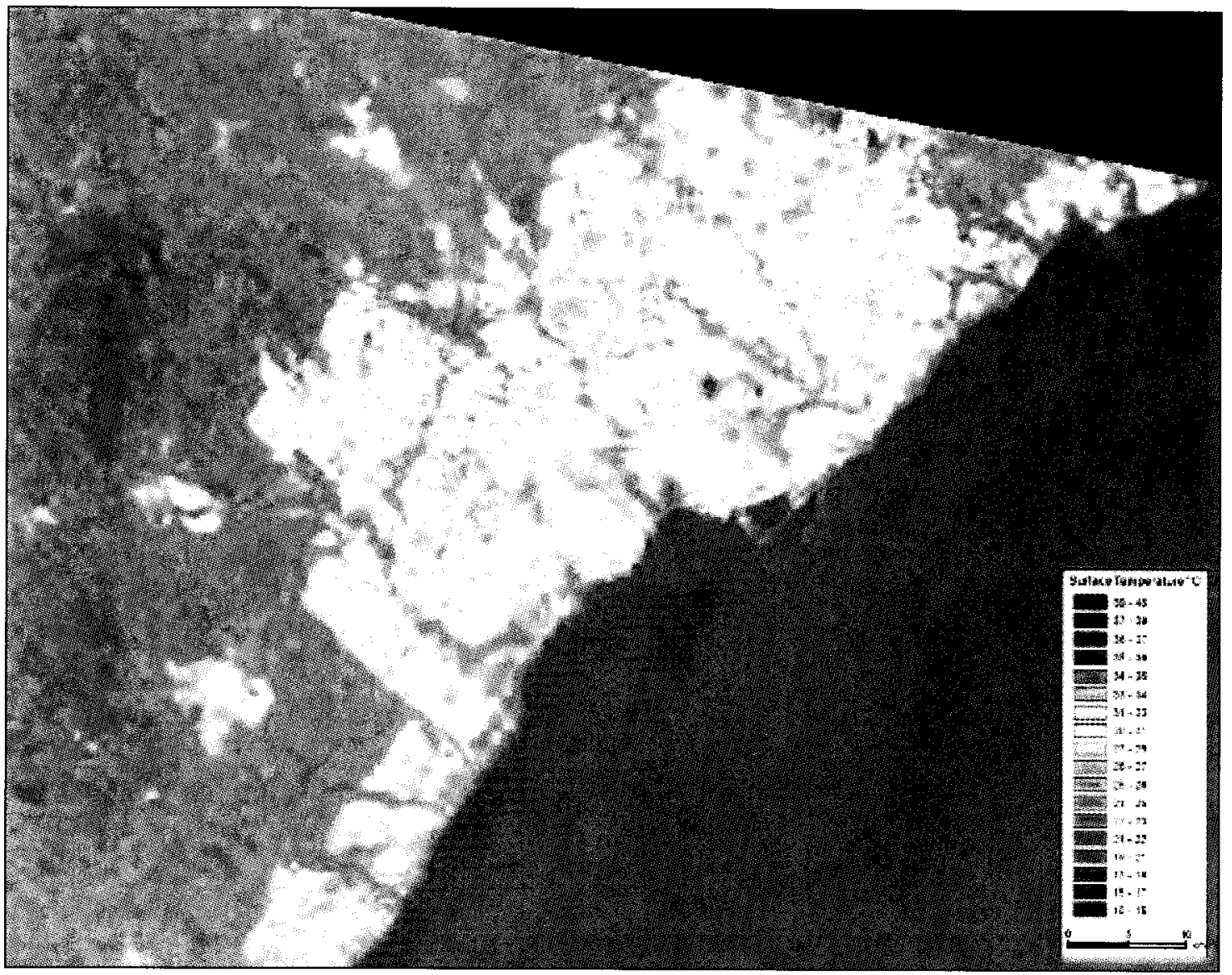

Figure II. Land Surface Temperature Map for August 25, 2008 


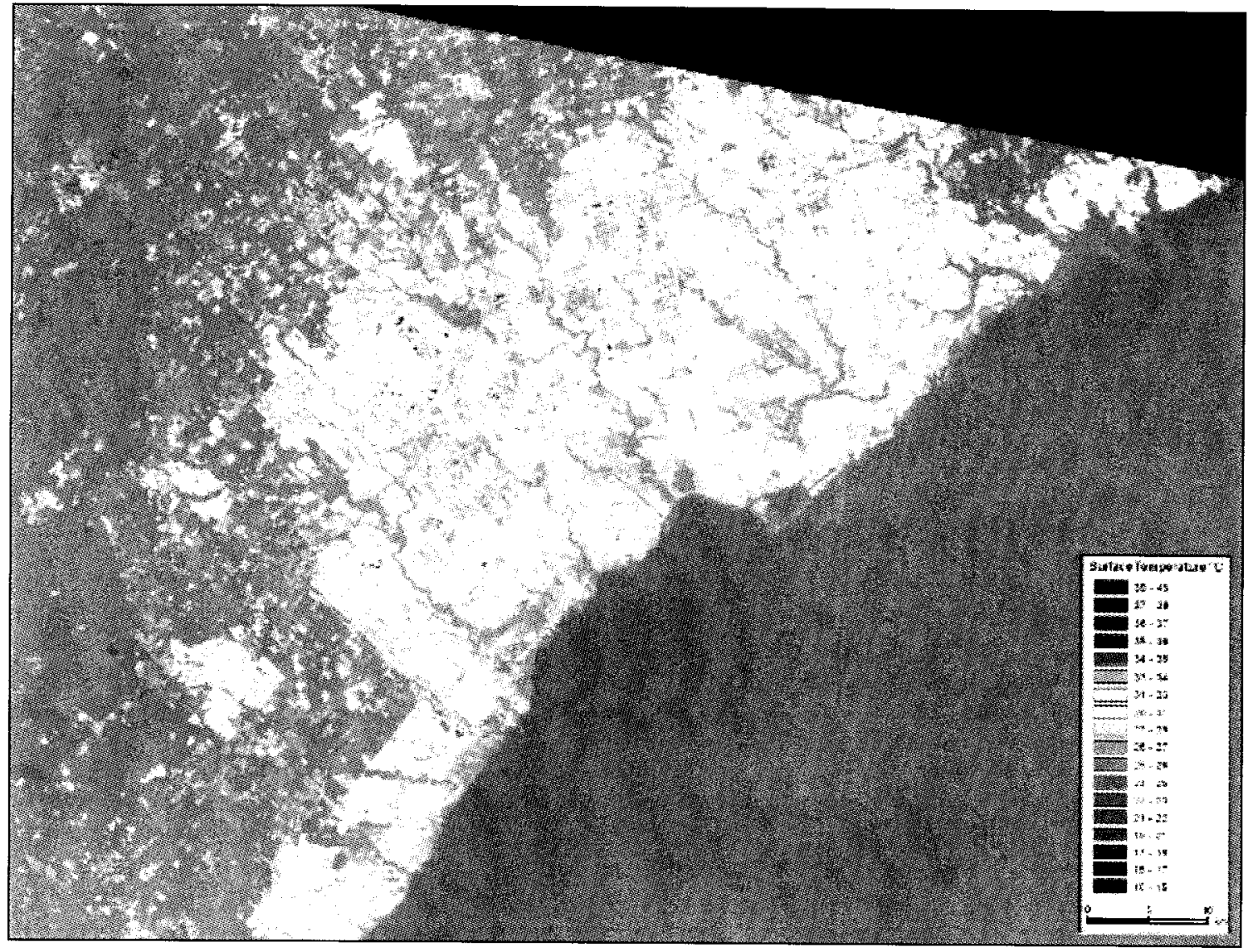

Figure IV. Land Surface Temperatures for September 3, 2008 